University of San Diego

Digital USD

2013-12-03

\title{
Quality of Life among Southwest American Indians and Alaska Natives Living with the Hepatitis C Virus
}

Rydell Todicheeney-Mannes PhD, RN, ACNS-BC

University of San Diego

Follow this and additional works at: https://digital.sandiego.edu/dissertations

Part of the Nursing Commons

\section{Digital USD Citation}

Todicheeney-Mannes, Rydell PhD, RN, ACNS-BC, "Quality of Life among Southwest American Indians and Alaska Natives Living with the Hepatitis C Virus" (2013). Dissertations. 444.

https://digital.sandiego.edu/dissertations/444

This Dissertation: Open Access is brought to you for free and open access by the Theses and Dissertations at Digital USD. It has been accepted for inclusion in Dissertations by an authorized administrator of Digital USD. For more information, please contact digital@sandiego.edu. 


\author{
UNIVERSITY OF SAN DIEGO \\ Hahn School of Nursing and Health Science \\ DOCTOR OF PHILOSOPHY IN NURSING
}

\begin{abstract}
QUALITY OF LIFE AMONG SOUTHWEST AMERICAN INDIANS AND ALASKA NATIVES LIVING WITH THE HEPATITIS C VIRUS
\end{abstract}

by

Rydell Todicheeney-Mannes, $\mathrm{PhD}(\mathrm{c}), \mathrm{RN}, \mathrm{ACNS}-\mathrm{BC}$

A dissertation presented to the

\title{
FACULTY OF THE HAHN SCHOOL OF NURSING AND HEALTH SCIENCE UNIVERSITY OF SAN DIEGO
}

\author{
In partial fulfillment of the \\ requirements for the degree \\ DOCTOR OF PHILOSOPHY IN NURSING
}

December 03, 2013

Dissertation Committee

Cynthia D. Connelly, PhD, RN, FAAN (Chairperson)

Jane M. Georges, $\mathrm{PhD}, \mathrm{RN}$

Joseph F. Burkard, DNSc, CRNA 


\begin{abstract}
Page
Background: Hepatitis C Virus is considered to be a global public health threat because seventy-five percent of infected persons have no symptoms and are unaware of their infection. It is significant to note that AI/ANs commonly contend with issues that prevent them from receiving or seeking medical care.
\end{abstract}

Objectives: The purpose of this study was to: (a) Characterize the level of depression, alcohol consumption, stigma, and quality of life; (b) Examine the relationship among the variables of age, gender, residing on an $\mathrm{AI} / \mathrm{AN}$ reservation, current partner status, depression, alcohol consumption, and stigma with quality of life in a sample of AI/ANs living with $\mathrm{HCV}$; and (c) Identify factors that explain the greatest amount of variance in the quality of life.

Design: A descriptive, cross-sectional, correlational design with purposive sampling of $101 \mathrm{AI} / \mathrm{AN}$ adults with HCV from the Southwestern U.S. was implemented.

Method: Instruments used to measure the influence of variables include the Center for Epidemiological Studies Depression scale, Alcohol Use Disorders Identification Test, HCV Stigma Scale, and MOS SF-12v2 Quality of Life questionnaire.

Results: Correlational analysis indicated a statistically significant inverse relationship between PCS and CES-D $(r=-.438, p=.000)$; statistically significant positive relationship between MCS and Age $(r=.205, p=.04)$; statistically significant inverse relationship between MCS and CES-D $(r=-.726, p=.000)$; statistically significant positive relationship between CES-D and AUDIT $(r=.400, p=.000)$ CES-D and Stigma $(\mathrm{r}=.485, \mathrm{p}=.000)$. Regression analysis indicated the overall models significantly 
predicts QOL - PCS and CES-D significantly contributed to the model; QOL - MCS and CES-D and AUDIT significantly contributed to the model.

Implications: The identification of factors that influence QOL in HCV patients has the potential to give direction to the development of nursing interventions or culturally based care that may improve life quality in AI/AN persons living with $\mathrm{HCV}$. This study will help to determine the level of depression, alcohol consumption, stigma, and QOL among AI/AN persons living with $\mathrm{HCV}$. These findings have important implications for $\mathrm{HCV}$ education, treatment, $\mathrm{AI} / \mathrm{AN}$ health care policy and practice improvements. 


\section{Copyright (C) Rydell Todicheeney-Mannes}

All rights reserved. 


\section{Dedication}

I am eternally grateful and dedicate this

To those who have Emerged before me,

To those who have Emerged with me, and

To those who will Emerge after me.

To my late grandmother who knew my potential

Mary Young White

To my parents for their support, spiritual wisdom, songs, and prayers

Elsie and Leroy Clark

To my spouse for being there, every step of the way

Scott G. Todicheeney-Mannes

To my siblings and their families for your love, songs, and prayers

Debbie, Donna, Linda, Timothy, Melshaw, Mershella, and Farrah

To my Navajo (Diné) Traditional relations:

Tótsohnii (Big Water clan) and Táchii’nii (Red-Running-Into-The-Water clan)

Tábąąha (Water's Edge clan) and Tódích'ii'nii (Bitter Water clan) 


\section{Acknowledgements}

I would like to thank the members of my dissertation committee for their support and encouragement throughout this entire doctoral sojourn.

Dr. Cynthia D. Connelly: Thank you for your guidance, expertise, and patience as my dissertation chairperson and supporting me throughout the quantitative process. I chose you as my chairperson, so that I could learn the quantitative process. I am eternally grateful to have stood on the shoulders of a truly, great nurse research scientist. Dr. Jane M. Georges: Thank you for your words of encouragement and reminding doctoral students to discover "other" areas of scholarship within a Critical Theory contextual lens. I am most grateful to you for navigating me through the deep, blue waters of the IRB process and was able to secure a second site effortlessly. In doing so, I was able to give a native "voice" surrounding Hepatitis $\mathrm{C}$ within Indian Country. Dr. Joseph Burkard: Thank you for your encouragement and supporting military veteran doctoral students. Your mentorship and leadership was instrumental in order for me to join other veteran scholars through the Jonas Nursing Scholars Program for Veterans Health. Through coursework and dissertation defense, my committee has been there to provide expertise, direction, and critique. I appreciate your time, energy, feedback, and every present support.

An appreciation also goes out to Patricia Calero for data management and editing. Thank you to Dr. Vicki Black for your last minute availability with editing.

I would also like to acknowledge the few AI/AN doctoral prepared nurses who I have met along the way that have paved the way and mentored me.

I would like to thank my study site's Administration, tribal Board Members, IRB Committee, Medical team, and support staff. You have all been instrumental in making my dissertation possible and allowing me to conduct research for native people.

I would also like to acknowledge another key element and would not have been possible without the funding mechanisms of: 1) Jonas Nursing Scholars Program for Veterans Health; 2) Nurse Faculty Loan program, and 3) Navajo Nation Graduate Trust Fund. 


\section{TABLE OF CONTENTS}

Chapter One - Introduction 1

Significance of the Problem 1

Purpose of the Study $\quad 4$

Specific Aims $\quad 6$

$\begin{array}{ll}\text { Conceptual Model } & 6\end{array}$

Quality of Life - Short Form-12v2 (SF-12v2) 7

Center for Epidemiologic Studies-Depression (CES-D) scale $\quad 8$

$\begin{array}{ll}\text { Alcohol Use Disorders Identification Test (AUDIT) } & \mathbf{8}\end{array}$

HCV Stigma Scale (modified) 9

Implications to Practice, Education, Research, and Policy 9

$\begin{array}{ll}\text { Chapter Two - Review of the Literature } & 11\end{array}$

$\begin{array}{ll}\text { Concepts } & 11\end{array}$

$\begin{array}{ll}\text { Quality of Life } & 11\end{array}$

$\begin{array}{ll}\text { Depression } & 16\end{array}$

$\begin{array}{ll}\text { Alcohol Consumption } & 28\end{array}$

$\begin{array}{ll}\text { Stigma } & 30\end{array}$

Conceptual Model 33

$\begin{array}{ll}\text { Chapter Three - Methodology } & 36\end{array}$

$\begin{array}{ll}\text { Specific Aims } & 36\end{array}$

$\begin{array}{ll}\text { Design } & 37\end{array}$

$\begin{array}{ll}\text { Sample } & 37\end{array}$

$\begin{array}{ll}\text { Sample Size } & 38\end{array}$ 
$\begin{array}{ll}\text { Setting } & 38\end{array}$

$\begin{array}{ll}\text { Protocol / Procedures } & 38\end{array}$

$\begin{array}{ll}\text { Data Collection } & \mathbf{4 0}\end{array}$

$\begin{array}{ll}\text { Instruments } & 40\end{array}$

Quality of Life - Short Form-12v2 (SF-12v2) 40

Center for Epidemiologic Studies-Depression (CES-D) scale 41

Alcohol Use Disorders Identification Test (AUDIT) 42

HCV Stigma Scale (modified) $\quad 44$

Data Analysis Plan $\quad 46$

$\begin{array}{lr}\text { Chapter Four - Results } & 48\end{array}$

$\begin{array}{ll}\text { Sample Characteristics } & 48\end{array}$

$\begin{array}{ll}\text { Hepatitis C } & 58\end{array}$

$\begin{array}{ll}\text { Hepatitis A } & 60\end{array}$

Hepatitis B

Research Aim \#1 62

Center for Epidemiologic Studies-Depression (CES-D) scale 62

Alcohol Use Disorders Identification Test (AUDIT) 63

$\begin{array}{ll}\text { HCV Stigma Scale (modified) } & 64\end{array}$

Quality of Life - Short Form-12v2 (SF-12v2) 66

$\begin{array}{ll}\text { Research Aim \#2 } & 67\end{array}$

$\begin{array}{ll}\text { QOL - PCS } & 68\end{array}$

$\begin{array}{ll}\text { QOL - MCS } & 68\end{array}$

$\begin{array}{ll}\text { Research Aim \#3 } & 69\end{array}$ 
Collinearity

$\begin{array}{ll}\text { Participant QOL - PCS } & 70\end{array}$

$\begin{array}{ll}\text { Participant QOL - MCS } & 71\end{array}$

$\begin{array}{ll}\text { Chapter Five - Discussion and Conclusion } & 73\end{array}$

$\begin{array}{ll}\text { Limitations of the Study } & 79\end{array}$

$\begin{array}{ll}\text { Implications and Recommendations } & \mathbf{8 0}\end{array}$

$\begin{array}{lr}\text { Nursing Practice Implications } & \mathbf{8 0}\end{array}$

$\begin{array}{lr}\text { Nursing Education Implications } & \mathbf{8 1}\end{array}$

$\begin{array}{lr}\text { Nursing Policy Implications } & 83\end{array}$

Nursing Research Implications

$\begin{array}{lr}\text { Conclusion } & 85\end{array}$

$\begin{array}{lr}\text { References } & 87\end{array}$ 


\section{LIST OF FIGURES}

Figure 1 Conceptual Model: QOL in AI/AN persons with $\mathrm{HCV}$ 


\section{LIST OF TABLES}

$\begin{array}{ll}\text { Table } 1 \text { Sample Characteristics } & 50\end{array}$

Table 2 Sample Characteristics $\quad 51$

Table 3 Sample Characteristics $\quad 52$

Table 4 Sample Characteristics - Native / Tribal Language 53

Table 5 Frequency - Treatment for Sexually Transmitted Diseases / Infections 55

Table 6 Sample Health Information / History and Clinical Characteristics 57

Table 7 Clinical Predictor Variable Descriptives 59

Table 8 Descriptive Variables Statistics $\quad 62$

Table 9 Descriptive Statistics - CES-D

Table 10 Descriptive Statistics - Patterns of Alcohol Consumption 64

Table 11 Stigma Subscale scores by Levels of Stigma 65

Table 12 Descriptive Statistics - HCV Stigma 66

Table 13 Descriptive Statistics - Quality of Life (SF-12v2) 67

Table 14 Correlation Matrix - Predictor Variables and QOL - PCS \& MCS 69

$\begin{array}{ll}\text { Table } 15 \text { Summary of Collinearity Statistics- PCS } & 71\end{array}$

$\begin{array}{ll}\text { Table } 16 \text { Coefficients for Model Variables - PCS } & 71\end{array}$

Table 17 Summary of Collinearity Statistics- MCS 72

Table 18 Coefficients for Model Variables - MCS 72 


\section{LIST OF APPENDICES}

Appendix A - Site 1 - Letter of Support

Appendix B - Site 2 - Letter of Support

Appendix C - University IRB Approval

Appendix D - University IRB Approval - Modification

Appendix E - Site 1 - IRB Approval

Appendix F - Site 2 - IRB Approval with Recommendations

Appendix G - Site 2 - IRB Approval

Appendix $\mathrm{H}$ - Site 1 - Invitation Letter for Study Participation

Appendix I - Site 2 - Invitation Letter for Study Participation

Appendix J - Site 1 - Research Participant Consent Form

Appendix K - Site 1 - Projectal Subject's Bill of Rights

Appendix L - Site 2 - Research Participant Consent Form

Appendix M - Site 2 - Projectal Subject's Bill of Rights

Appendix N - Site 1 - HCV Research Study Participant Incentive

Appendix O - Site 2-HCV Research Study Participant Incentive

Appendix R - AUDIT Scale Questionnaire 


\section{Chapter 1}

\section{Introduction}

\section{SIGNIFICANCE OF THE PROBLEM}

Hepatitis C Virus (HCV) is considered to be a global public health threat.

Alarmingly, $75 \%$ of infected persons have no symptoms and are unaware of their health status. When symptoms do occur, they may be mild and indistinguishable from hepatitis A or B viruses (Centers for Disease Control and Prevention (CDC), 2009a). According to Wise, Bialek, Finelli, Bell, and Sorvillo (2008), the acute case fatality rate is low; approximately $75 \%$ of infected persons suffer chronic illness. In addition to the physical manifestations and complications, chronic HCV is also associated with neuropsychiatric complaints, most notably fatigue and depression. Treatment is costly, causes difficult side effects, but is effective in eliminating the virus and reducing liver injury in fewer than $50 \%$ of diagnosed cases (The Indian Health Service [IHS] Provider, 2007). Currently, there is no vaccine against HCV; however, in 1998, recommendations for the prevention and control of HCV in high-risk groups were issued (CDC, 2001).

Despite the overall successes in the fight against viral hepatitis, disparities continue to exist. It is significant to note that American Indian/Alaskan Natives (AI/ANs) commonly contend with issues that prevent them from receiving or seeking medical care. These issues include cultural barriers, geographic isolation, educational level, and financial disparities (Jones, 2006). Some of the leading diseases and causes of 
death among AI/ANs are heart disease, cancer, unintentional injuries (accidents), diabetes, and stroke (CDC, 2003). In addition, Al/ANs have a high prevalence and risk factors for mental health, suicide, obesity, substance abuse, sudden infant death syndrome (SIDS), teenage pregnancy, liver disease, and hepatitis (IHS, 2009; Shore \& Manson, 1983).

In 2007, AI/ANs were twice as likely to develop a case of HCV, as compared to the White population. In $2005, \mathrm{Al} / \mathrm{ANs}$ ages 40 years and over, were $70 \%$ more likely to have Hepatitis B, than non-Hispanic Whites. The data on chronic Hepatitis B and HCV infection (past or present) are not included by the CDC in the National Notifiable Diseases Surveillance System reports, because they are undergoing data quality review. This data is not reported in the CDC Healthy People 2010 database (Office of Minority Health [OMH], 2009); the National Health and Nutrition Examination Surveys (NHANES) do not include groups who may be considered at higher risk for hepatitis infection (i.e., Indigenous people, those institutionalized or incarcerated, injection drug using homeless populations, etc.). Therefore, the reported hepatitis data provide conservative estimates of disease prevalence (McQuillan et al., 2010).

The HCV infection is one of the most important causes of chronic liver disease in the U.S.. It accounts for about $15 \%$ of acute viral hepatitis, 60 to $70 \%$ of chronic hepatitis, and approximately $50 \%$ of cirrhosis, end-stage liver disease, and liver cancer (Institute of Medicine [IOM], 2010a). Within the U.S. population, 1.6\%, or an estimated four million Americans, have antibody to $\mathrm{HCV}$, indicating ongoing or previous infection with the virus. The CDC (2009e) reports that hepatitis causes an estimated 15,000 deaths annually in the U.S. Research conducted by Scott and Garland (2008) with aboriginal 
North Americans found that the route of transmission was similar to the general U.S. population and included injection drug use and blood transfusion exposure. It is important to also note that a well-defined and key characteristic of $\mathrm{HCV}$ is its tendency to cause chronic liver disease; the liver injury can lead to cirrhosis, liver failure, and liver cancer (Butt, McGinnis, Skanderson, \& Justice, 2009).

Overall, the prevalence of acute HCV has declined substantially (from 5.2 cases per 100,000 population in 1995 to 0.5 cases per 100,000 population in 2007 ) among persons aged 25 - 39 years, the age group that historically maintained the highest rates of infection (CDC, 2009c). Improvements have also been made in reducing disparities in racial/ethnic-specific rates; during the years from 2004 - 2007 the incidence of acute $\mathrm{HCV}$ was similar across all racial/ethnic populations with the exception of $\mathrm{AI} / \mathrm{ANs}$, for whom rates were higher. Notably in 2007 , rates were similar across racial/ethnic populations other than $\mathrm{AI} / \mathrm{ANs}$, for whom the rate was 0.5 cases per 100,000 populations (CDC, 2009d). Close monitoring of the incidence in at-risk communities remains critical in the detection of the disparities (Smedley, Stith, \& Nelson, 2003).

Wise and colleagues (2008) propose that disease burden and mortality from HCV will increase in the U.S. in correlation to the increase in the numbers of persons with long-standing chronic infection increase. The mortality rates from 1995 - 2004 identified a total of 56,409 hepatitis C-related deaths. This increase was greater among males (144\%) than females (81\%), and among non-Hispanic blacks (170\%) and AIs (241\%) compared to non-Hispanic whites (124\%) and Hispanics (84\%) (CDC, 2009a; National Institute of Diabetes and Digestive and Kidney Diseases [NIDDK], 2006). Hepatitis C virus is an important cause of premature mortality. Despite small declines in recent 
years, rates have continued to increase among persons aged 55-64 years. This clearly supports the need for community-academic partnerships in research that addresses HCV mortality as it continues to increase substantially since 1995 (Lesser \& Oscós-Sánchez, 2007).

\section{PURPOSE OF THE STUDY}

The purpose of this study is twofold. First, it will examine the relationship between quality of life (QOL), depression, alcohol consumption, and stigma in this sample of AI/ANs living with $\mathrm{HCV}$. A review of the literature revealed a need for more quantitative research to examine the prevalence of depression in AI/ANs living with $\mathrm{HCV}$ and compare the effects of their HCV status, stigma, alcohol consumption, and depression on QOL dimensions. Second, this proposed study will fill a gap in the hepatitis and nursing literature by describing QOL and variables of depression, alcohol consumption, and stigma among AI/ANs living with $\mathrm{HCV}$. The results of this study will bring new knowledge within the context of AV/AN health and further the development a culturally based frameworks useful in assisting AI/AN HCV patients and health care providers (Giger \& Davidhizar, 2007).

This is a public health priority because depression generally has been associated with the outcomes of chronic diseases like $\mathrm{HCV}$ and has contributed to the high economic burden of health care costs (Bailey et al., 2009; Kaiser Family Foundation, 2009). The economic burden of $\mathrm{HCV}$ is directly related to the complications of cirrhosis and hepatocellular carcinoma (HCC). Hospitalizations account for a large proportion of the expenditures for HCV-related care. In 2004, approximately 419,000 hospital discharges in the U.S. were attributed to liver disease due to HCV (Everheart, 2008). In 
1997 , an estimated $\$ 1.8$ billion in medical care costs was associated with HCV infections (Leigh et al., 2001) while in 2011, the total healthcare cost associated with HCV infection was $\$ 6.5$ (\$4.3-\$8.2) billion (Razavi et al., 2013). Total cost is expected to peak in 2024 at $\$ 9.1$ billion ( $\$ 6.4-\$ 13.3$ billion). The majority of peak cost will be attributable to more advanced liver diseases-decompensated cirrhosis (46\%), compensated cirrhosis (20\%), and HCC (16\%). The maximum cost associated with mild to moderate fibrosis (F0-F3) occurred in 2007 at nearly $\$ 780$ million. The cost associated with compensated cirrhosis is expected to peak in 2022 at $\$ 1.9$ billion, while the peak cost for decompensated cirrhosis and $\mathrm{HCC}$ is predicted to occur in 2025 , with annual costs in excess of $\$ 4.2$ billion and $\$ 1.4$ billion, respectively (Razavi, 2013).

Patients living with HCV have a significant decrease in their QOL, although treatment success can alleviate this negative effect (Rodger, 1999). The rate of depression amongst $\mathrm{HCV}$ patients $(\mathrm{n}=157)$ was found to be $59 \%$, resulting in a significant reduction in health-related QOL (Gallegos-Orozco et al., 2003). The World Health Organization (WHO, 2010) reports depression is the leading cause of disability worldwide; moreover, the risk of depression is greater for persons living with chronic $\mathrm{HCV}$ and a common side effect due to $\mathrm{HCV}$ treatment medication.

Hepatitis $\mathrm{C}$ is associated with reduced health related QOL as reflected in the disturbances of behavioral, cognitive, physical, and social aspects of wellbeing and, therefore, leads to physical and psychological problems. Quality of life has also been shown to decrease in patients recently made aware of their HCV status. The reason for this decline in QOL seen after diagnosis, in the absence of treatment, may be secondary to a labeling phenomenon (Rodger, 1999). Furthermore, persons with 
HCV suffer from debilitating fatigue, pruritus, loss of self-esteem, depression, and complications of cirrhosis (Younossi, Boparai, McCormick, Price, \& Guyatt, 2001).

Specific Aims:

Aim \#1: Characterize the level of depression, alcohol consumption, stigma, and quality of life among a sample of Al/ANs living with $\mathrm{HCV}$.

Aim \#2: $\quad$ Examine the relationship among the variables of age, gender, residing on an $\mathrm{Al} / \mathrm{AN}$ reservation, current partner status, marital status, depression, alcohol consumption, and stigma with quality of life in a sample of $\mathrm{Al} / \mathrm{ANs}$ living with $\mathrm{HCV}$.

Aim \#3: Identify factors that explain the greatest amount of variance in the quality of life of AI/ANs living with HCV.

\section{CONCEPTUAL MODEL}

The framework underlying this study is derived from the literature based on the concepts of QOL, depression, alcohol consumption, and stigma (Figure 1). Living with a $\mathrm{HCV}$ diagnosis can be a significant stressor for $\mathrm{Al} / \mathrm{AN}$ persons and their families, social support system, and communities (Whitbeck, Adams, Hoyt, \& Chen, 2004). The responsibilities and burden of living with $\mathrm{HCV}$ and its complications can lead to reactions such as psychological stress, denial, anger, and even depression (Johnson, Gryczynski, \& Wiechelt, 2007; Neumeister et al., 2007). Over time, these responses may be short-lived and some patients, invariably, learn to cope with HCV and life in general. However, there may be some who experience prolonged and lingering feelings of stress and depression and are unable to adapt to living with $\mathrm{HCV}$. A potential explanation for 
the development of depressive symptoms based on the Transactional Model of Stress and Coping, is that persons living with HCV cope differently than persons who do not develop symptoms of depression, anger, or stress (Lazarus \& Folkman, 1984).

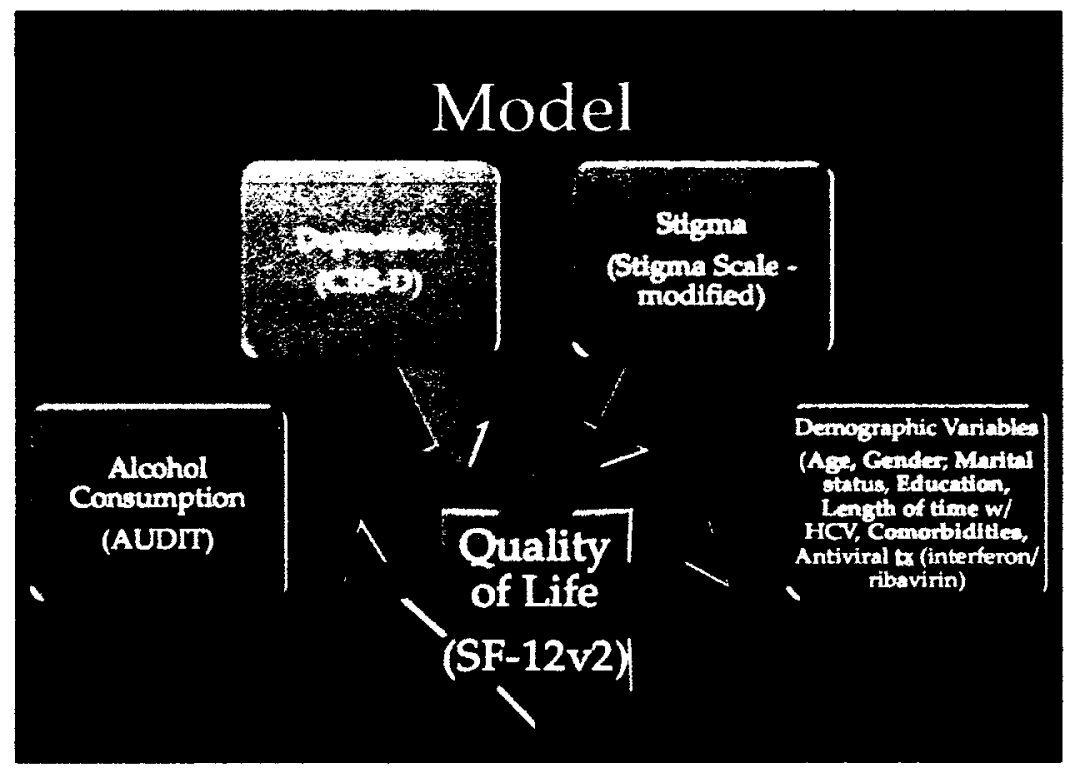

Figure 1 Conceptual Model: $Q O L$ in $A I / A N$ persons with $H C V$

Quality of Life - Short Form-12v2 (SF-12v2) - The Medical Outcomes Study (MOS) began as a prospective, four-year observational study of the influence of characteristics of providers, patients, and health systems on outcomes of care. Since that time, several measures of health status and QOL were developed and evaluated in this study (Stewart, Hays, \& Ware, 1988). The most widely used and best known is the SF36; it uses 36 items to cover eight dimensions: physical functioning, physically related role limitations, social functioning, pain, vitality, mental health, emotionally related role limitations, and general health perceptions. The SF-12v2 was adapted from this measure. For this study, the SF-12v2 (Appendix B) was applied to examine QOL in AI/AN HCV 
participants (Ware \& Sherbourne, 1992). The QOL of persons living with HCV has become increasingly important. There is now a paradigm shift in transforming goal therapy to improve QOL in addition to the reduction of symptoms, HCV suppression, and extension of survival.

Center for Epidemiologic Studies-Depression (CES-D) scale - The CES-D was developed by the CES at National Institute of Mental Health (NIMH) specifically to meet the need for a brief, inexpensive measure of depression suitable for application in community surveys (McDowell, 2006; Radloff, 1957). Cognitive problems, depression being most common, is often overlooked in routine clinical encounters. This failure to recognize this problem could influence treatment outcomes for persons living with $\mathrm{HCV}$ (Horsmans, 2005). An awareness of depression's prevalence among HCV persons and its potential mechanisms will encourage both patient and health care providers to be proactive in addressing depression affiliated with chronic HCV. The instrument is not explicitly tied to a theoretical framework but can screen for clinical depression in large epidemiological studies (Frank-Stromborg \& Olsen, 1997).

Alcohol Use Disorders Identification Test (AUDIT) - There is no theoretical framework that guides the AUDIT; however, this is a measure developed by the WHO as a screening instrument for hazardous and harmful alcohol consumption (Saunders, Aasland, Babor, de la Fuente, \& Grant, 1993). The use of heavy alcohol consumption is an important cofactor in the progression of $\mathrm{HCV}$-related liver disease leading to cirrhosis and HCC. Also, heavy alcohol consumption of more than 80 grams per day seriously compromises HCV illness or treatment. The NIH (2002) reports safe levels of alcohol consumption is unclear and that even moderate levels of consumption may accelerate 
$\mathrm{HCV}$ disease progression in some patients. Abstaining from alcohol is one of the most important factors in preserving liver health in persons with $\mathrm{HCV}$, and brief assessments have been found to be cost-effective ways to reduce alcohol consumption. The AUDIT provides a simple method of early detection of hazardous and harmful alcohol use in primary health care settings, which makes it an appropriate measure for this study (Appendix F). This instrument is the first of its type to be derived on the basis of a crossnational study (Saunders, Aasland, Amundsen, \& Grant, 1993).

HCV Stigma Scale (modified) - The concept of HCV stigma is based on the work of Goffman (1963), who pioneered the concept of stigma. It suggests that situations exist, which spoils one's social identity. Stigma related to HCV has been found to have negative effects on self-esteem, access to health care, employment, social support, and effects on their overall health status and well-being (Crockett \& Gifford, 2004). The standardized measure exploring HCV-related stigma in this study will utilize the HIV Stigma Scale (Berger, Ferrans, \& Lashley, 2001); this was modified and renamed the HCV Stigma Scale (Appendix C) by this researcher. The discrediting attributes of which Goffman spoke may take the form of physical deformity, blemishes of character, and tribal stigma (1963). Any or all of these forms of stigma can impact persons living with HCV. The Transactional Model of Stress and Coping for this descriptive correlational study includes concepts from Medical Outcomes Study QOL Model; this provides understanding of chronic illnesses and related factors that affect QOL.

\section{IMPLICATIONS TO RESEARCH, EDUCATION, PRACTICE, AND POLICY}

The identification of factors that influence QOL in HCV patients has the potential to give direction to the development of nursing interventions or culturally-based care that 
may improve life quality in AI/AN HCV patients (Bushy, 2008; Randall \& Muneta, 2000). This study will help to identify the level of depression, alcohol consumption, stigma, and QOL among AI/AN HCV patients. Additionally, the study will examine whether there is a relationship between depression, alcohol consumption, stigma, and QOL in Al/AN HCV patients. Persons with HCV may need training in coping skills to effectively deal with the stresses of living with hepatitis and life in general (EvansCampbell, 2008; Lillie-Blanton \& Roubideaux, 2005). The results of this study may have important implications for hepatitis education, treatment, AI health care policy, and practice improvements (Buffington \& Jones, 2007; Lowe, 2008). Information from this study may help nurses develop interventions to facilitate effective coping strategies and improve QOL of $\mathrm{HCV}$ patients. 
Chapter 2

Review of the Literature

The purpose of this chapter is to present a review and critique of published research and theoretical literature representative of the current knowledge base of QOL and persons living with HCV. The literature discussed here lends support to the significance of exploring Al/ANs with $\mathrm{HCV}$ as a way to further understand the relationships between depression, alcohol consumption, stigma, and QOL. This review of the literature examines the body of work and current state of the science.

The conceptual framework and underpinnings for this study is based on the literature and concepts of depression, alcohol consumption, stigma, and QOL. There is a dearth of research that collectively focuses on depression, alcohol consumption, stigma, and QOL within the hepatitis literature. It is through the contextual lens of QOL that this research can add to the science of $\mathrm{HCV}$ research and nursing practice. This study and its focused areas of concepts among HCV patients will expand on this area of scholarship with support of the current literature and science.

\section{Concepts}

\section{QUALITY OF LIFE}

In recent decades, there has been a broadened emphasis in the literature regarding QOL measurement of health outcomes. The importance of QOL ruminates beyond the scope of health indicators such as mortality and morbidity. This particular emphasis is 
comprised of: evaluating patient-reported functional health status' using the Duke Health Profile (Parkerson, 1994); describing physical, emotional, and social function using the McMaster Health Index instrument (Chambers, 1993); or measuring indicator of health status with the MOS SF-36 Health Survey (Ware, Kosinkski, \& Gandek, 2002). There is, however, a subjective component present within the context of defining QOL. It is those distinctive personal experiences and circumstances that shape an individuals' perspective on QOL (Gallegos-Orozco et al., 2003; Hennessy, Moriarty, Zack, Scherr, \& Backbill, 1994). This broadened research emphasis in QOL has produced variations in general health status and QOL instruments. They comprise of broad concepts of well-being indicators to a more focused, disease-specific measures anticipated to identify clinically significant changes associated with specific settings (Younossi et al., 2001).

The increased number of persons, over four million in the U.S., living with HCV has shifted the emphasis from a health care system focused only on curative measures and quantity of life to enhancement of QOL (CDC, 2001; IOM, 2010b). In 2005, 133 million Americans. approximately one out of every two adults - had at least one chronic illness (Foster, 2009; Wu \& Green, 2000). Moreover, the trajectory of chronic illness acquiesces suffering and reduces QOL (Alter, 2002; Strauss \& Dias Teixeira, 2006). In the latter part of the $20^{\text {th }}$ century, the WHO broadly defined health as a state of physical, mental, and social well-being not merely the absence of disease and infirmity (Grad, 2002).

The World Health Organization (1997) defines the term QOL as an individual's perception of his/her position in life in the context of the culture and value systems in which he/she live. And, in relation to his/her goals, expectations, standards, and 
concerns. It is a broad ranging concept affected in a complex way by the person's physical health, psychological state, level of independence, social relationships, personal beliefs, and his/her relationship to significant features of his/her environment (Bailey et al., 2009). Viktor Frankl $(1963,2004)$ asserts that QOL is tied to perception of meaning. This quest for meaning is central to the human condition as we are brought in touch with a sense of meaning when we reflect on that which we have created, loved, believed in, or left as a legacy.

The considerable influence on utilization of health care resources and substantial harm to one's well-being has necessitated further exploration of QOL in an AI/AN HCV population. The CDC (2000) views QOL as a broad multidimensional concept that usually includes subjective evaluations of both positive and negative aspects of life. The overall concept allows for an interdisciplinary focus among various disciplines and stakeholders to benchmark QOL as an overarching public health goal and national health standard of measure (NIDDK, 2006). The QOL standardized measure has many uses including: medication practice, research, audit, policy making, and in assessing the effectiveness and importance of varying treatments. It can also be beneficial in assessing variation in QOL across diverse populations, to compare subgroups within similar cultural groups and to measure differences across time in response to alteration in life circumstances (Stewart \& Ware, 1992). The literature review regarding SF-12v2 and AI/ANs yielded very few studies but other QOL studies focusing on AI/ANs were identified.

A study by Johnson, Nowatzki, \& Coons (1996) identified a sample population of Pima Indians $(n=54)$ living with diabetes mellitus (DM). Health status questionnaires 
were administered and QOL was measured in collaboration with an outpatient pharmacy in southern Arizona. The SF-36 Health Survey was utilized to assess QOL. Internal consistencies of the eight multi-item scales of the SF-36 were estimated. Nonparametric analyses were performed to determine relationships between mean SF-36 scale scores and various clinical and demographic variables. Favorable internal consistencies were observed for the multi-item scales, with the coefficient $\alpha$ ranging from 0.63 to 0.91 . The SF-36 scale scores were not influenced by sex or education level. Age was found to be significantly associated among four of the eight dimensions. Indicators of glycemic control were not significantly associated with any SF-36 multi-item scale scores. Subjects with more comorbid chronic conditions had significantly lower SF-36 scores. If the goal of maximizing AI health status is to be achieved, QOL assessment should be utilized as a means to monitor progress toward that goal.

Another population study provided evidence of poorer QOL among AI participants with comorbid DM and hypertension (HTN). The relationship between QOL and different types of help-seeking differed depending on the comorbidity status of the participants. Jiang, Beals, Whitsell, Robideaux, and Manson (2009) evaluated QOL of Als living with DM, HTN, or both conditions using the SF-36. They also explored how QOL is associated with help-seeking among AIs--with and without these chronic conditions. Secondary data analysis was conducted on data obtained from AI participants with DM and/or HTN from a larger epidemiological study of two AI tribes. The participants with DM and HTN had the lowest QOL on all eight subscales of the SF-36. Confirmatory factor analysis revealed the assumption of equivalent factor loadings for participants with and without DM and/or HTN was not satisfied. The usefulness of 
traditional healers (Novins, Beals, Moore, Spicer, \& Manson, 2004), a form of helpseeking, was significantly inversely related to physical factor scores for all the respondents except those with DM only.

Dwight et al. (2000) concluded disability and fatigue were more closely related to depression severity than to hepatic disease severity. The target population consisted of chronic hepatitis $\mathrm{C}(\mathrm{CHC})$ patients $(n=50)$ being evaluated through structured interviews using standardized measures. The objective was to examine the extent to which fatigue and functional disability correlate with severity of depressive symptoms in persons with HCV. Bonkovsky and Woolley (1999) also evaluated the effects of CHC infection on a sample of patients' perceptions and whether treatment with interferon improved QOL. The investigators concluded $\mathrm{CHC}$ patients with or without cirrhosis had significant reduction in QOL. A total of 642 patients with liver disease, enrolled in an interferon drug trial study for $\mathrm{CHC}$, were evaluated for QOL using the SF-36 and other measures derived from the MOS. Persons with $\mathrm{CHC}$ were compared with a healthy control group ( $n=750$ ); the CHC group at baseline reported lower HRQOL on all eight scales of the SF-36 $(p<.001$ for all). Persons without cirrhosis $(n=284)$ reported similar, however, slightly smaller reduction in QOL. Overall, successful interferon therapy provides meaningful improvements in QOL in persons with $\mathrm{CHC}$.

Fontana and colleagues (2002) used a large sample of CHC patients $(n=220)$ not receiving anti-viral therapy and the prevalence, type, and severity of emotional distress among was examined. This study involved a Brief Symptom Inventory (BSI) (Derogatis, 1993) and a 67-item questionnaire with an embedded SF-36 instrument (Fontana et al., 2002). The BSI provides patient-reported data and an overview of 
patient symptoms and intensity at a specific point in time. The Global Severity Index (GSI) is designed to help quantify severity-of-illness and provides a single composite score for measuring the outcome of a treatment program based on reducing symptom severity (Derogatis, 1993). This study showed clinically significant emotional distress being reported in $35 \%$ of persons with $\mathrm{CHC}$ not receiving antiviral therapy. In addition to depression (Wessely \& Pariante, 2002), a wide range of psychological symptoms was discerned that merits further inquiry into the causes and treatment of emotional distress in persons with CHC viral illness (Palmer, 2004).

\section{DEPRESSION}

According to the diagnostic criteria described by the Diagnostic and Statistical Manual of Mental Disorders (4th ed., text rev.; DSM-IV-TR; American Psychiatric Association, 2000), major depressive disorder is defined as experiencing either depressed mood or loss of interest or pleasure. Along with at least four other symptoms that reflect a change in functioning, such as problems with sleeping, eating, energy, concentration, and/or self image, for a period of two weeks or longer. Clinical depression is a serious medical illness that is much more than temporarily feeling sad or blue. It involves the disruptions in mood, concentration, sleep, activity level, interests, appetite, and social behavior.

Although depression is highly treatable, it is frequently a life-long condition in which periods of wellness alternate with recurrences of illness. One area of particular concern is suicide (Shaffer, 1988) when depression is left untreated. According to the IHS (2009b), AI/ANs die at higher rates than other Americans from alcoholism (517\%), tuberculosis (533\%), motor vehicle crashes (203\%), diabetes (210\%), unintentional 
injuries (150\%), homicide ( $87 \%)$, and suicide $(60 \%)$. The prevalence and manifestations contrast depending on background differences and areas of residence (Manson, Shore, \& Bloom, 1985).

The validity of using western measures of depression has also led to a concern with $\mathrm{AI} / \mathrm{AN}$ populations due to vast differences in cultural beliefs, mental illness, cultural labeling of different emotions, variability of depression manifestations (rarely DSM-IV criteria), and conceptual language differences (Manson, Ackerson, Dick, Baron, \& Fleming, 1990). A study of adult AIs of a Northwest Coast Tribe demonstrated little differentiation between physical and emotional distress (Somervell et al., 1992). There are many $\mathrm{AI} / \mathrm{AN}$ cultural differences that exist in seeking mental health services and in reporting distress. In addition, there is the much-researched phenomenon of historical trauma and distrust of the outside population among many AI/AN communities (Brave Heart, 1998; Evans-Campbell, 2008; Steinman, 2005; Weaver \& Brave Heart, 1999; Whitbeck, Adams, Hoyt, \& Chen, 2004).

$\mathrm{AI} / \mathrm{ANs}$ tend to have negative opinions of non-IHS providers, and the majority of AI/ANs prefer the utilization of their own traditional healing practices (Rhoades \& Rhoades, 2000). Compared to the general population, AI/AN individuals are inclined to underutilize mental health services, have higher therapy dropout rates, and are less likely to respond to treatment. The term depressed and anxious or any term relevant to a clinical psychological view are notably absent from most AI/AN languages and are not conceptualized in the AI/AN traditional health belief system. A culturally different expression of illness, such as ghost sickness and heartbreak syndrome, do not correspond to conventional DSM diagnostic criteria. 
Living in a stressful environment has potentially negative mental health consequences. Approximately $26 \%$ of $\mathrm{AI} / \mathrm{AN}$ live in poverty, as compared to $13 \%$ of the general population, and 10\% of Caucasian Americans. In a Northern Plains study, $61 \%$ of the children had experienced a traumatic event (Middlebrook, 2009). The AI/AN population reports higher rates of frequent distress than the general population. There is a high prevalence of substance abuse and alcohol dependence that is tied to a high risk for concurrent mental health problems. Alcohol abuse is a problem for a substantial portion of the AI/AN adult population, but varies widely among different tribes (National Alliance on Mental Illness, 2003).

The Great Smoky Mountain study found the prevalence of psychiatric disorders is similar among AI and Caucasian American youth in the same geographic area; however, there are significantly higher rates of substance abuse in AI children (Costello, Farmer, Angold, Burns, \& Erkanli, 1997). A study of ANs in a community mental health center found that substance abuse was the reason for $85 \%$ of men and $65 \%$ of women to seek mental health care. A study by Middlebrook (2009) found that Northern Plains' youth diagnosed with any depressive disorder, $60 \%$ also had substance disorders.

The prevalence of suicide is a strong indication for the necessity of mental health services in the Al/AN community (Bender, 2003, 2006; Borowsky, Resnick, Ireland, \& Blum, 1999; Broderick, 2009; Pettingell et al., 2008). AI/AN males have one of the highest documented suicide rates in the world. Suicide rates are particularly high among AI males, ages $15-24$, who account for $64 \%$ of all suicides by AI/AN individuals (Alcantara \& Gone, 2007; Wissow, Walkup, Barlow, Reid, \& Kane, 2001; Yoder, Whitebeck, Hoyt, \& LaFromboise, 2006). A study of Eskimo children in Nome, Alaska, 
found previous suicide attempts to be one of the most common problems for those seeking mental health care (Aoun \& Gregory, 1998; Kleinfeld \& Bloom, 1977).

Mental health programs are available for the AI/AN community, but are in need of improvement (Neligh, 1990). The IHS is a federal agency within the U.S. Department of Health and Human Services (U.S. DHHS) that is responsible for providing health care services to AI/ANs. There are 12 IHS Area Offices across the country; which oversee the delivery of health care services. They provide administrative and technical support and offer a variety of care services including mental health, alcohol and substance use prevention (IHS, 2008, 2011a). In a large national study (the Behavioral Risk Factor Surveillance System), 3,940 AI/AN adults were surveyed in 36 states concerning drinking patterns. Respondents were compared by age and sex to non-Hispanic White respondents. Contrary to stereotypes, AI/AN men reported lower levels of chronic drinking than non-Hispanic White men at older ages. AI/AN reported less current drinking but about the same amount of binge drinking as non-Hispanic Whites by age and sex, with all groups of women reporting low levels of chronic drinking (Denny \& Taylor, 2001).

Depression is a common and highly treatable disorder affecting over $17-20$ million Americans annually. When left untreated and/or under-treated, depression is the leading cause of suicide in the U.S. (IOM, 2002; Substance Abuse and Mental Health Services Administration (SAMHSA), 2011). Once identified, depression can almost always be successfully treated. Unfortunately, there is limited information available about the prevalence of mental illness between AI/AN--more specifically women. The two major studies conducted-The Epidemiologic Catchment Area Study and the 
National Comorbidity Survey-did not report data on AI/ANs. The prevalence among $\mathrm{AI} / \mathrm{AN}$ populations are problematic because they may be susceptible to unique factors that may affect their vulnerability to mental illness (Brave Heart \& DeBruyn, 1998). Awareness and knowledge is the first step to prevention and successful treatment.

Available evidence suggests mental illnesses impact approximately 20 percent of the total AI/AN population. The overall mental health picture for AI/ANs is not fully documented; previous studies are restricted by small sample sizes, limited funding, racial misclassification, and a focus on specific conditions (SAMHSA, 2011). In the AI/AN population, high lifetime risk rates of substance use disorders, anxiety disorders, and low socioeconomic conditions combine to give context to the greater risk for the development of depression (Dickerson \& Johnson, 2010).

Many minority women experience depression and stress brought on by persistent racism, gender bias, violence, poverty, large family size, and social disadvantages. Yet, access to culturally relevant therapy is rare; access to qualified mental health services is poor, and the quality is poor. According to the 2001 Surgeon General's report minority women with access to mental health services are less likely than White women to use them for reasons related to income and availability of health insurance, but also personal history and culture (U.S. DHHS, 2001). Duran et al. (2005) state among minority women, there is greater tendency to engage in other informal sources of help, such as prayer or support groups where women gather and talk with friends, hoping to gain what others often gain by having individual therapy. The main cause for not seeking outside treatment is lack of trust (Lowe, 2008).

Another reason minority women do not seek formal therapy is because of their 
respective cultures. There are other ways of regaining a sense of peace and well-being. Native American women and women of Alaskan descent often rely on traditional healers (Randall \& Muneta, 2000), who may work side by side with formal health providers in tribal mental health programs. AI/AN women have access to some mental health care services through IHS on their reservations, though finding culturally competent services can be a challenge.

The CES-D scale (Radloff, 1977) is a 20-item self-report questionnaire developed to measure and identify symptoms of depression or psychological distress in community populations (Myers \& Weissman, 1980; Roberts \& Vernon, 1983). The composited items were selected from previously validated scales and cover the major components of depressive symptomatology. The general population were being defined as nonpsychiatric persons over the age of 18. At the time of its development, researchers were interested in the health correlates of depressive symptoms and in tracking changes in severity of symptoms over time.

The scale has also been applied in many studies as a screen for the presence of depressive illness. Items were selected to represent the major components of depression on the basis of the clinical literature and factor analytic studies. It was designed to gauge the major components of depression that includes depressed mood, feelings of guilt and worthlessness, feelings of helplessness and worthlessness, psychomotor retardation, loss of appetite, and sleep disturbance.

It is not a clinical diagnostic measure for a depression diagnosis because it only assesses symptoms presenting in the past week and does not assess the complete range of depressive symptoms. However, it can be used as an indicator of symptoms. It is also an 
important measure for recognizing groups at-risk for depression, as well as the links between behavior and depressive symptoms (Breslau, 1985). It has been developed in the recognition of depressive symptoms in the general population; research supports the utility of the CES-D scale in assessment studies, and as a screening tool.

The scoring of CES-D begins with participants answering items about the regularity and length of depressive moods, thoughts, or feelings in the past week. Participants are asked to rate each item using a 0 to 3 -response scale; except for the four positive questions, on how often you have felt this way during the past week. A 0 response means rarely or none of the time (less than 1 day), 1 means some or a little of the time (1-2 days), 2 means occasionally or a moderate amount of time (3-4 days), and 3 means most or all of the time (5-7 days). In order to control for response bias, four items $(\# 4,8,12$, and 16) were worded in a positive direction.

The scores are summed to provide an overall score ranging from 0 to 60 ; higher scores indicate more severe depressive symptoms. The total severity is calculated by reverse scoring questions $\# 4,8,12$, and 16 (the items that control for response bias) and then summing all of the scores. A score of 16 or higher has been identified in early studies (Weissman, Sholomskas, Pottenger, Prusoff, \& Locke, 1977) and commonly taken as indicative of depressive illness. They represent a range of depressed mood, from average mood levels to high levels of depressed mood. If one's mood score is high, they are more likely to have trouble controlling other aspects of their life. An example would be that, a person might be at risk of abusing alcohol, tobacco, or other drugs excessively. Therefore, their score may serve, as a reminder that they need to learn to control their mood in other ways if one wants to be successful in living a healthier life. 
The interpretation of a CES-D score of less than 16 indicates clearly within the average range of scores for adults in the U.S. that depressed mood does not seem to be a current issue. Whereas, scores ranging from 16 to 24 , suggests borderline elevation of depressed symptoms, compared to other adults. While depressed mood may be a source of concern, and it may be worthwhile to learn methods to manage mood to prevent the level of depression from getting worse (Lewinsohn, Muñoz, Youngren, \& Zeiss, 1992; Muñoz, 1996). And, scores 24 or above would suggest a significant elevation of depressed symptoms and compared to others, it would be essential to decrease the level of depression.

The CES-D reliability and validity has been tested in African American, Asian American, French, Greek, Hispanic, Japanese, and Yugoslavian populations (Naughton \& Wiklund, 1993). It has also been translated into several languages, including Chinese (Cantonese and Mandarin), French, Greek, Japanese, and Spanish. The internal consistency as measured by Cronbach $\alpha$ is high across a variety of populations (generally around 0.85 in community samples and 0.90 in psychiatric samples) (Boyd, Weissman, Thompson, \& Myers, 1982; Husaini, Neff, Harrington, Hughes, \& Stone, 1980). Splithalf reliability is also high, ranging from 0.77 to 0.92 . Test-retest reliability studies ranging over 2-8 weeks show moderate correlations $(r=0.51-0.67)$, which is desirable for a test of symptoms expected to show change over time. One study comparing African American, Anglo-American, and Mexican American respondents showed no difference in measures of internal consistency reliability (Roberts, 1980). The validity of CES-D in an outpatient setting sample with depression, alcoholism, drug addiction, or schizophrenia has been examined. The correlation coefficients $(r)$ between CES-D scores 
and Symptom Checklist-90 (SCL-90), depression subscale scores were high, ranging from 0.73 to 0.89 . Correlations with the Hamilton Rating Scale for Depression (Ham-D) scores were variable and ranged from 0.49 for patients with acute depression to 0.85 for patients with schizophrenia. Correlations with the Raskin Scale were also variable, ranging from 0.28 for patients with acute depression to 0.79 for patients with schizophrenia (Weissman et al., 1977).

It should be noted that CES-D scores differ widely depending on one's condition in society. For example, although the mean score on the CES-D is 8.7 for people aged 25 to 74 , women tend to score higher than men. Moreover, among individuals living alone, the average CES-D score for men and women is 8.5 and 10.8, respectively. This is in contrast to people living with others showed that, the average CES-D score for men and women is 6.8 and 9.3, respectively. Interestingly, the average for women who are heads of households is 12.5. People with less education and lower income tend to score higher (Sayetta, 1980). An assessment of the aging population using the CES-D evaluated subsets of the original population including persons older than 64 . The coefficient $\alpha$ remained high $(>0.85)$ in this subgroup and test-retest correlations remained $>0.40$. For assessment of the measure in minority populations, the CES-D was evaluated for subsets of the original population including Blacks. The coefficient $\alpha$ remained high $(>0.85)$ in this subgroup; test-retest correlation was $<0.40$ for this group (Radloff, 1977). Group means should only be used in reference to other groups. The internal reliability and consistency is good for all groups tested (race, age, education). The CES-D design strengths and weaknesses clearly show it is not intended as a clinical diagnostic tool and that interpretations of individual scores should not be made (Radloff, 1977). 
Chapleski, Lamphere, Kaczynski, Lichtenberg, and Dwyer (1997) utilized the Center for Epidemiological Studies Depression Scale (CES-D) in a study of 309 Great Lakes AI elders from urban, rural, and reservation settings, with good internal consistency (Curyto et al., 1998). This study also supported earlier findings of an association between stressful life events, depressive symptoms, and decline in functional health status. Depression is among the most prevalent psychopathologies within AI/AN communities, but little is known about the validity and reliability of common assessment measures in this population. Beals, Manson, Keane, and Dick (1991) describes the factor structure of the CES-D scale, which was based on collected data from a sample $(n=605)$ of AI college students. Comparisons of the factor structure across gender indicated differences were due largely to one item: crying. A 3-factor model fit the data well and was judged the most parsimonious.

A clarified conceptual meaning of depression in individuals with $\mathrm{HCV}$ infection is proposed based on a critical review of literature. Moving beyond an exclusively biomedical perspective, depression in $\mathrm{HCV}$ is explained by a cluster of factors that incorporate physiological, psychological, and social dimensions. Symptom experience, stigma, and uncertainty are factors that span the complex nature of depression in persons with HCV. This broadened perspective incorporates individual and societal values and beliefs regarding $\mathrm{HCV}$ and encompasses the multidimensional complexity of depression in HCV. Hepatitis C-related depression presents an enormous challenge for nurses because of its interference with treatment adherence and significant negative impact on the person's QOL (Gallegos-Orozco et al., 2003). Nursing theorists, researchers, and clinicians may benefit from a clear conceptual understanding of the unique nature of 
depression in this growing segment of the U.S. population. This clarified conceptual meaning needs to be examined through qualitative, quantitative, and longitudinal studies with this population. It is hoped that future theorists, researchers, and practitioners will contribute to the conceptual understanding, resulting in improved QOL for this special population (Saunders \& Cookman, 2005).

Although the incidence of $\mathrm{HCV}$ is declining, a large reservoir of patients with CHC exists. Unless effective HCV antiviral regimens are developed, many patients with asymptomatic $\mathrm{HCV}$ may develop clinical symptoms in 15 to 20 years. Mood disorders are common in patients with $\mathrm{HCV}$ who are referred for psychiatric consultation. The drug interferon and ribavirin are the primary treatment for $\mathrm{CHC}$ but can induce depression and other mental and neuropsychiatric syndromes. Mood disorders associated with HCV may respond to psychiatric intervention (Dolan, 1999; Yates \& Gleason, 1998).

A veteran focused study examined the incidence of psychiatric comorbidities among veterans $(n=120)$ with CHC. This study assessed depression, anxiety sensitivity, post-traumatic stress symptoms, and alcohol consumption using standardized measures in veterans with chronic HCV. Lehman and Cheung's (2002) research revealed psychiatric comorbidities to be very common among veterans with chronic $\mathrm{HCV}$ and correlated poorly with diagnoses documented in the medical record. In chronic HCV veterans, clinically significant levels of depression (44.2\%), anxiety (38.1\%), post-traumatic stress disorder (20.8\%), and alcohol-related problems (26.7\%) were observed. Positive correlations were found between post-traumatic symptoms and depressive symptoms, anxiety sensitivity, and alcohol use problems (Nelligan et al., 2008). A correlation 
between depressive symptoms with anxiety was also identified. Overall, $79(65.8 \%)$ veterans had one or more possible contraindications to antiviral therapy: coexisting unstable psychiatric disorders, and/or recent substance use was found in $73.4 \%$ of these veterans. An implication for this study is a multidisciplinary approach that includes psychological assessment using standardized measures in the evaluation of these patients for antiviral therapy.

Another study examined CES-D scale reliability, construct, and predictive validity in a HCV patient sample $(n=116)$ of $62(53 \%)$ males and $54(47 \%)$ females. This longitudinal study tested the CES-D psychometric properties at three time intervals: prior to treatment, at four weeks, and 24 weeks post treatment. Clark, Mahoney, Clark, and Eriksen (2002) concluded that the CES-D is a reliable and valid instrument to screen for depressive symptoms in HCV patients. The instrument is able to detect the predicted increase in depression associated with $\mathrm{HCV}$. However, an examination of the sensitivity and specificity is needed to determine the most accurate cut-off score. The reliability $($ Cronbach $\alpha)=0.88$ Pretreatment, 0.89 Week 4 , and 0.90 Week 24 . The construct validity revealed four factors: negative affect, positive affect, somatic affect, and depressed affect. With the exception for two items, felt sad and couldn't get going, all items loaded distinctly with correlation coefficients in the range of $0.51-0.84$. The predictive validity testing revealed a statistically significant effect over time $(p<0.001)$ in the direction predicted (pretreatment $x=13.97$; post 4 weeks $x=19.54$, and 24 weeks $x=19.97)($ Clark et al., 2002). 


\section{ALCOHOL CONSUMPTION}

The patterns of alcohol consumption and its consequences differ considerably among minority groups. Although more research is needed, evidence supports prevention and treatment efforts may be more effective when based on cultural understanding of the ethnic / cultural contexts of drinking behaviors and their development (Botvin, Schinke, Epstein, Diaz, \& Botvin, 1995; Kumpfer, 1998). It is important to note the uniqueness of racial/ethnic populations including $\mathrm{AI} / \mathrm{AN}$ communities, which differ markedly in cultural characteristics and drinking behavior. Consequently, research does not support broad generalizations about specific subpopulations, many of whom have not been studied individually (Beauvais, 1998; Caetano, Clark, \& Tam, 1998).

Data from nationwide surveys of adults show that both current drinking (defined as consumption of 12 or more drinks in the past year) and heavy drinking are most prevalent among AI/ANs and Native Hawaiians and lowest among Asian American and Pacific Islanders (AAPIs) (Kim, Coletti, Williams, \& Hepler, 1995). Among all age and ethnic groups, men are more likely to drink than are women, and to consume large quantities in a single sitting. Heavy alcohol consumption is defined as five drinks on a single day at least once a month for adults and five drinks in a row at least once during the previous two weeks for adolescents (Johnston, O'Malley, \& Bachman, 2001; Stinson et al., 1998).

The medical consequences and research on alcohol's health effects on minority groups has concentrated largely on cirrhosis, a progressive and often fatal liver disease usually attributable to long-term heavy drinking (NIDDK, 2006). Analysis shows a 
strong correlation between death rates from liver cirrhosis, regardless of cause, and drinking levels nationwide (Singh \& Hoyert, 2000). Consistent with this association, deaths from chronic liver disease and cirrhosis are approximately four times more prevalent among AI/ANs than among the general U.S. population (Beauvais, 1998).

Data from a nationwide survey highlights the social consequences of drinking and driving prevalence in the past year: $19 \%$ among $\mathrm{Al} / \mathrm{ANs}, 11 \%$ for both Whites and Hispanics, 7\% for African Americans, and less than 6\% for AAPIs (Stinson et al., 1998). Alcohol-related fatal crashes are three times more prevalent among AI/ANs than among the general population (Beauvais, 1998), constituting 1 of the 10 leading causes of death among AI/ANs, along with alcohol-related suicide, homicide, and cirrhosis (Grossman, Sugarman, Fox, \& Moran, 1997).

The Alcohol Use Disorders Identification Test (AUDIT) is an instrument designed to identify persons with $\mathrm{HCV}$ and assess their hazardous and harmful patterns of alcohol consumption. The WHO developed the AUDIT as a simple method of screening for excessive drinking and to assist in brief assessment. This measure was developed and evaluated over a period of two decades, and has been found to provide an accurate measure of risk across gender, age, and cultures (Volk, Steinbauer, Cantor, \& Holzer, 1997). It can assist in identifying excessive drinking as the cause of the presenting illness.

It also provides a framework for intervention to help hazardous and harmful drinkers reduce or cease alcohol consumption and, thereby, avoid the harmful consequences of their drinking. The AUDIT also helps to identify alcohol dependence and some specific consequences of harmful drinking. It is particularly designed for 
health care practitioners and a range of health settings, but, with suitable instructions, it can be self-administered or applied by non-health professionals (Allen, Reinert, \& Volk, 2001).

\section{STIGMA}

Today, it is an increasingly acknowledged global reality that those most deeply affected by the HCV epidemic are also severely disadvantaged, whether based on race, gender or sexual orientation, age, or social class (International Council of Nurses (ICN), 2003; WHO, 2001). In addition to the physical challenges HCV presents, this illness carries with it a stigma that negatively impacts QOL for infected persons. The impact on affected persons consists of psychological stress, reduced self-esteem, depression, fear of disclosing HCV status, worsening disease state resulting in limited social support systems and resources (Astone-Twerell, Strauss, \& Munoz-Plaza, 2006; Van Brakel, 2006). The landmark Surgeon General's Report on Mental Health identifies stigma as a public health concern, providing leverage for advocacy (Link \& Phelan, 2006; U.S. DHHS, 1999). As in the case of most other stigmatized health conditions such as HIV/AIDS, mental illness, and sexually transmitted infections, fundamental structural inequalities, social prejudices, and social exclusion explain why women, the homeless, veterans, substance users, sexual minorities, and people of color are disproportionately impacted by HCV and the accompanying stigma and discrimination (IOM, 2010a).

The nearly two decade of global history of the HCV epidemic reinforces the well documented interaction of disease, stigma, and 'spoiled' social identities (Goffman, 1963) based on race, ethnicity, sexuality. In attempting to further understand AI/ANs living and experiencing HCV-related stigma, it is edifying to refer to the concept of 
stigma based on Goffman's scholarly work. Stigma is a term with a multitude of connotations and definitions. The concept of stigma first emerged within the social science research through the seminal work of Erving Goffman.

Goffman (1963) defined stigma as an attribute that is deeply discrediting and reduces the bearer from a whole person to a tainted, discounted one. It is seen among individuals' who are newly diagnosed with HCV and often judge themselves harshly. This diagnosis can bring on feelings or emotions of shame and uncleanliness. According to the Oxford Dictionary (2011), the definition of stigma is a mark of disgrace associated with a particular circumstance, quality, or person. The Greek and Latin origins of stigma also means to mark, brand, or tattoo. Merriam-Webster Dictionary (2011) describes stigma as a mark of shame or discredit; an identifying mark or characteristic; a specific diagnostic sign of a disease.

In general, individuals often first learn about $\mathrm{HCV}$ through negative media or images and adopt misinformation about the modes of $\mathrm{HCV}$ transmission. Because many individuals who may inject drugs have $\mathrm{HCV}$, there is often an automatic association between $\mathrm{HCV}$ and injection drug use. It is due to these assumptions and mischaracterizations towards the injection drug user that this association can lead to stigma. Link and Phelan (2001) posit that stigma exists when a label sets the person apart and links the person to undesirable stereotypes resulting in unfair treatment and discrimination. Stigma related to HCV illness can have profound negative impacts on an individual's personal and social relationships, workplace environment, community, and access to health care. Stigma occurs when individuals are negatively judged and/or discredited because they have $\mathrm{HCV}$. 
An exemplary research study by Buseh, Kelber, Stevens, and Park (2008) explored the relationship of symptom prevalence and intensity, perceptions of health, and stigma on QOL. This cross-sectional correlational descriptive study consisted of a sample of $(n=55)$ HIV-infected African Americans, all urban, age ranging 23-66 years $(M=48.84, S D=7.67)$, and average length of time since HIV diagnosis 10.79 years $(S D$ $=6.4$ ). The measures consisted of 5 instruments: (a) sociodemographic characteristics, (b) Holzemer Signs and Symptom Checklist for HIV (Holzemer, Hudson, Kirksey, Hamilton, \& Bakken, 2001), (c) a perception of health single-item question, (d) HIV Stigma Scale (Berger, Ferrans, \& Lashley, 2001), and (e) Holmes' HIV/AIDS-Targeted QOL Scale (Holmes \& Shea, 1998).

The most prevalent symptoms were fatigue ( $98 \%$ ), fear $(92.7 \%)$, shortness of breath $(92.7 \%)$, gastrointestinal upset $(85.5 \%)$, numbness $(80.0 \%)$, and headache (76.4\%). Symptoms with the highest reported prevalence and greatest intensity were gastrointestinal upset, body changes, fear, and fatigue. The intensity of symptoms was significantly correlated with measures of stigma $(r=.320, p<.025)$ and QOL $(r=-.425$, $p<.002)$. This study emphasizes the importance of incorporating a holistic view of the relationship of symptoms with QOL (Buseh et al., 2008).

Franke and colleagues (2010) conducted a study to validate a Spanish version and create a valid and reliable abridged version of the Berger HIV Stigma Scale in an urban Spanish-speaking population in Peru. The Spanish version of the full HIV Stigma Scale was shown to be internally reliable, demonstrated good construct validity, and was sensitive to change over time. This was an observational study in whcih HIV-infected adult participants were enrolled in order to examine the effectiveness of a community- 
based antiretroviral therapy adherence intervention. Approximately half of participants were female, and the median age at enrollment was 30.5 years. The full HIV Stigma Scale was abbreviated, containing 21 of the 40 original items, and revealed properties similar to the full Spanish version (Franke et al., 2010).

Moore, Hawley, and Bradley (2009) set out to identify and categorize stigmas associated with $\mathrm{HCV}$. This was a qualitative approach consisting of a sample $(n=39)$ of participants' written narratives describing stigmatic events. These narratives were in response to a question that incorporated a functional definition of stigma that was completed during support group meetings. Approximately $85 \%$ experienced hepatitis Crelated stigma and these findings expanded current knowledge of the stigma complexities. Upon qualitative data saturation, a total of five themes and 16 concepts emerged. Nursing practice implications consisted of a comprehensive structural and institutional application of policy. Also, population and peer education about $\mathrm{HCV}$ and potential stigma would be a worthy opponent to the problem at hand.

Interventions to reduce stigma are crucial for improving care, QOL, and emotional health for Al/ANs living with HCV. Extant research has shown that stigma can be lessened through an array of intervention strategies that include increasing knowledge and community awareness about $\mathrm{HCV}$, counseling treatment, acquiring new coping skills, and/or increasing contact with infected or affected individuals (Brown, Macintyre, \& Trujillo, 2003).

\section{CONCEPTUAL MODEL}

The framework underlying this study is derived from the literature based on the concepts of QOL, depression, alcohol consumption, and stigma (Figure 1). Living with a 
HCV diagnosis can be a significant stressor for AI/AN persons and their families, social support system, and communities (Whitbeck, Adams, Hoyt, \& Chen, 2004). The responsibilities and burden of living with $\mathrm{HCV}$ and its complications can lead to reactions such as psychological stress, denial, anger, and even depression (Johnson, Gryczynski, \& Wiechelt, 2007; Neumeister et al., 2007). Over time, these responses may be short-lived and some patients, invariably, learn to cope with HCV and life in general. However, there may be some who experience prolonged and lingering feelings of stress and depression and are unable to adapt to living with $\mathrm{HCV}$. A possible explanation for the development of depressive symptoms in patients with HCV is based on the Transactional Model of Stress and Coping, in that, persons who develop depressive symptoms may cope with HCV differently than persons who do not develop symptoms of depression, anger, or stress (Lazarus \& Folkman, 1984).

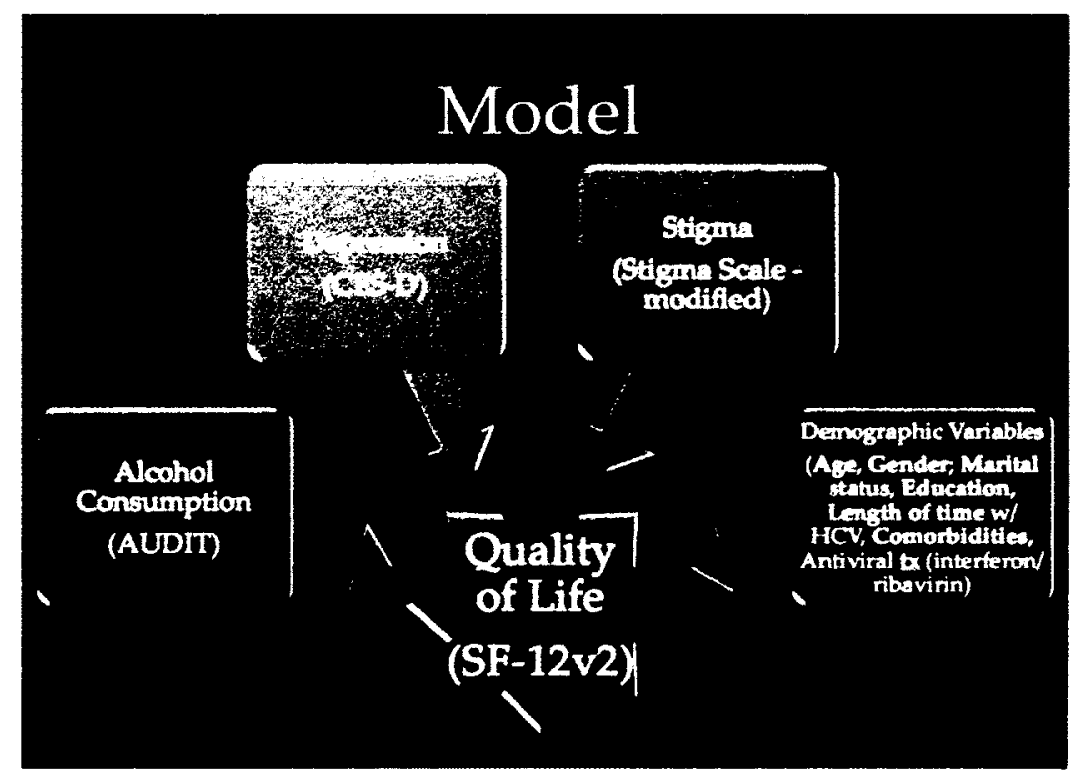

Figure 1 Conceptual Model: $Q O L$ in $A I / A N$ persons with $H C V$ 
In summary, this chapter presented a review and critique of published research and theoretical literature that is representative of the current knowledge of QOL, depression, alcohol consumption, and stigma. The literature discussed lends support to the importance of continuing to examine these relationships so that culturally appropriate interventions may be developed to improve life quality in AI/AN persons living with HCV. Through the contextual lens of QOL, this research can further add to the science of HCV research and practice. This study and its focused areas of concepts among HCV patients will expand this area of scholarship with the support of current literature and science. 


\section{Chapter 3}

\section{Methodology}

The purpose of this chapter is to describe the methodology employed in this study, to explore the relationships among depression, alcohol consumption, stigma, and QOL among AI/AN adults living with $\mathrm{HCV}$. The theoretical perspectives and underpinnings for this research study are based on QOL, depression, alcohol consumption, and stigma. This study aims to advance our understanding of the measurement of QOL among AI/AN HCV patients. This chapter will describe the research design, population and sample, instrument procedures, data collection approaches, data analysis strategies, and the protection of human subjects.

\section{Specific Aims:}

Aim \#1: Characterize the level of depression, alcohol consumption, stigma, and quality of life among a sample of AV/ANs living with HCV.

Aim \#2: Examine the relationship among the variables of age, gender, residing on an $\mathrm{Al} / \mathrm{AN}$ reservation, current partner status, marital status, depression, alcohol consumption, and stigma with quality of life in a sample of $\mathrm{AI} / \mathrm{ANs}$ living with $\mathrm{HCV}$.

Aim \#3: Identify factors that explain the greatest amount of variance in the quality of life of AI/ANs living with $\mathrm{HCV}$. 


\section{DESIGN}

A descriptive, correlational, cross-sectional survey design was used for this study. The goal of a descriptive correlational approach is to describe the data collected and relationships that exist among variables in a situation. Descriptive studies are aimed to find out what is, so observational and survey methods are frequently exercised to collect descriptive data (Borg \& Gall, 1989). Descriptive studies facilitate reporting summary data on measures of central tendency that includes the mean, median, mode, and deviance from the mean, variation, percentage, and correlation between variables. The crosssectional survey research design often goes beyond the descriptive statistics in order to draw inferences (Mertler \& Vannatta, 2002; Vogt, 2005).

\section{SAMPLE}

A purposive sample of individuals who are receiving health care services for their $\mathrm{HCV}$ disease were recruited from two health care programs serving AI/ANs in the Southwest region of the U.S. The inclusion criteria for this study consists of: a confirmed diagnosis of HCV with detectable HCV RNA levels at the beginning of medical treatment; may or may not be undergoing antiviral therapy with interferon and/or ribavirin; ability to read and comprehend English; ability to comprehend and complete study instruments; and voluntary willingness to participate in the research study. The exclusion criteria include: less than 18 years of age; psychiatric or medical disturbance that impedes full participation and informed consent process; or a potential participant's decision to decline research study participation. 


\section{SAMPLE SIZE}

Sample size was determined by power analysis applying a small effect size of 0.3 , level of significance $(\alpha=.05)$, with a statistical power $=.80$. The desired sample size $(n$ $=82$ ) for this study was calculated using Power and Precision 4 developed by Borenstein, Hedges, Rothstein, Cohen, \& Schoenfeld (2010). Power is the probability of detecting a particular effect size, given a specific alpha level and is determined by sample size, measurement error, alpha level, effect size, and number of control variables. A power of .80 or greater is desirable (Borenstein, Rothstein, Cohen, Schoenfeld, Berlin, \& Lakatos, 2000).

\section{SETTING}

The research setting for participant recruitment was at two health care programs serving AI/ANs in the areas of Southern California and Southwest Arizona. The first site consists of a tribal health care clinic providing a full spectrum of on-site and outreach services and programs to their communities and other AI/ANs residing within their catchment area. Site 2 is a facility funded directly by IHS and provides services to more than $35,000 \mathrm{AI} / \mathrm{ANs}$ within their catchment or service area unit. The second site consists of a hospital and provides comprehensive care ranging from primary care (inpatient \& outpatient) to tertiary care and specialty services. These site locations are considered ideal, target communities to this investigator's research study.

\section{PROTOCOL / PROCEDURES}

A collaborative effort with the clinic health care providers and medical staff was established to assist with identification and recruitment of potential study participants and obtain informed consent. When a potential participant had been identified, this 
investigator and/or health care staff provided an overall description and purpose of the research study. The participant(s) were informed about what would be gleaned from this research study's findings and how it has the potential for future programmatic development and community education focusing on improved HCV services.

The primary investigator was available to answer questions. Participants were informed that the standard of care would not be altered should they decide to not participate in this research study. An attempt to recruit adult participants of various age groups, equal number of gender, and a varied representation of AI/ANs who receive health services within these study sites. Recruitment included: (1) an invitation letter for study participation and research participant consent form; (2) an opportunity to review, ask questions, and (3) to choose to participant by signing the informed consent.

Participants who signed informed consent were interviewed by the primary investigator for approximately 60 minutes. This was to ensure that all survey instruments were completed at a time and setting appropriate, convenient, and private for the participants. A monetary incentive was provided in the form of a gift card or cash to acknowledge the participant's time and participation (Appendix $\mathrm{N}$ and $\mathrm{O}$ ). On 12 February 2011, the principal investigator completed the NIH Office of Extramural Research course in "Protecting Human Participants" prior to obtaining Institution Review Board (IRB) approval. The research study packet included: an Invitation Letter for Study Participation (Appendix $\mathrm{H}$ and I) explaining the research study and invitation; a Letter of Support from the healthcare organization's Executive Officer and/or IRB Chairperson (community / cultural stakeholders) (Appendix A and B); a Research Participant Consent Form and Projectal Subject's Bill of Rights (Appendix J, K, L, M); four standardized 
instrument questionnaires (Appendix $\mathrm{P}, \mathrm{Q}, \mathrm{R}, \mathrm{S}$ ), and Personal and Clinical Data Collection form (Appendix $\mathrm{T}$ and $\mathrm{U}$ ).

\section{DATA COLLECTION}

Approval was obtained from the University of San Diego IRB (Appendix C and D) and two study sites (Appendix E, F and G), respectively. The primary investigator met with eligible participants after their scheduled clinic appointments to explain the research study and to answer questions. The participants who agreed to participate were provided an opportunity to review and sign the research study informed consent form. Research data were de-identified with a coded number assigned by the primary investigator and data were securely stored.

\section{INSTRUMENTS}

Each of the key constructs in the proposed model were measured using self-report instruments. In the following section, a description of each of the instruments utilized to measure QOL, depression, alcohol consumption, and stigma is provided. Instruments were selected on the basis of their applicability for self-report, reliability and validity, and limited response burden. Demographic characteristics and clinical factors related to $\mathrm{HCV}$ are also described.

Quality of Life - Short Form-12v2 (SF-12v2) - The outcome variable, QOL will be measured using the SF-12v2 questionnaire, which has been widely implemented in social and psychological research. A 12-item instrument, the SF-12v2, is one of several multipurpose health surveys that measures health status and was constructed from a subset of 149 core items developed during the Medical Outcome Study (Stewart \& Ware, 1993). The physical component subscale (PCS) is an overall measure of physical health 
and a reflection of an individual's satisfaction with their perceived level of physical function, mobility and role limitations due to their health status. The mental component subscale (MCS) is an overall measure of mental health impacted by depression, sense of well-being, and the ability to participate in social activities.

The SF-12v2 is a 12 -item subset from the SF-36v2 and has demonstrated equivalent mean scores for the physical and mental component subscales of HRQOL among general and disease-specific populations (Scientific Advisory Committee of the Medical Outcomes Trust, 2002; Ware, Kosinski, Turner-Bowker, \& Gandek, 2002). This instrument measures the same eight health domains: Physical Functioning, Role-Physical, Bodily Pain, General Health, Vitality, Social Functioning, Role-Emotional, and Mental Health (Fleishman, Selim, \& Kazis, 2010).

The SF-12v2 reproduces more than $90 \%$ of the variance of the PCS and MCS of the SF-36 in the general U.S. population, takes significantly less time to complete than the SF-36, reducing burden on research participants, and demonstrated high two-week test-retest reliability correlations for both $\operatorname{PCS}(r=0.89)$ and $\operatorname{MCS}(r=0.76)$. Applied extensively in HRQOL research, the SF-12v2 survey is convenient, may be completed in less than two minutes, to monitor health changes, or analyze and compare disease burden in the general population (Cheak-Zamora, Wyrwich, \& McBride, 2009). The subscales of the SF-12v2 have been found to be internally consistent with reported Cronbach $\alpha$ of .87 (PCS) and .82 (MCS), respectively.

Center for Epidemiologic Studies-Depression (CES-D) scale - The CES-D scale (Radloff, 1977) is a 20-item self-report questionnaire developed to measure and identify symptoms of depression or psychological distress in community populations (Myers \& 
Weissman, 1980; Roberts, Vernon, \& Rhoades, 1989). The CES-D Questionnaire (v1.0), although it may be pragmatic to identify populations at risk of developing clinical depression or anxiety disorders, is not intended as a clinical diagnostic tool (Radloff, 1977). Since its introduction, the CES-D has been practical to assess depression risks in several populations (e.g., adolescent, elderly, ethnic and clinical populations) for whom it was not originally designed.

The 20-item scale measures the following six components: depressed mood, feelings of guilt and worthlessness, feelings of helplessness and hopelessness, psychomotor retardation, loss of appetite, and sleep disturbance (Radloff, 1977). The participants are asked to indicate how frequently they experienced the symptom within the past year on a scale ranging from rarely or none of the time to most or all of the time. Each frequency level on the CES-D is assigned a numerical score ranging from 1 to 4 .

The CES-D has been shown to be a reliable measure for assessing the number, types, and duration of depressive symptoms across racial, gender, and age categories (Knight, Williams, McGee, \& Olaman, 1997; Radloff, 1977; Roberts, Vernon, \& Rhoades, 1989). A high internal consistency has been reported with Cronbach's $\alpha$ coefficients ranging from .85 to .90 across studies (Radloff, 1977). Concurrent validity by clinical and self-report criteria, as well as substantial evidence of construct validity has been demonstrated (Radloff, 1977). However, there is evidence that the CES-D, while a useful measure of the level of depressive symptoms, may not be a good tool for screening for clinical depression or major depression (Roberts, Vernon, \& Rhoades, 1989).

$$
\text { Alcohol Use Disorders Identification Test (AUDIT) - The AUDIT is an }
$$
instrument designed to identify persons with $\mathrm{HCV}$ and assess their hazardous and 
harmful patterns of alcohol consumption. The WHO developed the AUDIT as a simple method of screening for excessive drinking and to assist in brief assessment. This measure was developed and evaluated over a period of two decades, and it has been found to provide an accurate measure of risk across gender, age, and cultures (Volk et al., 1997).

It can assist in identifying excessive drinking as the cause of the presenting illness. It also provides a framework for intervention to help hazardous and harmful drinkers reduce or cease alcohol consumption and, thereby, avoid the harmful consequences of their drinking. The AUDIT facilitates the identification of alcohol dependence and some specific consequences of harmful drinking. It is particularly designed for health care practitioners and a range of health settings, but, with suitable instructions, it can be self-administered or used by non-health professionals (Allen et al., 2001).

To score the AUDIT, each of the questions has a set of responses to choose from, and each response has a score ranging from 0 to 4 . The AUDIT consists of 10 items that can be administered quickly either verbally, written, or by computer in five minutes. Scoring: Questions 1 through 8 are scored $0,1,2,3$, or 4 points. Whereas, questions 9 and 10 are scored 0,2 , or 4 points. A score of $8+$ on the AUDIT generally indicates atrisk, harmful, or hazardous drinking (Allen, Litten, Fertig, \& Babor, 1997).

In the interview format, the interviewer records the score that corresponds to the patient's response in the box beside each question (Bohn, Babor, \& Kranzler, 1995). All the response scores are added and a Total score is recorded. The AUDIT can detect alcohol problems experienced in the last year. Total scores of eight or more are 
recommended as indicators of hazardous and harmful alcohol use, as well as possible alcohol dependence. A cut-off score of 10 will provide greater specificity but at the expense of sensitivity (Volk et al., 1997). Since the effects of alcohol vary with average body weight and differences in metabolism, establishing the cut off point for all women and men over age 65 one point lower at a score of 7 will increase sensitivity for these population groups.

Based on experience gained in a study of treatment matching with persons who had a wide range of alcohol problem severity, AUDIT scores were compared with diagnostic data that reflected low, medium, and high degrees of alcohol dependence. AUDIT scores in the range of $8-15$ represented a medium level of alcohol problems. Whereas, scores of 16 and above represented a high level of alcohol problems (Miller, Zweben, DiClemente, \& Rychtarik, 1992). On the basis of experience gained from the use of the AUDIT in this and other research, it is suggested that the following interpretation be given to AUDIT scores: Scores between 8 and 15 are most appropriate for simple advice focused on the reduction of hazardous drinking; Scores between 16 and 19 suggest brief counseling and continued monitoring; and AUDIT scores of 20 or above clearly warrant further diagnostic evaluation for alcohol dependence (Babor, de la Fuente, Saunders, \& Grant, 1992).

HCV Stigma Scale (modified) - Stigma, was measured using a modified version of the HIV Stigma Scale. The HCV Stigma Scale is a measure tailored for this study from the original version, the HIV Stigma Scale. This instrument measures stigma perceived by persons living with HIV in the U.S., and was developed based on the literature on stigma and psychosocial aspects of having HIV. The 40 items are centered 
on the experiences, feelings, and opinions about how persons living with HIV feel and how they are treated. The person living with HIV responds to these items using a fourpoint scale to indicate level of agreement or disagreement.

Psychometric analyses were performed and resulted in four factors emerging from exploratory factor analysis. Those four factors consist of: Personalized stigma, Disclosure concerns, Negative self-image, and Concern with public attitudes toward people living with HIV. Construct validity was supported by relationships with related constructs: self-esteem, depression, social support, and social conflict. The ranges of the coefficient $\alpha$ were between .90 and .93 for the four subscales and .96 for the 40 -item instrument provided evidence of internal consistency reliability. The HIV Stigma Scale was reliable and valid with a large, diverse sample of persons living with HIV (Berger, Ferrans, \& Lashley, 2001).

The scoring of the modified HIV Stigma Scale and subscales begins with participants answering items about some of the social and emotional aspects of having HCV. This first set of questions asks about some of the experiences, feelings, and opinions about how persons with HIV feel and how they are treated. Participants are asked to rate each item, and to circle each answer: Strongly disagree (SD), Disagree (D), Agree (A), or Strongly Agree (SA). Items are scored as follows; $\mathrm{SD}=1 ; \mathrm{D}=2 ; \mathrm{A}=3$; and $\mathrm{SA}=4$.

In order to control for response bias, two items (\#8 and 21) have been worded in a positive direction. If a subject selects a response in between two options (e.g.: between SD and D), a numerical value midway between the two options would be used (e.g.: 1.5). 
After reverse scoring these two items, each scale or subscale's score is calculated by simply summing up the raw values of the items belonging to that scale or subscale.

Subscale designations appear in small print in the far right margin of the instrument; it may be desirable to cover or delete those numbers before reproducing the instrument for administration to participants. Sixteen items belong to more than one subscale, reflecting the intercorrelations of the factors on which the subscales are based. The range of possible scores depends on the number of items in the scale. For the total HIV Stigma Scale, scores can range from 40 to 160 [ $1 \times 40$ items to $4 \times 40$ items]. For the personalized stigma subscale, scores can range from 18 to 72 . For the disclosure subscale, scores can range from 10 to 40 . For the negative self-image subscale, scores can range from 13 to 52 . For the public attitudes subscale, scores can range from 20 to 80 (Berger et al., 2001).

Demographic variables - Demographic characteristics and related clinical information collected included: gender, age, race, marital status, tribal affiliation, veteran status, level of education, $\mathrm{HCV}$ risk factor, type of $\mathrm{HCV}$ treatment, duration of $\mathrm{HCV}$ treatment.

\section{DATA ANALYSIS PLAN}

The Statistical Package for Social Sciences (SPSS) Version 20 was utilized for statistical data analysis. Prior to data analysis, each variable was examined using frequency distributions and visual representations. Once an analysis of the demographics of the study sample was completed (Hoskins \& Mariano, 2004), the overall scale and subscale scores of the CES-D, AUDIT, HCV Stigma (modified) scales and measurement of the QOL PCS and MCS scores were assessed in the research study sample. An 
assessment and internal reliability of the subscales was measured using Cronbach $\alpha$ (McDowell, 2006). Chi-square tests for categorical, ANOVAs, t-test, and bivariate correlations for continuous variables were used in order to measure and describe the relationships between the variables (Creswell, 2009). A multivariate multiple regression analysis was utilized to examine which variables explain the greatest amount of variance in QOL. In predictive analyses based on probability theory, the independent variables cause variation in the value of the dependent variable (Mertler \& Vannatta, 2002). The goal is to determine how accurately one can predict the value of an outcome (dependent) variable, QOL, based on the values of the predictor (independent) variables.

A diagnosis of $\mathrm{HCV}$ infection is often unexpected and can be devastating. There is a significant impact on the QOL among persons living with $\mathrm{HCV}$ infection. Not only do the clinical manifestations such as fatigue diminish functioning but also living with a chronic stigmatized illness with an uncertain future creates dilemmas around disclosure, accessing support, and sustaining self-esteem, employment, and relationships. In this research study, the focus is on identifying and describing the unmet health care needs and barriers to treatment was explored through the use of a descriptive study using a selfadministered survey comprised of the standardized measures of the SF-12v2, CES-D, AUDIT, HCV Stigma (modified), and selected demographic variables. 
Chapter 4

Results

The purpose of this study was to explore the relationship among depression, alcohol consumption, stigma, and quality of life among AI/ANs living with HCV. In this chapter, the sample is described, including their scores on the predictor variables of depression, alcohol consumption, stigma, and the outcome variable of quality of life. This chapter concludes with the findings related to the specific research aims.

\section{SAMPLE CHARACTERISTICS}

A purposive sample of $101 \mathrm{AI} / \mathrm{AN}$ participants living with $\mathrm{HCV}$ was recruited from the Southwest region of the U.S. The sample characteristics, including patient demographics and health information/history, were collected utilizing a Personal Data Collection form designed for this study (Appendix L). Clinical data consisting of laboratory results were collected for participants from study Site $2(n=65)$ (Appendix M). Relevant demographic, health information/history, and clinical data of the study sample are reported in Tables 1,2 , and 3 . The sample was fairly evenly distributed by gender with slightly more males $(54.5 \%, n=55)$ than females $(43.6 \%, n=44)$; $2 \%$ selfidentified as transgender or lesbian $(n=2)$. The mean age was 50.56 years $(S D=8.773)$ ranging from 23 to 70 years of age. Marital status was approximately equally distributed among individuals who were divorced or separated $(34.7 \%, n=35)$, single or never married $(32.7 \%, n=33)$, married or partnered $(27.7 \%, n=28)$, with the exception of 
widows/ers who composed $5 \%$ of the sample $(n=5)$. Similarly, the sample was evenly divided among individuals who had a primary partner $(49.5 \%, n=50)$ and those who did not $(49.5 \%, n=50)$. Out of those who reported having a primary partner, $88.2 \%(n=45)$ were partnered with someone of the opposite sex and $74.5 \%(n=38)$ currently living with their primary partner.

The major Native / Tribal languages among the participants was Kumeyaay (Diegueño) $(13.9 \%, n=14)$, Navajo (Diné) $(12.9 \%, n=13)$, and O'odham $(14.9 \%, n=$ 15). Approximately two-thirds $(65.3 \%, n=66)$ reported not residing on AI reservation or land. Education level was as follows: $1 \%(n=1)$ had attended graduate or professional school; $5 \%(n=5)$ had obtained a Bachelor's degree; $34.7 \%(n=35)$ had completed some college; $14.9 \%$ were High School graduates $(n=15) ; 19.8 \%(n=20)$ had obtained a GED, $16.8 \%(n=17)$ had completed some high school; $3 \%(n=3)$ had obtained an Associate's degree; and 5\% $(n=5)$ had completed Elementary school. This sample also reported their occupational status as unable to work or unemployed $(32.7 \%, n=33)$, disabled $(26.7 \%, n=27)$, or working full-time $(26.8 \%, n=27)$, with the majority describing their present or most recent job or occupation in the crafts, trades, factory work, retail, or labor industry $(57.4 \%, n=58)$. Over one-third $(38.6 \%, n=39)$ reported an annual income of all members of participants' household in the range of $\$ 0-\$ 10,000$.

The majority of the sample had not served in the U.S. Armed Forces $(91.1 \%, n=$ 92). There were only nine respondents who reported ever serving in the U.S. Armed Forces. There was a varied response regarding how easy it was to afford or access medical treatment for HCV. It ranged from very easy $20.8 \%(n=21)$, to somewhat easy $37.6 \%(n=38)$, somewhat difficult $18.8 \%(n=19)$, and very difficult $22.8 \%(n=23)$. 
Approximately two-thirds reported having a type of health care coverage other than Indian Health Services. The type of health care coverage composed of either having Medicaid $(33 \%, n=37)$ as their health care provider or having No other coverage at all $(33.9 \%, n=38)$. A summary of Sample Characteristics is presented in Tables $1-4$.

Table 1 Sample Characteristics

\begin{tabular}{|c|c|c|}
\hline Variable & $\boldsymbol{N}$ & $\%$ \\
\hline \multicolumn{3}{|l|}{ Age } \\
\hline $23-40$ & 13 & 12.9 \\
\hline $41-50$ & 34 & 33.7 \\
\hline $51-60$ & 43 & 42.6 \\
\hline $61-70$ & 11 & 10.0 \\
\hline \multicolumn{3}{|l|}{ Gender } \\
\hline Female & 44 & 43.6 \\
\hline Male & 55 & 54.5 \\
\hline Other & 2 & 2.0 \\
\hline \multicolumn{3}{|l|}{ Marital Status } \\
\hline Single / Never Married & 33 & 32.7 \\
\hline Married / Partnered & 28 & 27.7 \\
\hline Divorced / Separated & 35 & 34.7 \\
\hline Widowed & 5 & 5.0 \\
\hline \multicolumn{3}{|c|}{ Primary Partner (husband, wife, significant other) } \\
\hline Yes & 50 & 49.5 \\
\hline No & 50 & 49.5 \\
\hline Don't Know / Refuse & 1 & 1.0 \\
\hline \multicolumn{3}{|l|}{ Primary Partner's Gender } \\
\hline Same Sex & 6 & 5.9 \\
\hline Opposite Sex & 45 & 44.6 \\
\hline \multicolumn{3}{|c|}{ Currently lives with Primary Partner } \\
\hline Yes & 38 & 37.6 \\
\hline No & 13 & 12.9 \\
\hline
\end{tabular}


Table 2 Sample Characteristics

\begin{tabular}{|c|c|c|c|c|}
\hline Variable & & $\boldsymbol{N}$ & $\%$ & $\%$ of cases \\
\hline \multicolumn{5}{|l|}{ Reside on AI Reservation / Land } \\
\hline No & & 66 & 65.3 & \\
\hline \multicolumn{5}{|l|}{ Race / Ethnicity } \\
\hline Alaska Native & & 3 & 1.7 & 3.0 \\
\hline American Indian & & 96 & 55.8 & 95.0 \\
\hline Black / African American & & 3 & 1.7 & 3.0 \\
\hline Hispanic / Latino & & 14 & 8.1 & 13.9 \\
\hline Mexican / Mexican American & & 15 & 8.7 & 14.9 \\
\hline Native Hawaiian / Pacific Islander & & 1 & 0.6 & 1.0 \\
\hline White / Caucasian & & 35 & 20.3 & 34.7 \\
\hline \multirow[t]{2}{*}{ Other } & & 5 & 2.9 & 5.0 \\
\hline & Total & 172 & $100 \%$ & $170.3 \%$ \\
\hline \multicolumn{5}{|l|}{ Language } \\
\hline Native / Tribal & & 70 & 39.1 & 69.3 \\
\hline English & & 100 & 55.9 & 99.0 \\
\hline \multirow[t]{2}{*}{ Spanish } & & 9 & 5.0 & 8.9 \\
\hline & Total & 179 & $100 \%$ & $122.2 \%$ \\
\hline \multicolumn{5}{|l|}{ Education } \\
\hline Elementary & & & 5 & 5.0 \\
\hline Some High School & & & 17 & 16.8 \\
\hline High School graduate & & & 15 & 14.9 \\
\hline GED & & & 20 & 19.8 \\
\hline Some college & & & 35 & 34.7 \\
\hline Associate's degree & & & 3 & 3.0 \\
\hline Bachelor's degree & & & 5 & 5.0 \\
\hline Some graduate school & & & 1 & 1.0 \\
\hline
\end{tabular}


Table 3 Sample Characteristics

\begin{tabular}{lcc}
\hline \multicolumn{1}{c}{ Variable } & $N$ & $\%$ \\
\hline Occupational Status & & \\
Full-time & 27 & 26.8 \\
Part-time & 6 & 5.9 \\
Retired & 8 & 7.9 \\
Unable to work / Unemployed & 33 & 32.7 \\
Disabled / Handicapped & 27 & 26.7 \\
Income (total annual household) & & \\
$\quad$ 10,000 & 39 & 38.6 \\
10,001 - 20,000 & 17 & 16.8 \\
20,001 - 30,000 & 14 & 13.9 \\
30,001 - 40,000 & 9 & 8.9 \\
40,001 - 50,000 & 11 & 10.9 \\
50,001 - 100,000 & 5 & 5.0 \\
$\quad>100,001$ & 3 & 3.0 \\
Don't Know / Refused & 3 & 3.0 \\
Afford/Access Medical Treatment for HCV & & \\
Very easy & 21 & 20.8 \\
Somewhat easy & 38 & 37.6 \\
Somewhat difficult & 19 & 18.8 \\
Very difficult & 23 & 22.8 \\
Job Category - present or most recent job / occupation & & \\
Professional / Administrative & 9 & 8.9 \\
Clerical / Sales & 11 & 10.9 \\
Crafts / Trades / Labor & 58 & 57.4 \\
Healthcare / Technical & 15 & 14.9 \\
Hospitality / Service Industry & 3 & 3.0 \\
Military / Government & 1 & 1.0 \\
Unemployed / Retired & 4 & 4.0 \\
U.S. Armed Forces & & \\
Yes & 9 & 8.9 \\
No & 92 & 91.1 \\
\hline & & \\
\hline & & \\
\hline & & \\
\hline
\end{tabular}


Table 4 Sample Characteristics - Native / Tribal Language

\begin{tabular}{|c|c|c|}
\hline Variable & $N$ & $\%$ \\
\hline \multicolumn{3}{|l|}{ Native / Tribal Language } \\
\hline Algonquian & 1 & 1.0 \\
\hline Apache & 6 & 6.0 \\
\hline Cahuilla & 1 & 1.0 \\
\hline Cahuilla-Cupeño & 1 & 1.0 \\
\hline Cherokee & 6 & 6.0 \\
\hline Chickasaw & 1 & 1.0 \\
\hline Choctaw & 2 & 2.0 \\
\hline Crow & 1 & 1.0 \\
\hline Hocak & 1 & 1.0 \\
\hline Hopi & 3 & 3.0 \\
\hline Kumeyaay (Diegueño) & 14 & 14.0 \\
\hline Lakota & 4 & 4.0 \\
\hline Luiseño & 9 & 9.0 \\
\hline Luiseño- Cupeño & 5 & 5.0 \\
\hline Menominee & 1 & 1.0 \\
\hline Miwok & 1 & 1.0 \\
\hline Navajo (Diné) & 13 & 13.0 \\
\hline O'odham & 15 & 15.0 \\
\hline Ojibwe & 2 & 2.0 \\
\hline Potawatomi & 1 & 1.0 \\
\hline Quechan & 1 & 1.0 \\
\hline Shoshone & 1 & 1.0 \\
\hline Sioux & 1 & 1.0 \\
\hline Tlingit & 1 & 1.0 \\
\hline Washo & 2 & 2.0 \\
\hline Yaqui & 3 & 3.0 \\
\hline Yukian & 1 & 1.0 \\
\hline Yup'ik & 2 & 2.0 \\
\hline
\end{tabular}

The next section of the Personal Data Collection form focuses on the sample characteristics of health information and history. Over half of the participants, $50.9 \%$ ( $n$ 
$=58)$ stated that they had not received treatment for HCV. Also reported, were those participants who received $\mathrm{HCV}$ injection plus oral medications $(17.5 \%, n=20)$, traditional or ceremonial healing $(13.2 \%, n=15)$, complementary and alternative medicine treatment $(8.8 \%, n=10)$. The primary reason for individuals to get tested for HCV based on the percentage of cases $(79.2 \%, n=80)$ was having risk factors, even though they were asymptomatic at the time of testing. The other significant reasons for getting tested were due to either blood donor screening or evaluation of elevated liver enzymes, $61.4 \%(n=62)$ and $24.8 \%(n=25)$, respectively. A summary of Sample Health Information/History and Clinical Characteristics is presented in Table 6. The HCV signs and/or symptoms reported most often experienced were fatigue $(78.3 \%, n=$ $72)$, dark urine $(62 \%, n=57)$, and arthralgia $(56.5 \%, n=52)$.

Slightly more than half of the participants, $(53.5 \%, n=54)$ reported knowing that they were a contact of a person with confirmed or suspected acute or chronic HCV infection - $(14.9 \%, n=15)$ did not know. In the six months before symptom onset (regardless of gender / sexual preference), over half $52.5 \%(n=53)$ and $51.5 \%(n=52)$ responded as to having zero male or female sex partners. The number of participants who have ever been treated for a sexually transmitted disease or infection was $72.3 \%$ ( $n=$ 73). A summary of Frequency - Treatment for Sexually Transmitted Diseases / Infections is presented in Table 5 .

Over $80 \%(86.1 \%, n=87)$ reported ever using illicit or illegal drugs. Those who had ever used or shared a needle or syringe to inject drugs intravenously not prescribed by a health care worker was $62.4 \%(n=63)$. Fifty-four $(53.5 \%)$ had ever used or shared equipment to inject drugs intravenously not prescribed by a health care worker. 
Approximately two-thirds of participants $(32.7 \%, n=33)$ had been diagnosed with diabetes mellitus by a medical doctor; and of those, $97 \%(n=32)$ did not share their diabetic supplies.

Table 5 Frequency - Treatment for Sexually Transmitted Diseases / Infections

\begin{tabular}{lcc}
\hline \multicolumn{1}{c}{ Sexually Transmitted Disease / Infection } & $\boldsymbol{N}$ & \% of cases \\
\hline Bacterial Vaginosis & 4 & $5.5 \%$ \\
Chlamydia & 21 & $28.8 \%$ \\
Gonorrhea & 25 & $34.2 \%$ \\
HepB Virus & 1 & $1.4 \%$ \\
HepC Virus & 32 & $43.8 \%$ \\
Herpes, Genital & 7 & $9.6 \%$ \\
HIV / AIDS & 11 & $15.1 \%$ \\
Pelvic Inflammatory Disease & 10 & $13.7 \%$ \\
Syphilis & 3 & $4.1 \%$ \\
Trichomonas & 13 & $17.8 \%$ \\
Vaginitis & 5 & $6.8 \%$ \\
Venereal Disease & 5 & $6.8 \%$ \\
Pediculosis Pubic (crabs) & 1 & $1.4 \%$ \\
\hline
\end{tabular}

Seventy-nine (78.2\%) participants who reported not ever having an accidental stick or puncture with a needle or other object contaminated with blood. A majority of participants, $99 \%(n=100)$, responded as never undergoing or receiving long-term kidney hemodialysis. Approximately $16 \%(15.8 \%, n=16)$ had ever received blood or blood products by transfusion before July 1992; years received range between 1973 and 1991. Those who responded as not ever having received any outpatient intravenous infusions and/or injections were $93.1 \%(n=94)$.

Slightly over half $(54.5 \%, n=55)$ reported not ever and $15.8 \%(n=16)$ did not know if they ever been in contact with a person's blood who had hepatitis. Slightly less 
than $2 / 3 \mathrm{rds}(60.4 \%, n=61)$ responded as not ever and $20.8 \%(n=21)$ did not know if they ever had been exposed to someone else's blood who had hepatitis. The number of participants who were ever employed in a medical or dental field involving direct contact or exposure mucosally or to non-intact skin with human blood or infected needles was $10.9 \%(n=11)$ with frequent or infrequent exposures, 5 and 6 , respectively. A large number, $94.1 \%(n=95)$ stated they did not ever work as a public safety or emergency worker having direct contact or exposure mucosally or to non-intact skin with human blood or infected needles; $96 \%(n=97)$ responded as not ever being a resident of a longterm care facility.

In terms of treatment and law enforcement, $63.4 \%(n=64)$ of participants responded as not ever being a resident of an inpatient drug treatment program. Also, those who were not ever a resident of a halfway house were $72.3 \%(n=73)$. The number of participants reported ever being incarcerated was $83.2 \%(n=84)$. The length of incarceration categories and frequencies are: $\leq 30$ days, $31-180$ days, $181-540$ days, $541-720$ days, and $\geq 721$ days, $42.9 \%(n=36), 16.7 \%(n=14), 10.7 \%(n=9), 9.5 \%(n$ $=8)$, and $20.2 \%(n=17)$, respectively. Those who have ever received a tattoo(s) or have any part of their body pierced (other than their ear) was $78.2 \%(n=79)$ and $22.8 \%(n=$ 23), respectively.

The following section pertains to transplant and blood risk, there were no participants, $100 \%(n=101)$ who had ever been diagnosed and / or treated by a medical doctor for hemophilia. The majority, $98 \%(n=99)$ had not ever received blood clotting factor concentrates produced before 1987. Those participants who ever received dental work / oral surgery or surgery (other than oral) prior to their HCV diagnosis was $76.2 \%$ 
$(n=77)$ and $57.4 \%(n=58)$, respectively. There were no participants who had ever received a solid organ transplant before July 1992.

Table 6 Sample Health Information / History and Clinical Characteristics

\begin{tabular}{lcc}
\hline \multicolumn{1}{c}{ Variable } & $N$ & $\%$ of cases \\
\hline Treatments received - HCV & 58 & $57.4 \%$ \\
No treatment & 20 & $19.8 \%$ \\
HCV injection + oral medication & 15 & $14.9 \%$ \\
Traditional or ceremonial healing & 10 & $9.9 \%$ \\
Complementary and alternative treatment & 8 & $7.9 \%$ \\
HCV injection only & 2 & $2.0 \%$ \\
HCV oral medication only & 1 & $1.0 \%$ \\
HCV surgery - organ transplant & & \\
Reasons for HCV testing & 80 & $79.2 \%$ \\
Screening - asymptomatic, risk factors & 62 & $61.4 \%$ \\
Blood / organ donor screening & 25 & $24.8 \%$ \\
Elevated liver enzymes & 9 & $8.9 \%$ \\
Follow-up testing for previous marker of viral hepatitis & 8 & $7.9 \%$ \\
Screening - symptomatic, no risk factors & 2 & $2.0 \%$ \\
Symptoms of acute hepatitis & 2 & $2.0 \%$ \\
Prenatal screening & & \\
\hline
\end{tabular}

The final section will report the Clinical Data collected from study Site 2. The data collected from study Site $2(n=65), 64 \%$ of total study sample $(n=101)$ focuses on the clinical characteristics of laboratory and diagnostic results. The data collected was not complete due to the diagnostic tests being not done or tests not performed. There are specific laboratory tests performed in HCV disease screening and management. A summary of the Clinical Predictor Variable Descriptives is presented in Table 7. 


\section{HEPATITIS C}

The hepatitis $\mathrm{C}$ antibody (anti-HCV) is the initial test in determining if HCV infection is present. A positive finding indicates the body's response to $\mathrm{HCV}$ infection and the body is making antibodies in order to fight the infectious process. Sixty (92\%) had a confirmed true positive for anti-HCV, which indicates infection with HCV in the past. This type of positive test result warrants additional confirmation testing to determine whether or not the anti-HCV is a true positive.

The hepatitis $\mathrm{C}$ recombinant immunoblot assay (RIBA) is the confirmation test for the hepatitis $\mathrm{C}$ antibody. A positive RIBA test result confirms the detection of a true positive anti-HCV, which suggests $\mathrm{HCV}$ infection in the past. More than half of the participants from Study site $2(n=40)$ had a positive RIBA test result showing past infection of HCV. Again, with a positive RIBA test, an HCV RNA viral load (quantitative) would need to be performed in order to detect the presence of HCV in the body.

The next test, HCV polymerase chain reaction (PCR), is a qualitative test utilized to confirm whether $\mathrm{HCV}$ is present. A positive test result confirms there is chronic $\mathrm{HCV}$ infection. More than $80 \%(n=54)$ had HCV PCR positive results confirming chronic $\mathrm{HCV}$ infection, which is a more accurate test in detecting very low $\mathrm{HCV}$ levels versus the quantitative test method. In contrast, only eight participants had a negative HCV PCR test as a result from either successful response to $\mathrm{HCV}$ drug therapy or spontaneous clearing of $\mathrm{HCV}$. An equivocal test results for one participant indicates there was some reactivity but not sufficient to be considered a positive HCV PCR finding. 
Table 7 Clinical Predictor Variable Descriptives

\begin{tabular}{|c|c|}
\hline Variable & $N(\%)$ \\
\hline \multicolumn{2}{|l|}{ Anti-HCV } \\
\hline Positive§ & $60(100.0)$ \\
\hline \multicolumn{2}{|l|}{ RIBA } \\
\hline Positive§ & $40(100.0)$ \\
\hline \multicolumn{2}{|l|}{ HCV PCR } \\
\hline Positive & $54(87.1)$ \\
\hline Negative & $8(12.9)$ \\
\hline \multicolumn{2}{|l|}{ HCV Genotype } \\
\hline Type 1A & $27(67.5)$ \\
\hline Type 1B & $4(10.0)$ \\
\hline Type 2B & $5(12.5)$ \\
\hline Type 3A & $3(7.5)$ \\
\hline Type 4A/C/D & $1(2.5)$ \\
\hline \multicolumn{2}{|l|}{ Total anti-HAV } \\
\hline Positive & $28(75.7)$ \\
\hline Negative & $8(21.6)$ \\
\hline Equivocal & $1(2.7)$ \\
\hline \multicolumn{2}{|l|}{ IgM anti-HAV } \\
\hline Negative§ & $55(100.0)$ \\
\hline \multicolumn{2}{|l|}{ HBsAG } \\
\hline Positive & $1(1.8)$ \\
\hline Negative & $55(98.2)$ \\
\hline \multicolumn{2}{|l|}{ Total anti-HBc } \\
\hline Positive & $5(20.8)$ \\
\hline Negative & $19(79.2)$ \\
\hline \multicolumn{2}{|l|}{ IgM Anti-HBc } \\
\hline Positive & $1(1.9)$ \\
\hline Negative & $53(98.1)$ \\
\hline
\end{tabular}

Globally, HCV consists of six distinct genotypes and is further classified into many subtypes. These genotypes are considered to be the genetic structure of the virus and lay the groundwork for the standard of care and predicted response in HCV 
treatment. Genotyping is useful in disease management in terms of medication regimen, dosing, and duration. In the U.S., genotypes 1, 2, and 3 are most common. However, genotype 1 is most difficult to treat and accounts for $70-75 \%$ of all $\mathrm{HCV}$ infections. The data collected from study site 2 shows that 25 participant's HCV genotyping were not done or tests were not performed and that antiviral treatment was not indicated. Whereas, $67.5 \%(n=27), 10.0 \%(n=4), 12.5 \%(n=5), 7.5 \%(n=3), 2.5 \%(n=1)$ tested as genotype $1 \mathrm{~A}, 1 \mathrm{~B}, 2 \mathrm{~B}, 3 \mathrm{~A}$, and $4 \mathrm{~A} / 4 \mathrm{C} / 4 \mathrm{D}$, respectively.

\section{HEPATITIS A}

The hepatitis A virus (HAV) is considered to be highly contagious and the most prevalent type of hepatitis. It is an acute inflammatory condition of the liver with the majority of cases being acquired by ingestion of the virus, which is shed in the stool of

infected persons, mostly fecal-oral transmission. A concern for those who are living with $\mathrm{HCV}$ is this distinct class of viral illness affecting the liver. Many of the $\mathrm{HCV}$ risk factors also pose risk for $\mathrm{HAV}$ infection, which require screening, testing, and prevention. The vaccine for $\mathrm{HAV}$ is recommended to all eligible persons and especially those with liver disease and $\mathrm{HCV}$ risk factors as a preventative measure according to CDC vaccination guidelines.

The confirmation of HAV by testing for Total anti-HAV is required to detect presence of any antibody against HAV and also indicate infection. Total anti-HAV appears early during the course of infection and remains detectable for lifetime. It also provides lifelong protection against HAV infection or disease. There was an equal distribution for those participants who tested positive for Total anti-HAV or tests not performed, $(75.7 \%, n=28)$. A positive interpretation results in either acute HAV or past 
HAV infection. A little over $21.6 \%(n=8)$ tested negative for total anti-HAV and $2.7 \%$ $(n=1)$ resulted in a test result of equivocal. An equivocal result means that there is some reactivity, however, not enough to be positive or negative based on laboratory reporting criteria.

The IgM anti-HAV test is associated with active or recent infection with HAV. The presence of IgM antibodies is usually detected in the blood as early as two-weeks after being infected with HAV or when symptoms of HAV are present, and last for a few months after symptoms subside. A large proportion $(n=55)$ had negative IgM anti-HAV test results, indicating no active or recent infection with HAV.

\section{HEPATITIS B}

The HBsAg, Hepatitis B surface antigen, is a marker of current infection. The presence of HBsAg may also indicate either acute or chronic HBV infection. In this sample, 55 participants tested negative for $\mathrm{HBsAg}$ and one tested positive, indicating current infection.

The total anti-HBc, antibody to Hepatitis B core antigen, is a nonspecific marker of acute, chronic, or resolved HBV infection. It appears at the onset of symptoms in acute Hepatitis B and persists for life. While is it not a marker of vaccine-induced immunity, it may be utilized in pre-vaccination testing to determine previous exposure to HBV infection. There were 19 participants that tested negative and 5 tested positive for total anti-HBc.

The IgM antibody to Hepatitis B core antigen is a test that identifies antigens, which is a substance on the surface of a virus that causes the immune system to recognize it and respond. An exposure to an antigen is viewed as foreign material and the body 
takes the necessary steps to neutralize the antigen by producing antibodies. Therefore, a positive IgM anti-HBc test result indicates recent infection with $\mathrm{HBV}$. The presence of IgM anti-HBc also may indicate acute HBV infection. A large majority $(n=53)$ tested negative; $(n=1)$ tested positive; and $(n=11)$ did not have an IgM anti-HBc done or test was not performed.

\section{Research Questions Findings}

Aim \#1: What is the level of depression, alcohol consumption, stigma, and quality of life among a sample of $\mathrm{AI} / \mathrm{ANs}$ living with $\mathrm{HCV}$.

The use of descriptive statistics, means, standard deviations, and range were calculated in order to describe the levels of depression, alcohol use, stigma, and quality of life (PCS and PCS) in a sample of AI/ANs living with HCV (Table 8).

Table 8 Descriptive Variables Statistics

\begin{tabular}{|c|c|c|c|}
\hline Variable & $\boldsymbol{M}$ & SD & Cronbach's $\alpha$ \\
\hline CES-D & 20.33 & 13.301 & .920 \\
\hline AUDIT & 14.10 & 10.005 & .889 \\
\hline STIGMA & 97.07 & 19.756 & .942 \\
\hline Personalized & 42.14 & 11.019 & .94 \\
\hline Disclosure & 26.21 & 5.328 & .78 \\
\hline Negative Self Image & 29.29 & 6.54 & .80 \\
\hline Public Attitudes & 49.51 & 11.016 & .92 \\
\hline QOL - PCS & 41.32 & 11.075 & .868 \\
\hline $\mathrm{QOL}-\mathrm{MCS}$ & 46.56 & 11.774 & .879 \\
\hline
\end{tabular}

\section{Depression (CES-D)}

The reliability coefficient for CES-D in this study $\alpha=.92$ is consistent with previously reported $\alpha$ 's .85 to .90 (Radloff, 1977); .87 (Hodge \& Kipnis, 1996); .88 
(Clark, Mahoney, Clark \& Eriksen, 2002). The overall CES-D profile for this sample had a mean of $20.33(S D=13.301)$ and scores ranging from 0 to 50 . Higher scores on the CES-D indicate higher levels of distress. Less than half of the sample $(42.6 \%, n=43)$ had scores greater than 21 , which is indicative of possibility of major depression that may require further evaluation and treatment. A total of $39(38.6 \%)$ scored less than 15 , showing no depressive symptomatology, and $19(18.8 \%)$ scored between 15 and 21 , indicating the presence of mild to moderate depression. A summary of Descriptive Statistics - CES-D is presented in Table 9.

Table 9 Descriptive Statistics - CES-D

\begin{tabular}{lll}
\hline \multicolumn{1}{c}{ CES-D scores } & $N$ & $\%$ \\
\hline No depression $(0-14)$ & 39 & 38.6 \\
Mild to moderate depression $(15-21)$ & 19 & 18.8 \\
Possibility of major depression $(22-50)$ & 43 & 42.6 \\
\hline
\end{tabular}

\section{Alcohol Use Disorders Identification Test (AUDIT)}

The AUDIT score profile of this sample consisted of a mean of $5.23(S D=8.082)$ scores ranging from 0 to 40 . Those surveyed scoring in the range of $0-7$ (no hazardous drinking) was $76.2 \%(n=77)$. A range of scores between $8-15$ indicate advice to reduce hazardous drinking for $13.9 \%(n=14)$ of participants.

In contrast, $2.0 \%(n=2)$ scored 17 , which necessitates brief counseling and continued monitoring; $7.9 \%(n=8)$ scored between $21-40$ indicating need for further diagnostic evaluation for alcohol dependence. The reliability coefficient of the AUDIT in this study was .89 and is consistent with previous findings .86 (Barry \& Fleming, 1993; Sinclair, McRee \& Babor, 1992). A summary of the Descriptive Statistics - 
Patterns of Alcohol Consumption is presented in Table 10.

Table 10 Descriptive Statistics - Patterns of Alcohol Consumption

\begin{tabular}{lcc}
\hline \multicolumn{1}{c}{ AUDIT scores } & $N$ & $\%$ \\
\hline No hazardous drinking $(0-7)$ & 77 & $76.2 \%$ \\
Advise to reduce hazardous drinking $(8-15)$ & 14 & $13.9 \%$ \\
Brief counseling and continued monitoring $(16-20)$ & 2 & $2.0 \%$ \\
Further diagnostic evaluation for alcohol dependence $(21-40)$ & 8 & $7.9 \%$ \\
\hline
\end{tabular}

\section{HCV STIGMA}

The overall total stigma score for this sample consisted of a mean of 97.07 ( $S D=$ 19.756) scores ranging from 54 to 145 . The personalized subscale scores ranged from 18 to 70 with a mean of $42.14(S D=11.019)$. The level of stigma was evenly distributed for both levels of stigma categories. The minimal to low stigma scores ranged from 18 to 40 $(46.5 \%, n=47)$ and moderate to high stigma scores range from 41 to $64(48.5 \%, n=49)$. The personalized stigma addressed the perceptions or consequences of other people knowing that the participant is living with $\mathrm{HCV}$, losing friendships, feeling that others are displaying avoidant behavior, or having regret in divulging to some people.

The reliability coefficient of Stigma in this study is .942 which is consistent with previous findings .96 (Berger, Ferrans \& Lashley, 2001). The reliability coefficients for each of the subscales ranged from .79 to .92 in this study compared to the reliability coefficients for each of the subscales as reported by Berger, Ferrans \& Lashley (2001) which range from .90 to .93 . A summary of Stigma Subscale scores by Levels of Stigma is presented in Table 11. 
Table 11 Stigma Subscale scores by Levels of Stigma

\begin{tabular}{lccc}
\hline \multicolumn{1}{c}{ HCV Stigma } & $\begin{array}{c}\text { Sample } \\
\text { Scores }\end{array}$ & $\begin{array}{c}\text { Minimal to Low Stigma } \\
(16-\mathbf{4 0})\end{array}$ & $\begin{array}{c}\text { Moderate to High Stigma } \\
(\mathbf{4 1}-\mathbf{6 4 )}\end{array}$ \\
\hline Personalized & $18-70$ & $46.5 \%, n=47$ & $48.5 \%, n=49$ \\
Disclosure & $13-38$ & $97 \%, n=98$ & $n=0$ \\
Negative self-image & $16-47$ & $91.1 \%, n=92$ & $8.9 \%, n=9$ \\
Public attitudes & $23-76$ & $19.8 \%, n=20$ & $71.3 \%, n=72$ \\
\hline
\end{tabular}

The disclosure subscale scores ranged from 13 to 38 with a mean of $26.21(S D=$ 5.328). The level of disclosure stigma by category for minimal to low stigma largely consisted of scores ranging from 17 to $38(97 \%, n=98)$. A majority perceived this level of stigma by having control of their personal health status or information, keeping their HCV status a secret, or worry that others who know of their HCV status would tell others.

The negative self-image subscale scores ranged from 16 to 47 with a mean of $29.29(S D=6.540)$. Slightly more than $90 \%$ experienced a minimal to low level of perceived stigma relative to negative self-image which dealt with feeling unclean, not as good as others, or like a bad person because of $\mathrm{HCV}$. The level of negative self-image stigma by category for minimal to low stigma consisted of scores ranging between 16 to $39(91.1 \%, n=92)$, and moderate to high stigma with scores ranging between 41 to 47 $(8.9 \%, n=9)$.

The public attitudes subscale scores ranged from 23 to 76 with a mean of 49.51 $(S D=11.016)$. The level of public attitudes stigma by category for minimal to low stigma consisted of scores ranging between 23 to $40(19.8 \%, n=20)$, and moderate to high stigma with scores ranging between 41 to $64(71.3 \%, n=72)$. This revealed a 
moderate to high level of perceived stigma regarding the public's attitudes and what most people think about a person with $\mathrm{HCV}$ or what most people with $\mathrm{HCV}$ can expect when others learn they have HCV. A summary of the Descriptive Statistics-HCV Stigma is presented in Table 12.

Table 12 Descriptive Statistics - HCV Stigma

\begin{tabular}{lcccc}
\hline \multicolumn{1}{c}{ HCV Stigma } & $\begin{array}{c}\text { Sample } \\
\text { Scores }\end{array}$ & $\begin{array}{c}\text { Range } \\
\text { Scores }\end{array}$ & $\boldsymbol{M}$ & $\boldsymbol{S D}$ \\
\hline Total Stigma Score & $54-145$ & $40-160$ & 97.07 & 19.756 \\
$\quad$ Personalized subscale & $18-70$ & $18-72$ & 42.14 & 11.019 \\
Disclosure subscale & $13-38$ & $10-40$ & 26.21 & 5.328 \\
Negative self-image subscale & $16-47$ & $13-52$ & 29.29 & 6.54 \\
Public attitudes subscale & $23-76$ & $20-80$ & 49.51 & 11.016 \\
\hline
\end{tabular}

\section{Quality of Life (SF-12v2)}

The outcome variable, QOL was measured using the SF-12v2 questionnaire, a 12item instrument consisting of two subscales: physical component subscale (PCS) and mental component subscale (MCS). The PCS is an overall measure of physical health and a reflection of a person's satisfaction with their perceived level of physical function, mobility and role limitations due to their health status. In contrast, the MCS is an overall measure of mental health impacted by depression, sense of well-being, and the ability to participate in social activities. The reliability coefficients for each of the subscales ranged from $.868(\mathrm{PCS})$ and $.879(\mathrm{MCS})$ in this study compared to the reliability coefficients for PCS and MCS as reported by Ware et al. (2002) which ranged from .89 and .86 , respectively. 
The overall range of sample scores for PCS is $20-63$ with a mean of $41.32(S D=$ 11.075). Almost $3 / 4^{\text {th }}(71.3 \%, n=72)$ reported participant's physical health being worse than the typical U.S. person. Less than a third $28.7 \%(n=29)$ reported participant's physical health better than the typical U.S. person. The range of scores for MCS is 21 71 with a mean of $46.56(S D=11.774)$. Over half, $58.4 \%(n=59)$ reported participant's mental health is worse than the typical U.S. person; $41.6 \%(n=42)$ reported mental health better than the typical U.S. person. A summary of Descriptive Statistics - Quality of Life $(S F-12 v 2)$ is presented in Table 13.

Table 13 Descriptive Statistics - Quality of Life (SF-12v2)

\begin{tabular}{lcc}
\hline \multicolumn{1}{c}{ Quality of Life (SF-12v2) } & $N$ & $\%$ \\
\hline Physical health better than typical US person & 29 & 28.7 \\
Physical health worse than typical US person & 72 & 71.3 \\
Mental health better than typical US person & 42 & 41.6 \\
Mental health worse than typical US person & 59 & 58.4 \\
\hline
\end{tabular}

Aim \#2: What is the relationship among the variables of age, gender, residing on an AI/AN reservation, current partner status, depression, alcohol consumption, stigma, and quality of life (PCS, MCS) in a sample of Al/ANs living with HCV.

Chi-square tests for categorical variables, ANOVA or t-test for continuous variables by categorical variables, and correlations between continuous variables were used to examine bivariate relationships between participant characteristics and quality of life (PCS and MCS). 


\section{Participant QOL - PCS}

One-way ANOVA indicated a statistically significant relationship between PCS and gender $(F=4.8, p=.03)$, and trending toward significance is the relationship between PCS and residence on AI reservation/land $(F=3.46, p=.06)$. Correlational analysis indicated a statistically significant inverse relationship between PCS and CES-D score $(r=-.438, p=.000)$; trending toward significance is the inverse relationship between PCS and Stigma $(r=-.183, p=.06)$. A summary of the Correlation MatrixPredictor Variables and $Q O L$ is presented in Table 12.

\section{Participant QOL - MCS}

Correlational analysis indicated a statistically significant positive relationship between MCS and Age $(r=.205, p=.04)$; statistically significant inverse relationship between MCS and CES-D score $(r=-.726, p=.000)$ and MCS and Stigma $(r=-.279, p$ $=.005$ ). Statistically significant inverse relationships were found between Age and CES$\mathrm{D}(r=-.220, p=.027) ;$ Age and Stigma $(r=-.212, p=.034)$; Age and AUDIT $(r=-$ $.243, p=.01)$; and trending toward significance for having a current primary partner $(r=$ $.172, p=.08)$

Residence on AI reservation/land was statistically significant inversely related with AUDIT $(r=-.225, p=.02)$ and approaching significance for having a current primary partner $(r=.189, p=.06)$. A statistically significant positive relationship was found between CES-D and AUDIT $(r=.400, p=.000)$; CES-D and Stigma $(r=.485, p$ $=.000) ;$ AUDIT and Stigma approached a statistically significant positive relationship $(r$ $=.192, p=.05$ ). A summary of the Correlation Matrix - Predictor Variables and $Q O L$ $-P C S \& M C S$ is presented in Table 14. 
Table 14 Correlation Matrix - Predictor Variables and $Q O L-P C S \& M C S$

\begin{tabular}{lrrrrrrrrr}
\hline & 1 & 2 & 3 & 4 & 5 & 6 & 7 & 8 & 9 \\
\hline 1 QOL - PCS & 1.000 & & & & & & & & \\
2 Gender & $.217^{*}$ & 1.000 & & & & & & & \\
3 Age (in years) & -.078 & -.074 & 1.000 & & & & & & \\
4 Resides on AI Reservation & .184 & .081 & .090 & 1.000 & & & & & \\
5 QOL - MCS & .165 & .144 & $.205^{*}$ & .081 & 1.000 & & & & \\
6 Current Primary Partner & .012 & .000 & .172 & .189 & .100 & 1.000 & & & \\
7 CES-D & $-.438^{* *}$ & -.158 & $-.220^{*}$ & -.130 & $-.726^{* *}$ & -.088 & 1.000 & & \\
8 AUDIT & -.124 & .046 & $-.243^{*}$ & $-.225^{*}$ & -.148 & -.027 & $.400^{* *}$ & 1.000 & \\
9 STIGMA & -.183 & -.175 & $-.212^{*}$ & -.075 & $-.279 * *$ & -.023 & $.485^{* *}$ & $.192^{*}$ & 1.000 \\
\hline
\end{tabular}

* Correlation significant at 0.05 (2-tailed)

** Correlation significant at 0.01 (2-tailed)

Aim \#3: Identify factors that explain the greatest amount of variance in the quality of life in a sample of AI/ANs living with $\mathrm{HCV}$.

Simultaneous multiple regression analyses were conducted to examine the amount of variance in the DV. A multiple regression approach is appropriate whenever a quantitative variable is to be examined in relationship to predictor variables (Cohen, Cohen, West \& Aiken, 2003). This standard multiple regression strategy was suitable because all independent variables are viewed as having equal importance, there were no apriori hypotheses, and regression diagnostic procedures did not detect problems with multicollinearity among the predictor variables.

\section{Collinearity}

Collinearity describes a situation when a high correlation is detected between two or more predictor variables. When high correlations are detected, they can pose problems when attempting to draw inferences about the relative contribution of each predictor variable to the success of the model. In the use of simultaneous multiple regression 
method, the researcher specifies the set of predictor variables that comprises the model (Mertler \& Vannatta, 2013).

When testing for assumptions, the predictors are not highly correlated. This is supported by Pearson correlations not being $>0.9$, Variance Inflation Factor (VIF) $<10$, and tolerance $>0.2$. A formal method for determining the presence of multicollinearity is the VIF. The VIF measures how much variance of estimated regression coefficients are inflated when compared to having uncorrelated predictors (Hair, Black, Babin, \& Anderson, 2010). Tolerance was used as an indicator of multicollinearity and estimated and calculated by regressing the predictor variables onto the remaining variables included in the multiple regression analysis. There were no outliers and the outcome was normally distributed. Tolerance statistics exceed 0.1 for all variables indicating multicollinearity is not evident. A summary of collinearity statistics - PCS and MCS is presented in Table 15 and 17 , respectively.

Quality of Life

\section{Participant QOL - PCS}

Regression results indicate the overall model significantly predicts participants' quality of life: Participant Quality of Life - Physical Health, $R^{2}=.252, R_{\text {adj }}^{2}=.195, F(7,92)=$ $4.429, p=.000$. This model accounts for $25 \%$ of the variance in QOL-PCS. A summary of the regression coefficients indicated only one (CES-D) of the seven variables significantly contributed to the model (Table 16). 
Table 15 Summary of Collinearity Statistics- PCS

\begin{tabular}{lcc}
\hline & \multicolumn{2}{c}{ Collinearity Statistics } \\
\cline { 2 - 3 } & Tolerance & VIF \\
\hline Gender & .941 & 1.063 \\
Age (in years) & .880 & 1.137 \\
Reside on AI Reservation/Land & .909 & 1.100 \\
Current Primary Partner & .932 & 1.073 \\
CES-D & .651 & 1.535 \\
AUDIT & .753 & 1.328 \\
STIGMA & .748 & 1.337 \\
\hline
\end{tabular}

Table 16 Coefficients for Model Variables - PCS

\begin{tabular}{lrrrr}
\hline \multicolumn{1}{c}{ Independent Variables } & \multicolumn{1}{l}{ B } & \multicolumn{1}{l}{ B } & \multicolumn{1}{l}{$\boldsymbol{l}$} & \multicolumn{1}{l}{$\boldsymbol{p}$} \\
\hline Gender & 2.00 & .097 & 1.045 & .299 \\
Age (in years) & -.208 & -.166 & -1.727 & .087 \\
Reside on AI Reservation/Land & 3.252 & .141 & 1.495 & .138 \\
Current Primary Partner & -.579 & -.026 & -.283 & .778 \\
CES-D & -.396 & -.480 & -4.297 & .000 \\
AUDIT & .054 & .040 & .380 & .705 \\
STIGMA & .017 & .030 & .285 & .776 \\
\hline
\end{tabular}

Multiple $\mathrm{R}=.502 \quad R^{2} \mathrm{adj}=.195$

$R^{2}=.252 \quad F(7,92)=4.42, p=.000$

\section{Participant QOL - MCS}

Regression results indicate the overall model significantly predicts participants' quality of life: Participant Quality of Life - Mental Health, $R^{2}=.569, R_{\text {adj }}^{2}=.536, F(7$, $92)=17.352, p=.000$. This model accounts for $56 \%$ of the variance in QOL-MCS. A summary of the regression coefficients in Table 16 indicated two (CES-D and AUDIT) of 
the seven variables significantly contributed to the model. A summary of the Coefficients for Model Variables - MCS is presented in Table 18.

Table 17 Summary of Collinearity Statistics- MCS

\begin{tabular}{lcc}
\hline & \multicolumn{2}{c}{ Collinearity Statistics } \\
\cline { 2 - 3 } & Tolerance & VIF \\
\hline Gender & .941 & 1.063 \\
Age (in years) & .880 & 1.137 \\
Reside on AI Reservation/Land & .909 & 1.100 \\
Current Primary Partner & .932 & 1.073 \\
CES-D & .651 & 1.535 \\
AUDIT & .753 & 1.328 \\
STIGMA & .748 & 1.337 \\
\hline
\end{tabular}

Table 18 Coefficients for Model Variables - MCS

\begin{tabular}{lrrrr}
\hline \multicolumn{1}{c}{ Independent Variables } & \multicolumn{1}{c}{ B } & \multicolumn{1}{c}{ B } & \multicolumn{1}{c}{$\boldsymbol{c}$} & \multicolumn{1}{c}{$\boldsymbol{p}$} \\
\hline Gender & 1.148 & .052 & .736 & .463 \\
Age (in years) & .122 & .091 & 1.242 & .217 \\
Reside on AI Reservation/Land & .160 & .006 & .090 & .928 \\
Current Primary Partner & .413 & .018 & .248 & .805 \\
CES-D & -.729 & -.824 & -9.714 & .000 \\
AUDIT & .257 & .177 & 2.239 & .028 \\
STIGMA & .067 & .113 & 1.424 & .158 \\
\hline
\end{tabular}

Multiple $\mathrm{R}=.754 \quad R^{2} \mathrm{adj}=.536$

$R^{2}=.569 \quad F(7,92)=17.35, p=.000$ 


\section{Chapter 5}

\section{Discussion and Conclusion}

This chapter will provide a brief summary of the research study, relate the findings to prior research, and suggest possible directions for future studies. This descriptive correlational study was conducted to examine factors associated with quality of life among AI/AN adults living with HCV. This chapter concludes with the findings related to specific research aims that may have important implications for hepatitis education, treatment, $\mathrm{AI} / \mathrm{AN}$ health policy, and practice improvements.

$\mathrm{HCV}$ is a silent epidemic that is taking a toll on Indian Country and; generating considerable concern and raising important public health challenges including long-term health, financial, and social consequences. Quality of life, and not just health, has emerged as an important issue for $\mathrm{AI} / \mathrm{ANs}$ living with $\mathrm{HCV}$. However, research on quality of life in AV/ANs with HCV remains limited and is virtually nonexistent. Information from this study may help nurses develop interventions that facilitate effective coping strategies and help to advance the science to improve QOL among AI/ANs living with HCV.

In the study reported here, depression scores indicated that $38.6 \%$ had no depressive symptomatology; $18.8 \%$ reported the presence of mild to moderate depression, and $42.6 \%$, had scores suggesting possibility of major depression. An analysis by gender indicated a difference in depressive symptomatology where half of all 
women in this sample $(n=22)$ had a score indicating the possibility of having major depression. Given the dearth of inquiry on depression and AI/ANs living with HCV, these findings are congruent in many ways with the overall $\mathrm{AI} / \mathrm{AN}$ women specific mental health challenges and opportunities (Duran et al, 2004).

Not surprisingly, the changes HCV brings can lead many with the condition to feel anxious, irritable, and even depressed. Among AI/AN people, there is a wide range of beliefs about illness, healing, and health. For the Al/AN population, the overall concept of mental illness and beliefs as to why and how it develops contain many diverse meanings and interpretations. Frequently there is an experiential disconnect between physical illness and psychological distress (Hodge, Limb, \& Cross, 2009). They are often not adequately distinguished and AI/ANs may express emotional distress in ways not consistent with standard diagnostic categories. This could explain the range of responses overall and between gender regarding depression as measured by the CES-D.

There is a growing body of evidence suggesting that persons with HCV have a higher prevalence of mental health illness, and persons with mental health illness have four to nine times the prevalence of HCV (Rifai \& Rosenstein, 2005, U.S. DHHS, 1999 \& 2001). Depression is common, and therefore, it is important to find support through support groups, trusted friends and family, or online communities. Interacting with others living with $\mathrm{HCV}$, persons can learn about the challenges other people are facing, find strength and impart coping strategies with each another. The pervasiveness of stigma that's associated with seeking mental health care keeps AI/ANs from seeking and ultimately receiving the necessary treatment.

It is essential for nursing and other health care providers to recognize the 
seriousness of co-occurring depression in persons infected with HCV. Overall, the CESD provides a reliable and valid measure to screen for depressive symptoms in this population. However, discourse bringing increased attention and focus on depression within AI/AN communities is imperative to provide effective care and HCV disease management.

The level of alcohol consumption measured by the AUDIT indicated for this sample there was no association or implication of harmful or hazardous drinking. An analysis between gender and AUDIT showed non- significant relationship. The relationship between residing on an AI reservation / land and pattern of alcohol consumption was significant which is concerning in conjunction with prior findings of depression significantly more common among alcoholics than non-alcoholics (Nurngerger, Foroud, Flury, Meyer \& Wiegand, 2002; Norton, Redd \& Bryan, 2002).

There is empirical evidence for co-morbidity of mood and anxiety disorders among $\mathrm{Al} / \mathrm{AN}$ women with any lifetime substance use disorders. In this sample these comorbidity rates among $\mathrm{AI} / \mathrm{AN}$ women were higher than rates in non- $\mathrm{Al} / \mathrm{AN}$ women reported in other studies (Duran et al, 2004). The level of consumption warrants further analysis in relation to $\mathrm{HCV}$ to determine safe levels of alcohol consumption, given there was a large group of respondents scoring below the cut-off score of not having harmful or hazardous drinking pattern of alcohol.

Stigma produces many challenges for Al/ANs living with $\mathrm{HCV}$ and their social networks, communities, and place in society. Despite the development and support by legislation, policy, and guidelines to protect and serve persons living with HCV, evidence continues to report stigma within their communities and even health care delivery 
systems. There was moderate to high level of personalized stigma reported as consequences of family or community discovering they are living with $\mathrm{HCV}$, losing friendships, sensing others displaying avoidant behavior, or expressing regret in divulging their $\mathrm{HCV}$ status to others. Due to the size of some $\mathrm{AI} / \mathrm{AN}$ reservations, social networks and kinships tend to magnify their place in those communities. Notably, there are few health care delivery systems and thus it is commonplace to exchange and share local/tribal community news. This close knit community of AI/ANs creates apprehension for disclosure, which could lead to friends and family discovering their HCV status and negatively impact their social support.

A moderate to high level of stigma regarding public attitudes also dealt with issues surrounding what most people think about a person with HCV or what most people with HCV can expect when others learn they have HCV. The attitudes of health care providers were thought to have been detrimental for those seeking medical treatment or access of health care services, this has the potential to cause damaging effects, isolation, depression, and increased disease burden and coping with their HCV status (Zickmund, Ho, Masuda, Ippolito, \& LaBrecque, 2003). The majority of participants noted living with HCV lead to being stigmatized because of the whole association of HCV with injecting drug use or engagement with high-risk behavior. This misinformation leads to assumptions that all persons living with HCV have a history of injection drug use in spite of the many ways HCV can be acquired (Butt, 2008). In many ways, much like society in general, AI/AN communities also lack compassion and understanding about the injective drug using population. 
A minimal to low level of stigma related to disclosure centered around having control of one's personal health status or information, keeping their HCV status confidential, or being concerned that others who knew of their HCV status would disclose to others. Some participants resolved to avoid disclosing their HCV status to prevent any sort of discrimination or added stigma even from certain health or social services worker, family, and friends. Disclosure was also seen by many to result in being judged or condemned by their own family members, tribal community, and healthcare setting. A segment of stigma that was not explored in this study and merits further examination is how disclosure affects access to housing, employment, and access public resources.

A minimal to low level of stigma related to negative self-image concentrate on factors like feeling unclean, not as good as others, or like a bad person due of their $\mathrm{HCV}$ status. Beyond the physical symptoms of $\mathrm{HCV}$, the condition can take its toll on the mental or feeling aspects of life quality. There were shared emotional responses where participants often expressed feelings of shame and stigma from when they first heard their diagnoses of HCV and after years of living with their illness, to today. Often, participants conveyed their reluctance in revealing their diagnosis with others, which further lead to feelings of isolation and loneliness.

The area of research in the concept of stigma has been overlooked within AI/AN populations. And, more specifically within the context of living with $\mathrm{HCV}$. The overall relationship between $\mathrm{HCV}$ and stigma requires further study and deconstruction in order to gain an appreciation and fully understand the current state of stigma within an indigenous worldview. This allows for positive systematic changes in the provision of 
$\mathrm{AI} / \mathrm{AN}$ healthcare, policy, and practice that can serve as a guide and provide quality care to $\mathrm{AI} / \mathrm{ANs}$ living with $\mathrm{HCV}$, bringing increased $\mathrm{HCV}$ knowledge and awareness to AI/AN communities, their leaders, and stakeholders.

The results are consistent when comparing participants with the general population norm; more than half of the study sample scored below general population norms on both the PCS, MCS, and all eight health domain subscales (Younossi, 2001). This is an indication that the participants have worse physical and mental health than the typical U.S. person. Alarmingly, when taking into account gender differences, there was a significantly larger percent of female scores below the general population norm than males for both PCS and MCS.

Again many of these factors need to be further explored to draw inferences on specific health domains that impact quality of life. It can be postulated that many of the barriers demographically could be factors that impact quality of life. Many of the potential demographics may include: type of health care coverage, HCV treatment disparities, HCV symptoms, Education level, Income, Access to care, and HCV risk factors, to name a few. However, other factors not included in this study could explain quality of life and include cognitive function and co-morbidities, (Córdoba et al, 2003, Hussain et al, 2001).

Correlation and simultaneous multiple regression analyses were conducted to determine how well age, gender, residing on AI reservation / land, marital status, current partner, depression, alcohol consumption, and stigma predicted quality of life. For the QOL-PCS outcome, the simultaneous multiple regression model with seven predictors produced $R^{2}=.252$, indicating these predictors account for approximately $25 \%$ of the 
variability in QOL-PCS. Depression was the only independent variable to contribute to the model. In contrast for the QOL-MCS outcome, the simultaneous multiple regression model with all seven predictors produced $R^{2}=.569$, indicating these predictors account for approximately $57.0 \%$ of the variability in QOL-MCS. The regression analysis indicated the model significantly predicts QOL-MCS.

\section{Limitations of the Study}

The results of the analyses must be viewed in the context of their limitations. Due to the small/unique sample available for the study, results may not be generalizable beyond the specific population from which the sample was drawn. Data was collected via a survey comprised of four measures: Personal Data, QOL, CES-D, AUDIT, and STIGMA. It is possible that some questions were not culturally equivalent for AI/ANs populations.

All measures was administered by the PI, thus participants could be influenced by social desirability and human memory during self-report, which can consequently influence data accurateness. Respondent burden could be a limitation to the data accurateness, the length of the survey may have influenced responses, for instance several participants appeared to be anxious about time even though the PI provided the opportunity to complete the questionnaire before, during or after their appointment, or at a later time of the convenience.

In addition, cross-sectional data allows for analysis at one point in time and longitudinal data are needed both to describe the course of QOL and determine the impact of depressive symptoms plus the co-occurring conditions on the health of the 
participants. Nonetheless, these findings are important because typically studies still do not examine the co-occurrence of psychosocial issues particularly in AI/AN with $\mathrm{HCV}$.

This study was the first to tailor the STIGMA scale for use with AI/AN with HCV and, it demonstrated acceptable content validity, further testing of the STIGMA scale is needed to ensure reliability and validity among HCV populations.

\section{Implications and Recommendations}

\section{Nursing Practice Implications}

$\mathrm{HCV}$ is a silent disease and considered a public health threat. Through robust research and advancing the science is critical in order to improve and develop care models targeting $\mathrm{HCV}, \mathrm{AI} / \mathrm{ANs}$ populations are underrepresented in national studies (Lead, 2012). The American Association for the Study of Liver Diseases (AALSD) also argue what is necessary to effectively manage liver disease is advancing clinical guidelines as new treatment options are on the horizon and constantly evolving. There is a mandate to remain vigilant in prevention thus advocacy is a key strategies.

The current study was completed using a descriptive cross-sectional survey design. Additional research is needed and could be implemented using a longitudinal design to determine if changes over time become perceptible. Further investigation can use qualitative methods to build the theoretical foundation based on AI worldview and mixed methods to guide practice through research.

Nurses, as advocates and change agents, can facilitate the improvement in QOL, reducing the burden of disease, and closing the gaps in healthcare inequality. In terms of the issues of depression, investments can be made in providing evaluation of activities already in use among other health care models to establish practice-based evidence rather 
than expecting evidence-based practices not developed or tested in AI/AN communities to work effectively.

The discourse among health care disciples about screening and prevention on alcohol use and improving HCV treatment services for eligible participants that have low risk or abstinence from alcohol use is needed. A key strategy is to decrease stigma and bring increased awareness and structural, systematic changes with the involvement of key community advisory stakeholders to educate their tribal community, health delivery system, and government. Stigma has an impact. Through education and dialogue, increased knowledge will reduce and eliminate the burden of stigma.

The advent of new treatment strategies aims to achieve higher efficacy with shorter duration, easier administration, and client adherence. The role for nurses is: to provide continued HCV medication management and support during treatment, to ensure adherence, and include interdisciplinary team members. HCV medication side effects are common; patients and family members need support and encouragement throughout treatment as it affects their quality of life. Given the wide range and potential seriousness of adverse reactions, clients need close and regular monitoring from nurses at regular intervals. Adherence and support during treatment is undoubtedly one of the key factors for success in achieving a sustained viral response, which is an outcome that is a state of being cured.

\section{Nursing Education Implications}

The role of nursing is essential in helping patients, families, and communities become active participants in healthcare. While the traditional methods of nursing education for patients has fallen short in terms of targeting chronic disease and yield 
positive behavior change, the use of motivational interviewing has been shown to an effective method in facilitation, adoption, and implementation to improve treatment outcomes for patients and their support systems (Bishop and Jackson, 2013). An element of cultural competence must also be an emphasis as there are many variations of $\mathrm{AI} / \mathrm{AN}$ culture that is dynamic, shared, symbolic, learned, and integrated (Dunn, 2002). This transformational educational approach will align nursing educators and healthcare systems initiative as exemplary accountable care organizations (ACOs).

An expansion on cultural competence would be to explore another area that may impact health outcomes. Nurses can involve lay community health workers (CHWs) to provide education, support, and outreach based on the needs through community-based interdisciplinary intervention (Tyler, Nyamathi, Stein, Koniak-Griffin, Hodge, \& Gelberg, 2013). The utilization of CHWs in tribal communities are frontline public health workers and considered by elders and lay community as trusted members and have a close understanding of their community.

This relationship and collaboration with nursing enables CHWs to serve as intermediaries between health care organizations and $\mathrm{AI} / \mathrm{AN}$ communities to facilitate access to services and improve quality and cultural competence health care service delivery. To further strengthen communities, nursing educators can engage AI/AN community advisory boards (CAB) to effectively target those areas of need and develop partnerships focusing on HCV Awareness, Prevention, Testing, Risk reduction, and HCV Treatment and Support (American Academy of Nursing, 2013). This innovative approach will allow nurses to evaluate innovative health care models and, in turn, can 
bring it back to CABs and provide cultural competent educational models of sustainability and community participatory research (Warne, 2006).

Depression, alcohol consumption, and stigma are all serious problems related on some level to the QOL of AI/ANs living with $\mathrm{HCV}$. Nurses have a responsibility to meet the need of this population, however, this study, like previous studies indicate that HCV knowledge is poor among some health care professionals. It is imperative for the QOL of AI/ANs living with HCV that nurses continue to explore this 'silent killer' using both qualitative and quantitative methods. It is through research and evidence that is culturally based with interventions grounded on $\mathrm{AI} / \mathrm{AN}$ worldviews that is critical in educating others about effective treatment.

\section{Nursing Policy Implications}

The nation's recent healthcare climate change of improving access to care and the U.S. government's commitment in providing preventive care and services is paramount and timely. This is considered to be the most significant and far reaching health care reform since the establishment of Medicaid and Medicare. The overarching goal of the Patient Protection and Affordable Care Act (ACA) has the potential to benefit those living with HCV by improving access to needed health care services and treatment; and diagnosing viral hepatitis earlier and preventing new HCV infections.

The ACA mirrors many local government's HCV Strategic goals to improve access to care and treatment, strengthen community health centers, end discrimination against pre-existing conditions (stigma), and prioritize reduction of health disparities. While the expansion of healthcare coverage is currently underway, barriers still exist, as some states have yet to agree on expanding Medicaid services to their eligible citizens. 
Also, those who are undocumented citizens will not be covered by the ACA. Other challenges include: legal immigrants will continue to be ineligible for Medicaid for the first 5 years in the U.S.; may not be affordable for some citizens; and requires continued funding from Congress. The continued realization of ACA will require innovative nursing and healthcare leadership and visionary providers, advocates, government, and stakeholders the ensure ACA sustainability through partnerships.

\section{Nursing Research Implications}

A future consideration is to include qualitative study emphasizing illness experience of $\mathrm{Al} / \mathrm{AN}$ persons living with $\mathrm{HCV}$. This would provide an $\mathrm{AI} / \mathrm{AN}$ perspective and worldview into the psychosocial consequences of living with HCV. It would also be vital to examine illness narratives and find relationships from depression and stigma results. This would impart another level of valuable information needed to gain a better understanding in how persons explain the burden of depression or stigma, successful coping, and the unique features associated with living with depression, stigma, and HCV infection.

The need for future studies is evident. Further examination of depression, alcohol consumption, stigma, and quality of life in different communities of AI/ANs living with $\mathrm{HCV}$ is needed. Notably, larger and longitudinal studies are needed to determine potential cause and effect relationships among depression, alcohol consumption, stigma, and quality of life prior to designing and testing interventions aimed at increasing health and quality of life in this population. In adequately addressing the health concerns identified through this study, further research and expansion of other AI/AN HCV population groups needs to focus on: data quality and accuracy to address under- 
representation of $\mathrm{AI} / \mathrm{ANs}$ in population health data, the lack of access to health care services for Al/ANs in both rural and urban settings, lack of incorporation of traditional health care practices, the efficacy of health promotion and disease prevention activities, and the lack of health insurance coverage among AI/ANs.

The limitations of the mental health care system along with the systematic and cultural barriers to care that impede health care services utilization and access for AI/ANs. There is an urgent call for future research to address gaps in public health knowledge about mental health care among AI/ANs, especially research focused on pathways and barriers to care, financial infrastructure for $\mathrm{AI} / \mathrm{AN}$ mental health and testing interventions. Future research for depression may include and focus on: interventions to build community support for mental health care; theoretical models for contextualizing care within communities and systems of care; and development of brief interventions embedded in community settings, or delivered by telephone. Overall, additional research is necessary to elucidate the complexities of $\mathrm{HCV}$ infection that impact $\mathrm{AI} / \mathrm{AN}$ populations.

\section{Conclusion}

The purpose of this study was to examine the relationship between depression, alcohol consumption, stigma, and quality of life in the AI/AN populations. A review of the literature reveals a need for additional research to examine the how AI/ANs are living with $\mathrm{HCV}$ and compare the effects of their $\mathrm{HCV}$ status, stigma, alcohol consumption, and depression on QOL dimensions. Findings indicate depression is significantly related to $\mathrm{QOL}$, with stigma approaching significance for $\mathrm{AI} / \mathrm{AN}$ with $\mathrm{HCV}$ infection. 
The information regarding $\mathrm{HCV}$ infection in the U.S. is improving but there are still many opportunities for improvement and narrowing the gaps in our knowledge. These developments are necessary to enable better prevention, screening, testing, treatment, disease management of $\mathrm{HCV}$, and to guide research, planning for those with hepatitis $\mathrm{C}$ disease. The government, health care delivery systems, and stakeholders have put in place, underpinned by the Affordable Care Act, a comprehensive response to address the health care issues for the uninsured and underinsured.

The advent of new therapies, innovative research, infrastructure, and health policy there are yet many challenges and opportunities in raising the health status of those persons living with HCV. The paradigm of care aligns itself very much with the philosophy of nursing. Through the continued efforts of nursing scholarship and leadership and recent introduction of unified national health structure for our health services, the opportunity to develop a collective nursing approach to this disease should not be overlooked. 


\section{References}

Alcantara, C., \& Gone, J. (2007). Reviewing suicide in Native American communities: Situating risk and protective factors within a transactional-ecological framework. Death Studies, 31(5), 457-477.

Allen, J.P., Litten, R.Z., Fertig, J.B. \& Babor, T. (1997). A review of research on the Alcohol Use Disorders Identification Test (AUDIT). Alcoholism: Clinical and Experimental Research, 21(4), 613-619.

Allen, J.P., Reinert, D.F., \& Volk, R. (2001). The alcohol use disorders identification tests: An aid to recognition of alcohol problems in primary care patients. Preventive Medicine, 33, 428-433.

Alter, M. (2002). Viral hepatitis: Hepatitis c. In: W. R. Kim, R. S. Brown Jr., N. A. Terrault, H. El-Serag (Eds.), Burden of liver disease in the United States: Summary of a workshop [Special Article], Hepatology, 36(1), 2002.

American Academy of Nursing. (2013). Immediate Release: Leading nursing academy says more testing and education needed to avert epidemic. Retrieved from https://aan.memberclicks.net/assets/PressReleaseLinks/2013/2013-07-25hepatitis_c_virus.pdf

American Psychiatric Association. (2000). Diagnostic and statistical manual of mental disorders. (4th ed., text rev.). Washington, DC: American Psychiatric Publishing, Inc.

Aoun, S.L., \& Gregory, R.J. (1998). Mental disorders of Eskimos who were seen at a community mental health center in western Alaska. Psychiatric Services, 49(11), $1485-1487$. 
Astone-Twerell, J., Strauss, S.M., \& Munoz-Plaza, C. (2006). Stigma: Hepatitis c and drug abuse. National Development and Research Institutes, Inc.

Babor, T.F., de la Fuente, J.R., Saunders, J., \& Grant, M. (1992). AUDIT: The Alcohol Use Disorder Identification Test. Guidelines for use in primary health care. Geneva, Switzerland: World Health Organization.

Bailey, D.E., Landerman, L., Barroso, J., Bixby, P., Mishel, M.H., Muir, A.J., et al. (2009). Uncertainty, symptoms, and quality of life in persons with chronic hepatitis C. Psychosomatics, 50(2), 138-46.

Barry, K.L., \& Fleming, M.F. (1993). The Alcohol Use Disorders Identification Test (AUDIT) and the SMAST-13: Predictive validity in a rural primary care sample. Alcohol and Alcoholism, 28(1), 33-42.

Beals, J., Manson, S.M., Keane, E.M., \& Dick, R.W. (1991). Factorial structure of the Center for Epidemiologic Studies-Depression scale among American Indian college students. Psychological Assessment: A Journal of Consulting and Clinical Psychology, 3(4), 623-627.

Beauvais, F. (1998). American Indians and alcohol. Alcohol Health \& Research World, 22(4), 253-259.

Bender, E. (2003). Study identifies suicide risk factors in Native-American youth. Psychiatric News, 38(11), 28.

Bender, E. (2006). APA, AACAP suggest ways to reduce high suicide rates in Native Americans. Psychiatric News, 4l(12), 6. 
Berger, B.E., Ferrans, C.E., \& Lashley, F.R. (2001). Measuring stigma in people with HIV: Psychometric assessment of the HIV stigma scale. Research in Nursing and Health, 24(6), 518-529.

Bishop, C.J., \& Jackson, J. (2013). Motivational interviewing: How advanced practice nurses can impact the rise of chronic diseases. The Journal of Nurse Practitioners, $9(2), 105-109$.

Bohn, M.J., Babor, T.F., \& Kranzler, H.R. (1995). Alcohol Use Disorders Identification Test (AUDIT): Validation of a screening instrument for use in medical settings. Journal of Studies on Alcohol, 56(4), 423-432.

Bonkovsky, H.L., \& Woolley, J.M. (1999). Reduction of health-related quality of life in hepatitis C and improvement with interferon therapy. Hepatology, 29(1), 264-270.

Borenstein, M.T., Hedges, L., Rothstein, H., Cohen, J., \& Schoenfeld, D. (2010). Power and precision [Software Program].

Borenstein, M.T., Rothstein, H., Cohen, J., Schoenfeld, D., Berlin, J., \& Lakatos, E. (2000). Power and Precision v2: A Computer Program for Statistical Power Analysis and Confidence Intervals [CD-Rom]. Lawrence Erlbaum.

Borg, W.R., \& Gall, M.D. (1989). Educational Research (5th ed.). White Plains, NY: Longman, Inc.

Borowsky, I., Resnick, M., Ireland, M., \& Blum R. (1999). Suicide attempts among American Indian and Alaska Native youth. Risk and Protective Factors. Archives of Pediatric Adolescent Medicine, 153, 573-576.

Botvin, G.J., Schinke, S.P., Epstein, J.A., Diaz, T., \& Botvin, E.M. (1995). Effectiveness of culturally focused and generic skills training approaches to alcohol and drug 
abuse prevention among minority adolescents: Two-year follow-up results. Psychology of Addictive Behaviors, 9(3), 183-194.

Boyd, J.H., Weissman, M.M., Thompson, W.D., \& Myers, J.K. (1982). Screening for depression in a community sample: Understanding the discrepancies between depression symptom and diagnostic scales. Archives of General Psychiatry, $39(10), 1195-1200$.

Brave Heart, M. (1998). The return to the sacred path: Healing the historical trauma and historical unresolved grief response among the Lakota. Smith College Studies in Social Work, 68(3), 287- 305.

Brave Heart, M., \& DeBruyn, L.M. (1998). The American Indian holocaust: Healing historical unresolved grief. American Indian and Alaska Native Mental Health Research, 8, 60-82.

Breslau, N. (1985). Depressive symptoms, major depression, and generalized anxiety: A comparison of self-reports on CES-D and results from diagnostic interviews. Psychiatry Research, 15(3), 219-229.

Broderick, E. (2009). Activities of the substance abuse and mental health services administration to prevent suicides among American Indians. Testimony before Senate Committee on Indian Affairs, February 26, 2009.

Brown, L., Macintyre, K., \& Trujillo, L. (2003). Interventions to reduce HIV/AIDS stigma: What have we learned? AIDS Education and Prevention, 15(1), 49-69

Buffington, J., \& Jones, T. (2007). Integrating viral hepatitis prevention into public health programs serving people at high risk for infection: Good public health. Public Health Reports, 122, 1-5. 
Buseh, A.G., Kelber, S.T., Stevens, P.E., \& Park, C.G. (2008). Relationship of symptoms, perceived health, and stigma with quality of life among urban HIVinfected African American men. Public Health Nursing, 25(5), 409-419.

Bushy, A. (2008). Conducting culturally competent rural nursing research. Annual Review of Nursing Research, 26, 221-236.

Butt, A.A., McGinnis, K.A., Skanderson, M., \& Justice, A.C. (2009). Hepatitis c treatment completion rates in routine clinical care. Liver International, 30(2), 240-250.

Butt, G. (2008). Stigma in the context of hepatitis c: Concept analysis. Journal of Advanced Nursing, 62(6), 712-724.

Caetano, R., Clark, C.L., \& Tam, T. (1998). Alcohol consumption among racial/ethnic minorities: Theory and research. Alcohol Health \& Research World, 22(4), 233241.

Centers for Disease Control and Prevention. (2000). Measuring healthy days: Population assessment of health-related quality of life. Atlanta, GA: CDC.

Centers for Disease Control and Prevention. (2001). National hepatitis C prevention strategy: A comprehensive strategy for the prevention and control of hepatitis $\mathrm{c}$ virus infection and its consequences. Atlanta, GA: CDC. Retrieved from http://www.cdc.gov/hepatitis/HCV/Strategy/PDFs/NatHepCPrevStrategy.pdf

Centers for Disease Control and Prevention. (2003). Health disparities experienced by American Indians and Alaska Natives. Morbidity and Mortality Weekly Report, $52(30), 697-724$. 
Centers for Disease Control and Prevention. (2009a). About the Division of Viral Hepatitis. Retrieved from http://www.cdc.gov/hepatitis/AboutUs

Centers for Disease Control and Prevention. (2009b). Reference for the interpretation of hepatitis $\mathrm{C}$ virus (HCV) test results. Retrieved from http://www.cdc.gov/hepatitis/HCV/PDFs/hev_graph.pdf

Centers for Disease Control and Prevention. (2009c). Report on the status of state viral hepatitis plans for the Institute of Medicine executive summary of responses $(\mathrm{n}=55)$. National Hepatitis TA Center, New York State Department of Health. Centers for Disease Control and Prevention. (2009d). Status of state electronic disease surveillance systems-United States, 2007. Morbidity and Mortality Weekly Report, 58(29), 804-807.

Centers for Disease Control and Prevention. (2009e). Surveillance for acute viral hepatitis - United States, 2007. Morbidity and Mortality Weekly Report, 58(No. SS-3).

Chambers, L.R. (1993). The McMaster Health Index Questionnaire: An update. In S. J. Walker \& R. M. Rosser (Eds.), Quality of Life Assessment: Key Issues in the 1990 s (2nd ed.). New York, NY: Springer.

Chapleski, E.E., Lamphere, J.K., Kaczynski, R., Lichtenberg, P.A., \& Dwyer, J.W. (1997). Structure of a depression measure among American Indian elders: Confirmatory factor analysis of the CES-D scale. Research on Aging, 19(4), 462485 . 
Cheak-Zamora, N.C., Wyrwich, K.W., \& McBride, T.D. (2009). Reliability and validity of the SF-12v2 in the medical expenditure panel survey. Quality of Life Research, $18(6), 727-735$

Clark, C.H., Mahoney, J.S., Clark, D.J., \& Eriksen, L.R. (2002). Screening for depression in a hepatitis $\mathrm{C}$ population: the reliability and validity of the Center for Epidemiologic Studies Depression Scale (CES-D). Journal of Advanced Nursing, 40(3), 361-369.

Cohen, J., Cohen, P., West, S.G., \& Aiken, L. S. (2003). Applied multiple regression/correlation analysis for the behavioral sciences (3rd ed.). Mahwah, NJ: Lawrence Erlbaum Associates.

Córdoba, J., Flavià, M., Jacas, C., Sauleda, S., Esteban, J.1., Vargas, V., Esteban, R., \& Guardia, J. (2003). Quality of life and cognitive function in hepatitis C at different stages of liver disease. Journal of Hepatology, 39(2), 231-238.

Costello, E.J., Farmer, E.M., Angold, A., Burns, B.J., \& Erkanli, A. (1997). Psychiatric disorders among American Indian and White youth in Appalachia: The Great Smoky Mountains Study. American Journal of Public Health, 87(5), 827-832.

Creswell, J.W. (2009). Research design: Qualitative, quantitative, and mixed methods approaches (3rd ed.). Thousand Oaks, CA: Sage Publications, Inc.

Crockett, B., \& Gifford, S. (2004). 'Eyes wide shut': Narratives of women living with hepatitis C in Australia. Women \& Health, 39(4), 117-137.

Curyto, K.J., Chapleski, E.E., Lichtenberg, P.A., Hodges, E., Kaczynski, R., \& Sobeck, J. (1998). Prevalence and prediction of depression in American Indian elderly. Clinical Gerontologist: The Journal of Aging and Mental Health, 18(3), 19-37. 
Denny, C., \& Taylor, T. (2001). Alcohol drinking patterns of adult American Indians and Alaska Natives: Finding from the Behavioral Risk Factor Surveillance System, 1993-1997. Centers for Disease Control and Prevention, Atlanta, GA (p. 20). Abstract \#020, 13th Annual Conference, Indian Health Service Research Program, Albuquerque, NM.

Derogatis, L.R. (1993). Symptom checklist-90-revised: Administration, scoring, and procedures manual. (3rd ed.). Minneapolis, MN: National Computers Systems.

Dickerson, D.L., \& Johnson, C.L. (2010). Mental Health and Substance Abuse Characteristics Among a Clinical Sample of Urban American Indian/Alaska Native Youths in a Large California Metropolitan Area: A Descriptive Study. Community Mental Health Journal. Retrieved from http://www.springerlink.com/content/d4r7432713566k55/fulltext.pdf Dolan, M. (1999). The Hepatitis C Handbook. Berkeley, CA: North Atlantic Books. Dunn, A.M. (2002). Culture competence and the primary care provider. Journal of Pediatric Health Care, 16(3), 105-111.

Duran, B., Oetzel, J., Lucero, J., Jiang, Y, Novins, D.K., Manson, S., et al. (2005). Obstacles for rural American Indians seeking alcohol, drug, or mental health treatment. Journal of Consulting and Clinical Psychology, 73(5), 819-829.

Duran, B., Sanders, M., Skipper, B., Waitzkin, H., Malcoe, L.H., Paine, S., \& Yager, J. (2004). Prevalence and correlates of mental disorders among Native American women in primary care. American Journal of Public Health, 94(1), 71-77. 
Dwight, M.M., Kowdley, K.V., Russo, J.E., Ciechanowski, P.S., Larson, A.M., \& Katon, W.J. (2000). Depression, fatigue, and functional disability in patients with chronic hepatitis c. Journal of Psychosomatic Research, 49(5), 311-317.

Evans-Campbell, T. (2008). Historical trauma in American Indian/Native Alaska communities: A multilevel framework for exploring impacts on individuals, families, and communities. Journal of Interpersonal Violence, 23(3), 316-338.

Everhart, J.E. (2008). The burden of digestive diseases in the United States. US Department of Health and Human Services, Public Health Service, National Institutes of Health, National Institute of Diabetes and Digestive and Kidney Diseases. Washington, DC: US Government Printing Office, 2008; NIH Publication No. 09-6443.

Fleishman, J.A., Selim, A.J., \& Kazis, L.E. (2010). Deriving SF-12v2 physical and mental health summary scores: A comparison of different scoring algorithms. Quality of Life Research, 19(2), 231-241.

Fontana, R.J., Hussain, K.B., Schwartz, S.M., Moyer, C.A., Su, G.L., \& Lok, A.S.F. (2002). Emotional distress in chronic hepatitis $C$ patients not receiving antiviral therapy. Journal of Hepatology, 36(3), 401-407.

Foster, G.R. (2009). Quality of life consideration for patients with chronic hepatitis C. Journal of Viral Hepatitis, 16(9), 605-611.

Frank-Stromborg, M., \& Olsen, S.J. (1997). Instruments for clinical health-care research (2nd ed.). Sudbury, MA: Jones and Bartlett Publishers, Inc.

Franke, M.F., Munoz, M., Finnegan, K., Zeladita, J., Sebastian, J.L., Bayona, J.N., et al. (2010). Validation and abbreviation of an HIV stigma scale in an adult Spanish- 
speaking population in urban Peru. AIDS and Behavior, 14(1), 189-199.

Frankl, V.E. (1963). Man's search for meaning: An introduction to logotherapy. New York: Washington Square Press.

Frankl, V.E. (2004). Man's search for meaning. New York: Blackstone Audio, Inc.

Gallegos-Orozco, J.F., Fuentes, A.P., Argueta, J.G., Perez-Pruna, C., Hinojosa-Becerril, C., Sixtos-Alonso, M.S., et al. (2003). Health-related quality of life and depression in patients with chronic Hepatitis C. Archives of Medical Research, $34(2), 124-129$.

Giger, J., \& Davidhizar, R. (2007). Promoting culturally appropriate interventions among vulnerable populations. Annual Review of Nursing Research, 25, 293-316.

Goffman, E. (1963). Stigma: Notes on the management of spoiled identity. New York, NY: Simon \& Schuster, Inc.

Grad, F.P. (2002). Public Health Classics: The Preamble to the Constitution of the World Health Organization Bulletin of the World Health Organization, 80(12).

Grossman, D.C., Sugarman, J.R., Fox, C., \& Moran, J. (1997). Motor-vehicle crashinjury factors among American Indians. Accident Analysis and Prevention, 29(3), 313-319.

Hair, J.F. Jr., Black, W.C., Babin, B.J., \& Anderson, R.E. (2010). Multivariate data analysis (7th ed.). Upper Saddle River, N.J.: Pearson Prentice Hall.

Hennessy, C.H., Moriarty, D.G., Zack, M.M., Scherr, P.A., \& Brackbill, R. (1994). Measuring health-related quality of life for public health surveilliance. Public Health Reports, 109(5), 665-672. 
Hodge, D.R., Limb, G.E., \& Cross, T.L. (2009). Moving from colonization toward balance and harmony: A Native American perspective on wellness. Social Work, 54(3), 211-219.

Hodge, F.S., \& Kipnis, P. (1996). Utilization of the CES-D scale in a Native American population. Chaper 3: Demoralization: A useful concept for case management with Native Americans. In Peter Manoleas (Ed.), The cross-cultural practice of clinical case management in mental health. Binghamton, N.Y.: Haworth Press, Inc.

Holmes, W.C., \& Shea, J.A. (1998). A new HIV/AIDS-targeted quality of life (HATQoL) instrument development, reliability, and validity. Medical Care, 36(2), 138154.

Holzemer, W.L., Hudson, A., Kirksey, K.M., Hamilton, M.J., \& Bakken, S. (2001). The revised sign and symptom check-list for HIV (SSC-HIVrev). The Journal of the Association of Nurses in AIDS Care. 12(5), 60-70.

Horsmans, Y. (2005). Chronic hepatitis, depression and interferon. Journal of Hepatology, 42(6), 788-789.

Hoskins, C.N., \& Mariano, C. (2004). Research in nursing and health: Understanding and using quantitative and qualitative methods (2nd ed.). New York, NY: Springer Publishing Company, Inc.

Husaini, B.A., Neff, J.A., Harrington, J.B., Hughes, M.D., \& Stones, R.H. (1980). Depression in rural communities: Validating the CES-D scale. Journal of Community Psychology, 8(1), 20-27. 
Hussain, K.B., Fontana, R.J., Moyer, C.A., Su, G.L., Sneed-Pee, N., \& Lok, A.S.F. (2001). Comorbid illness is an important determinant of health-related quality of life in patients with chronic hepatitis C. The American Journal of Gastroenterology, 96(9), 2737-2744.

Indian Health Service. (2008). Regional Differences in Indian Health, 2002-2003 Edition. (DHHS ISSN 1095-483X). Washington, DC: U.S. Government Printing Office. Indian Health Service. (2009a). IHS fact sheets: Year 2009 profile. Retrieved from http://info.ihs.gov/Profile09.asp

Indian Health Service. (2009b). Trends in Indian Health, 2002-2003 Edition. (DHHS ISSN 1095-2896). Washington, DC: U.S. Government Printing Office. Indian Health Service. (2011a). IHS Fact Sheets. Indian Health Disparities. Retrieved from http://www.ihs.gov/PublicAffairs/IHSBrochure/Disparities.asp Institute of Medicine. (2002). Reducing suicide: A national imperative. Chapter 2: Magnitude of the problem. In S. K. Goldsmith, T. C. Pellmar, A. M. Kleinman, \& W. E. Bunney (Eds.), Reducing Suicide: A National Imperative (p. 49). Washington, D.C.: The National Academies Press.

Institute of Medicine. (2010a). Hepatitis and liver cancer: A national strategy for prevention and control of hepatitis B and C. Washington, DC: The National Academies Press.

Institute of Medicine. (2010b) IOM report recommends steps to reduce threats posed by hepatitis $\mathrm{B}$ and $\mathrm{C}$, which disproportionately affect minorities. News from the National Academies. Retrieved from http://www8.nationalacademies.org/onpinews/newsitem.aspx?RecordID=12793 
International Council of Nurses. (2003). Nurses fighting AIDS stigma, caring for all. Information and action tool kit. Geneva, Switzerland. Retrieved from http://www.icn.ch/images/stories/documents/publications/ind/indkit2003.pdf

Jiang, L., Beals, J., Whitsell, N.R., Robideaux, Y., \& Manson, S.M. (2009). Healthrelated quality of life and help seeking among American Indians with diabetes and hypertension. Quality of Life Research, 18(6), 709-718.

Johnson, J.A., Nowatzki, T.E., \& Coons, S.J. (1996). Health-related quality of life of diabetic Pima Indians. Medical Care, 34(2), 97-102.

Johnson, J.L., Gryczynski, J., \& Wiechelt, S.A. (2007). HIV/AIDS, substance abuse, and hepatitis prevention needs of Native Americans living in Baltimore: In their own words. AIDS Education \& Prevention, 19(6), 531-544.

Johnston, L.D., O'Malley, P.M., \& Bachman, J.G. (2001). Monitoring the future: National survey results on drug use, 1975-2000. Volume I: Secondary School Students. NIH Pub. No. 01-4924. Bethesda, MD: National Institute on Drug Abuse.

Jones, D. (2006). The persistence of American Indian health disparities. American Journal of Public Health, 96(12), 2122-2134.

Kaiser Family Foundation. (2009). A profile of American Indians and Alaska Natives and their health coverage. Race, Ethnicity, \& Health Care (Issue Brief No. 7977). Menlo Park, CA: The Henry J. Kaiser Family Foundation.

Katz, M.H. (2006). Multivariable analysis: A practical guide for clinicians (2nd ed.). New York, NY: Cambridge University Press.

Kim, S., Coletti, S.D., Williams, S.C., \& Hepler, N.A. (1995). Substance abuse 
prevention involving Asian/Pacific Islander American communities. In: G. J. Botvin; S. Schinke, \& M. A. Orlandi (Eds.), Drug Abuse Prevention in Multiethnic Youth (pp. 295-326). Thousand Oaks, CA: Sage Publications.

Kleinfeld, J., \& Bloom, J. (1977). Boarding schools: Effects on the mental health of Eskimo adolescents. American Journal of Psychiatry, 134, 411417.

Knight, R.G., Williams, S., McGee, R., \& Olaman, S. (1997). Psychometric properties of the center for epidemiologic studies depression scale (CES-D) in a sample of women in middle life. Behavior Research \& Therapy, 35(4), 373-380.

Kumpfer, K.L. (1998). Selective prevention interventions: The Strengthening Families Program. In: R. S. Ashery, E. B. Robertson, \& K. L. Kumpfer (Eds.), Drug Abuse Prevention Through Family Interventions: NIDA Research Monograph No. 177. NIH Pub. No. 99-4135 (p. 160-207). Rockville, MD: National Institute on Drug Abuse.

Lazarus, R.S., \& Folkman, S. (1984). Stress, Appraisal, and Coping. New York, NY: Springer.

Lehman, C.L., \& Cheung, R.C. (2002). Depression, anxiety, post-traumatic stress, and alcohol-related problems among veterans with chronic hepatitis c. The American Journal of Gastroenterology, 97(10), 2640-2646.

Leigh, J.P., Bowlus, C.L., Leistikow, B.N., \& Schenker, M. (2001). Costs of hepatitis c. Archives of Internal Medicine, 161(18), 2231-2237.

Lesser, J., \& Oscós-Sánchez, M. (2007). Community-academic research partnerships with vulnerable populations. Annual Review of Nursing Research, 25, 317-337. 
Lewinsohn, P. M., Muñoz, R.F., Youngren, M.A., \& Zeiss, A.M. (1992). Control Your Depression. New York, NY: Fireside Books.

Lillie-Blanton, M., \& Roubideaux, Y. (2005). Understanding and addressing the health care needs of American Indians and Alaska Natives editorial. American Journal of Public Health, 95(5), 759-761.

Link B.G., \& Phelan, J.C. (2001). Conceptualizing stigma. Annual Review Sociology, 27(3), 363-385.

Link B.G., \& Phelan, J.C. (2006). Essay focus: Stigma and its public health implications. The Lancet, 367(9509), 528-529.

Lowe, J. (2008). A cultural approach to conducting HIV/AIDS and hepatitis c virus education among Native American adolescents. Journal of School Nursing, 24(4), 229-238.

Manson, S.M., Ackerson, L.M., Dick, R.W., Baron, A.E., \& Fleming, C.M. (1990). Depressive symptoms among American Indian adolescents: Psychometric characteristics of the Center for Epidemiologic Studies Depression Scale (CESD). Psychological Assessment: A Journal of Consulting and Clinical Psychology, 2(3), 231-237.

Manson, S.M., Shore, J.H., \& Bloom, J.D. (1985). The depressive experience in American Indian communities: A challenge for psychiatric theory and diagnosis. In A. Kleinman \& B. Good (Eds.), Culture and depression: Studies in the anthropology and cross-cultural psychiatry of affect and disorder. Berkeley, CA: University of California Press. 
McDowell, I. (2006). Measuring health: A guide to rating scales and questionnaires (3rd ed.). New York, NY: Oxford University Press, Inc.

McQuillan, G.M., Kruszon-Moran, D., Denniston, M.M., \& Hirsch, R. (2010). Viral hepatitis. NCHS Data Brief, no. 27. (DHHS Publication No. (PHS) 2010-1209). Hyattsville, MD: National Center for Health Statistics.

Merriam-Webster Dictionary. (2011). Merriam-Webster, Incorporated. Retrieved from http://www.merriam-webster.com/dictionary/stigma

Mertler, C.A., \& Vannatta, R.A. (2013). Advanced and multivariate statistical methods: Practical application and interpretation (5th ed.). Los Angeles, CA: Pyrczak Publishing.

Middlebrook, D. (2009). Suicide among American Indian/Alaska Native youth: Risk and protective factors and implications for policy and research. Presentation at Adolescent Suicide: Addressing Disparities Through Research, Programs, Policy, and Partnerships meeting, September 21-23, 2009. Sponsored by CDC, IHS, and SAMHSA.

Miller, W.R., Zweben, A., DiClemente, C.C., \& Rychtarik, R.G. (1995). Motivational enhancement therapy manual: A clinical research guide for therapists treating individuals with alcohol abuse and dependence. Project MATCH Monograph Series, Vol. 2., NIH Pub. No.94-3723. Rockville, MD: National Institute on Alcohol Abuse and Alcoholism.

Montazeri, A., Vahdaninia, M., Mousavi, S.J., Adasi-Lari, M., Omidvari, S., \& Tavousi, M. (2011). The 12-item medical outcomes study short form health survey 2.0 (SF- 
12v2): A population-based validation study from Tehran, Iran. Health and Quality of Life Outcomes, 9(12), 1-8.

Moore, G.A., Hawley, D.A., \& Bradley P. (2009). Hepatitis C: Experiencing stigma. Gastroenterology Nursing, 32(2), 94-104.

Muñoz, R.F. (1996). The healthy management of reality. Retrieved from http://www.medschool.ucsf.edu/latino/pdf/healthy_management.pdf

Munro, B.H. (2005). Statistical methods for health care research (5th ed.). Philadelphia PA: Lippincott Williams \& Wilkins.

Myers, J.K., \& Weissman, M.M. (1980). Use of a self-report symptom scale to detect depression in a community sample. American Journal of Psychiatry, 137(9), $1081-1084$.

National Alliance on Mental Illness. (2003). American Indian \& Alaska Native: Resource manual. Arlington, VA: NAMI.

National Institute of Diabetes and Digestive and Kidney Diseases. (2006). Chronic hepatitis C: Current disease management (NIH Publication No. 07-4230). Retrieved from http://www.digestive.niddk.nih.gov/ddiseases/pubs/chronichepc/index.htm

National Institutes of Health. (2002). NIH Consensus Statement on Management of Hepatitis C: 2002. NIH Consensus and State-of-the-Science Statements, 19(3), 146.

Naughton, M.J., \& Wiklund, I. (1993). A critical review of dimension-specific measures of health-related quality of life in cross-cultural research. Quality of Life Research 2(6), 397-432. 
Neligh, G. (1990). Mental health programs for American Indians: Their logic, structure and function. American Indian and Alaska Native Mental Health Research: The Journal of the National Center Monograph Series, Vol. 3, Monograph 3, Summer.

Nelligan, J.A., Loftis, J.M., Matthews, A.M., Zucker, B.L., Linke, A.M., \& Hauser, P. (2008). Depression comorbidity and antidepressant use in veterans with chronic hepatitis c: Results from a retrospective chart review. The Journal of Clinical Psychiatry, 69(5), 810-816.

Neumeister, A., Pilcher, L., Erickson, J., Langley, L., Murphy, M., Haukaas, N., et al. (2007). Hepatitis-c prevalence in an urban Native-American clinic: A prospective screening study. Journal of the National Medical Association, 99(4), 389-392.

Norton, H.E., Redd, J.T., \& Bryan, R.T. (2009). Hepatitis c diagnoses in an American Indian primary care population. Journal of Health Disparities Research and Practice, 3(2), 59-66.

Novins, D., Beals, J., Moore, L., Spicer, P., \& Manson, S. (2004). Use of biomedical services and traditional healing options among American Indians: Sociodemographic correlates, spirituality, and ethnic identity. Medical Care, $42(7), 670-679$.

Nurnberger, J.I., Foroud, T., Flury, L., Meyer, E.T., \& Wiegand, R. (2002). Is there a genetic relationship between alcoholism and depression? Alcohol Research \& Health, 26(3), 233-240. 
Office of Minority Health. (2009). Hepatitis and American Indians/Alaska Natives.

Retrieved from

http://minorityhealth.hhs.gov/templates/content.aspx?lvl=3\&lvlid=541\&ID=6494

Oxford Dictionary. (2011). Oxford University Press. Retrieved from

http://oxforddictionaries.com/definition/stigma?region=us

Palmer, M. (2004). Dr. Melissa Palmer's Guide to Hepatitis and Liver Disease: What

You Need to Know (Rev. ed.). New York, NY: Penguin Group.

Parkerson, G.R., Jr. (1994). User's guide for the Duke Health Profile (DUKE). Durham,

NC: Duke University Medical Center.

Pettingell, S., Bearinger, L., Skay, C., Resnick, M., Potthoff, S., \& Eichhorn, J. (2008).

Protecting urban American Indian young people from suicide. American Journal of Health Behavior, 32(5), 465-476.

Radloff, L.S. (1977). The CES-D scale: A self-report depression scale for research in the general population. Applied Psychological Measurement, 1(3), 385-401.

Randall, L.L., \& Muneta, B. (2000). Spirituality among American Indians in health and disease: Culturally appropriate recommendations for health care providers. Home Health Care Management Practice, 12(5), 25-30.

Rempel, J.D., \& Uhanova, J. (2012). Hepatitis c virus in American Indian/Alaskan Native and Aboriginal peoples of North America. Viruses, 4(12), 3912-31.

Rhoades, E.R., \& Rhoades, D.A. (2000). Traditional Indian and modern western medicine. In E. R. Rhoades (Eds.), American Indian health: Innovations in health care, promotion, and policy (pp. 401-417). Baltimore, MD: The Johns Hopkins University Press. 
Rifai, M.A., Rosenstein, D.L. (2005). Hepatitis c and psychiatry. FOCUS: The Journal of Lifelong Learning in Psychiatry, 3(2), 194-202.

Roberts, R., Vernon, S.W., \& Rhoades, H.M. (1989). Effects of language and ethnic status on reliability and validity of the CES-D with psychiatric patients. Journal of Nervous and Mental Disease, 177(10), 581-592.

Roberts, R.E. (1980). Reliability of the CES-D in different ethnic contexts. Psychiatry Research, 2(2), 125-134.

Roberts, R.E., \& Vernon, S.W. (1983). The center for epidemiologic studies depression scale: Its use in a community sample. American Journal of Psychiatry, 140, 4146.

Rodger, A.J., Jolley, D., Thompson, S.C., Lanigan, A., \& Crofts, N. (1999). The impact of diagnosis of hepatitis C virus on quality of life. Hepatology, 30(5), 1299-1301.

Salkind, N.J. (2008). Statistics for people who (think they) hate statistics (3rd ed.). Thousand Oaks, CA: Sage Publications, Inc.

Saunders, J.B., Aasland, O.G., Amundsen, A., \& Grant, M. (1993). Alcohol consumption and related problems among primary health care patients: WHO Collaborative Project on Early Detection of Persons with Harmful Alcohol Consumption I. Addiction, 88(3), 349-362.

Saunders, J.B., Aasland, O.G., Babor, T.F., de la Fuente, J.R., \& Grant, M. (1993). Development of the alcohol use disorders identification test (AUDIT): WHO collaborative project on early detection of persons with harmful alcohol consumption. II. Addiction, 88(6), 791-804. 
Saunders, J.C., \& Cookman, C.A. (2005). A clarified conceptual meaning of hepatitis crelated depression. Gastroenterology Nursing, 28(2), 123-129.

Sayetta, R.B. (1980). Basic data on depressive symptomatology: United States, 19741975. National Health Survey-National Center for Health Statistics. Hyattsville, MD: DHEW Publication No. (PHS) 80-1666.

Scientific Advisory Committee of the Medical Outcomes Trust. (2002). Assessing health status and quality-of-life instruments: Attributes and review criteria. Quality of Life Research, 11(3), 193-205.

Scott, J., \& Garland, N. (2008). Chronic liver disease in Aboriginal North Americans. World Journal of Gastroenterology, 14(29), 4607-4615.

Shaffer, D. (1988). The epidemiology of teen suicide: An examination of risk factors. Journal of Clinical Psychiatry, 49(9, Suppl), 36-41.

Shore, J.H., \& Manson, S. (1983). American Indian psychiatric and social problems. Transcultural Psychiatry, 20, 159-180.

Sinclair, M., McRee, B. \& Babor, T.F. (1992). Evaluation of the Reliability of AUDIT. University of Connecticut School of Medicine, Alcohol Research Center, (unpublished report).

Singh, G.K., \& Hoyert, D.L. (2000). Social epidemiology of chronic liver disease and cirrhosis mortality in the United States, 1935-1997: Trends and differentials by ethnicity, socioeconomic status, and alcohol consumption. Human Biology, 72(5), 801-820. 
Smedley, B.D., Stith, A.Y., \& Nelson, A.R. (Eds.). (2003). Unequal treatment:

Confronting racial and ethnic disparities in health care. Washington, DC: National Academies Press.

Somervell, P.D., Beals, J., Kinzie, J.D., Boehnlein, J., Leung P., \& Manson, S.M. (1992).

Use of the CES-D in an American Indian village. Culture, Medicine and Psychiatry, 16(4), 503-517.

Steinman, E. (2005). Native Americans suffer from historical trauma, researcher says. The United Methodist Church News, July 27, 2005. Retrieved from http://www.umc.org/site/c.gjJTJbMUIuE/b.928147/k.CB36/Native_Americans_s uffer_from_hist orical_trauma_researcher_says.htm

Stewart, A.L., \& Ware, J.E. (1993). Measuring functioning and well-being (3rd ed.). Durham, NC: Duke University Press.

Stewart, A.L., \& Ware, J.E. (Eds.). (1992). Measuring functioning and well-being: The medical outcomes study approach. Durham, NC: Duke University Press.

Stewart, A.L., Hays, R.D., \& Ware, J.E., Jr. (1988). The MOS short form general health survey. Reliability and validity in a patient population. Medical Care, 26(7), 724735.

Stinson, F.S., Yi, H., Grant, B.F., Chou, P., Dawson, D.A., \& Pickering, R. (1998). Drinking in the United States: Main findings from the 1992 National Longitudinal Alcohol Epidemiologic Survey (NLAES). NIH Pub. No. 99-3519. Bethesda, MD: National Institute on Alcohol Abuse and Alcoholism.

Strauss, E., \& Dias Teixeira, M.C. (2006). Quality of life in hepatitis c. Liver International, 26(7), 755-765. 
Substance Abuse and Mental Health Services Administration. (2011). Leading change: A plan for SAMHSA's Roles and Actions, 2011-2014. (DHHS Pub No. SMA114629). Rockville, MD: SAMHSA.

The Indian Health Service Provider. (2007). Liver disease: A significant cause of morbidity and mortality in American Indian and Alaska Native peoples. The IHS Primary Care Provider, 32(6), 161-166. Phoenix, AZ: McMahon, B.J., Redd, J.T., Bialek, S.R., Bell, B.P., \& Cheek, J.E.

Tyler, D., Nyamathi, A., Stein, J.A., Koniak-Griffin, D., Hodge, F., \& Gelberg, L. (2013). Increasing hepatitis $\mathrm{c}$ knowledge among homeless adults: Results of a community-based interdisciplinary intervention. The Journal of Behavioral Health Services Research [Epub Ahead of Print], 1-12.

U.S. Department of Health and Human Services. (1999). Mental health: A report of the surgeon general. Rockville, MD: U.S. Department of Health and Human Services, Substance Abuse and Mental Health Services Administration, Center for Mental Health Services, National Institutes of Health, National Institute of Mental Health. Retrieved from http://www.surgeongeneral.gov/library/mentalhealth/pdfs/c1.pdf U.S. Department of Health and Human Services. (2001). Mental Health: Culture, Race, and Ethnicity - A Supplement to Mental Health: A Report of the Surgeon General. Rockville, MD: U.S. Department of Health and Human Services, Substance Abuse and Mental Health Services Administration, Center for Mental Health Services.

Van Brakel, W.J. (2006). Measuring health-related-stigma: A literature review. Psychology, Health \& Medicine, 11(3), 307-334. 
Vogt, W.P. (2005). Dictionary of statistics \& methodology: A nontechnical guide for the social sciences (3rd ed.). Thousand Oaks, CA: Sage Publications, Inc.

Volk, R.J., Steinbauer, J.R., Cantor, S.B., \& Holzer, C.E. (1997). The alcohol use disorders identification test (AUDIT) as a screen for at-risk drinking in primary care patients of different racial/ethnic backgrounds. Addiction, 92(2), 197-206.

Ware, J.E., Jr., \& Sherbourne, C.D. (1992). The MOS 36-item short-form health survey (SF-36), I. Conceptual framework and item selection. Medical Care, 30(6), 473483.

Ware, J.E., Jr., Kosinksi, M., \& Gandek, B. (2002). SF-36 health survey: Manual and interpretation guide. Lincoln, RI: QualityMetric, Inc.

Ware, J.E., Jr., Kosinski, M., Turner-Bowker, D.M., \& Gandek, B. (2002). How to score version 2 of the SF-12 health survey. Lincoln, RI: QualityMetric, Inc.

Warne, D. (2006). Research and educational approaches to reducing health disparities among American Indians and Alaska Natives. Journal of Transcultural Nursing, 17(3), 1-6.

Weaver, H.N., \& Brave Heart, M.Y. (1999). Examining two facets of American Indian identity: Exposure to other cultures and the influence of historical trauma. Journal of Human Behavior in the Social Environment, 2(1/2), 19-33.

Weissman, M.M., Sholomskas, D., Pottenger, M., Prusoff, B.A., \& Locke, B.Z. (1977). Assessing depressive symptoms in five psychiatric populations: a validation study. American Journal of Epidemiology, 106(3), 203-214.

Wessely, S., \& Pariante, C. (2002). Fatigue, depression and chronic hepatitis c infection. Psychological Medicine, 32(1), 1-10. 
Whitbeck, L.B., Adams, G.W., Hoyt, D.R., \& Chen, X. (2004). Conceptualizing and measuring historical trauma among American Indian people. American Journal of Community Psychology, 33(3-4), 119-130.

Wise, M., Bialek, S., Finelli, L., Bell., B.P., \& Sorvillo, F. (2008). Changing trends in hepatitis C-related mortality in the United States, 1995-2004. Hepatology, 47(4), $1128-1135$.

Wissow, L., Walkup, J., Barlow, A., Reid, R., \& Kane, S. (2001). Cluster and regional influences on suicide in a Southwestern American Indian tribe. Social Science and Medicine, 53, 1115-1124.

World Health Organization. (1997). Measuring quality of life. Retrieved from http://whqlibdoc.who.int/publications/2010/9789241563949_eng.pdf

World Health Organization. (2001). Health and freedom from discrimination. Geneva: WHO. Retrieved from http://www.who.int/hhr/activities/q_and_a/en/Health_and_Freedom_from_Discri mination_English_699KB.pdf

World Health Organization. (2010). Mental health and development: Targeting people with mental health conditions as a vulnerable group. Retrieved from http://whqlibdoc.who.int/publications/2010/9789241563949_eng.pdf

Wu, S.Y., \& Green, A. (2000). Projection of chronic illness prevalence and cost inflation. Santa Monica, CA: RAND Health.

Yates, W.R., \& Gleason, O. (1998). Hepatitis C and depression. Depression and Anxiety, 7(4), 188-193. 
Yoder, K.A., Whitbeck, L.B., Hoyt, D.R., \& LaFromboise T. (2006). Suicidal ideation among American Indian youths. Archives of Suicide Research, 10(2), 177-190.

Younossi, Z.M., Boparai, N., McCormick, M., Price, L.L., \& Guyatt, G. (2001). Assessment of utilities and health related quality of life in patients with chronic liver disease. American Journal of Gastroenterology, 96(2), 579-583.

Younossi, Z.M., Boparai, N., Price, L.L., Kiwi, M.L., McCormick, M., \& Guyatt, G. (2001). Health-related quality of life in chronic liver disease: The impact of type and severity of disease. The American Journal of Gastroenterology, 96(7), 2199 2205.

Zickmund, S., Ho. E.Y., Masuda, M., Ippolito, L., \& LaBrecque, D.R. (2003). "They treated me like a leper": Stigmatization and the quality of life of patients with hepatitis c. Journal of General Internal Medicine, 18(10), 835-844.

Zucker, D.M. (2012). The American Academy of Nursing Policy Brief Hepatitis C Screening and Testing: A Call for a National Response. Retrieved from http://www.aannet.org/assets/docs/PolicyResources/policybrief\%205\%2025\%20 $\% 2012 \% 20$ hep $\% 20$ c.pdf 
Appendix A

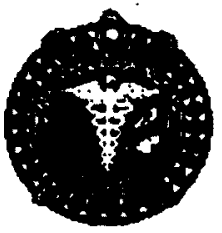

\section{Indian Health Council, Inc.}

Tuesday. Auạust 30, 2011

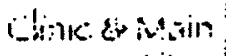

Criti:

se lia Livisli kire

balle Cork: P.A

$4 \pm 1,52$

anI FO. Pas : (ot

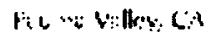

!n

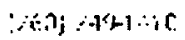

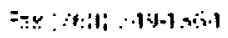

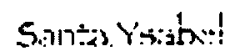
S-tollia: Clini-

?.C: For i:

Sd: Yod x. C C

. y $\pm 1, \pi$.

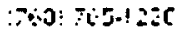

whes intlian - culth coin

andivio

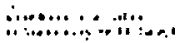

Unlifersity or San nityo

Institufional Revlew Boart

Alln: Jane H. Georges. PhD, RN

5998 slcolo Park

San Disgo, CA 02110

Re: Letter of Suppurt

Dar Dr. Goorgas:

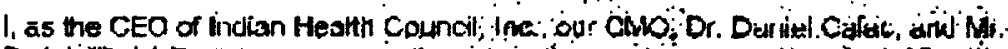

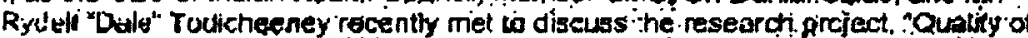

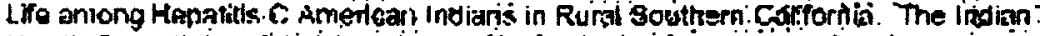

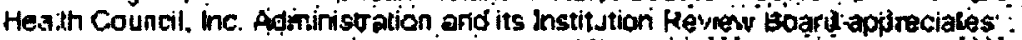

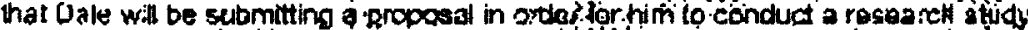
as part of his Dostor uf Philesophy in Nersing discertalion:at tha Univisity of San. Dieco tathn Sciviol of Nursing ond Hejlth Sclemive;

We understand ingt ar individual's leulings dind the experience of their. Hepatitis o

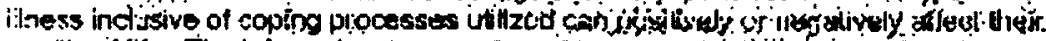

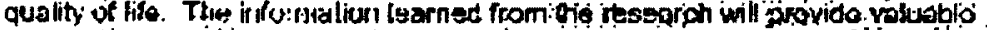

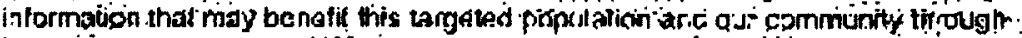

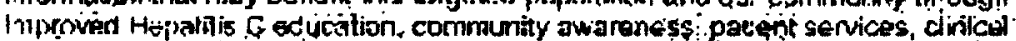
manisglient, ar.d.ptogram development. We are pledsed to provide Dala a letter of suppost in this valuab a researth endeavor. He may uslize the Ir ciop. Hesilsh

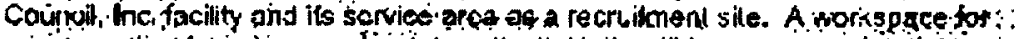

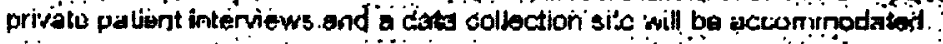

It would be ai hornor and a privilege to be of asciance n suppurtiong this research

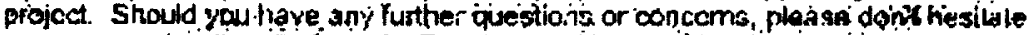

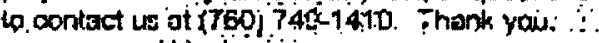

Respeclfutly yours:

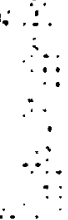

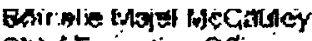

Chlef Exocltivo Oflicior

Qnrie: Y. Calbe AHD:

Aumipisilration de zartumint

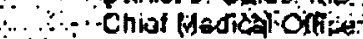

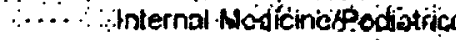

cc: Dals' didcheeneri: 


\section{Appendix B}

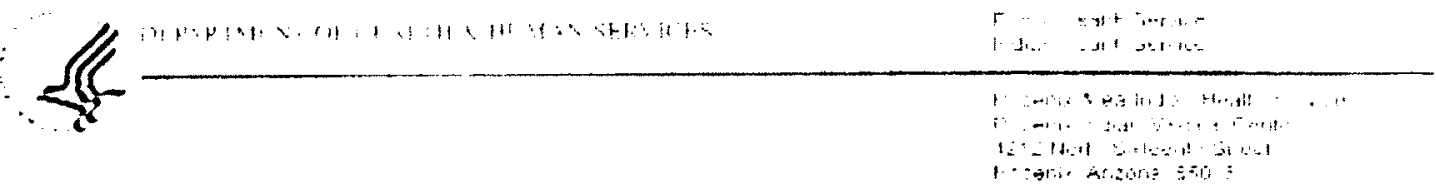

Ju.: is. $210: 2$

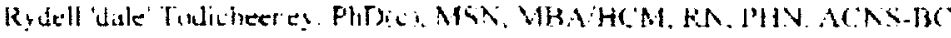

Dow ond Candsiats

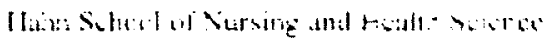

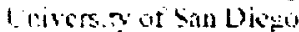

5008 Alcilla Park

San Nier' Califingias 9210

Dear Hr. Todicheens,

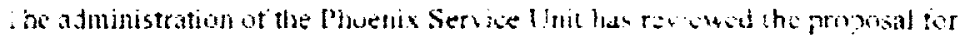

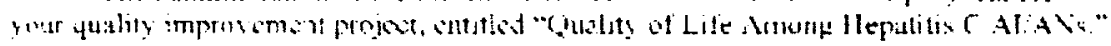

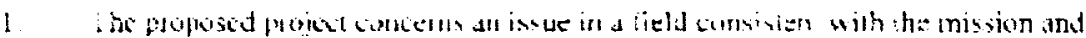
primliesul the Phowis Ind an Mad cal Cemtes

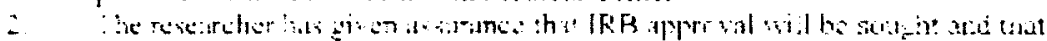

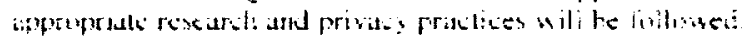

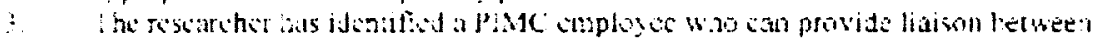
the retearcher abild tie 5 ro.

This proied has the endorsement of the Phocrix Service L nit adm.histation to weh

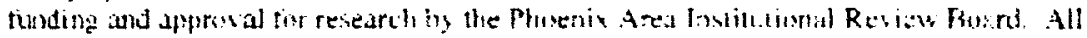

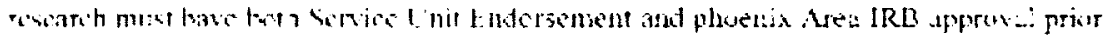

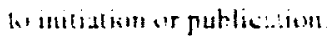

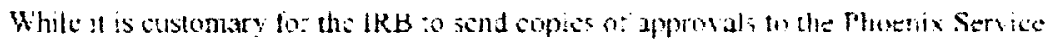

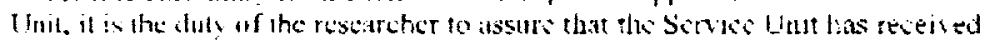

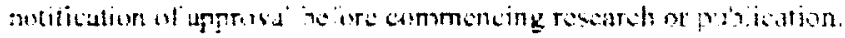

inn:tents.

Jehin Molins. MD. In

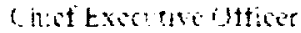

Phomis Intian Medical conter

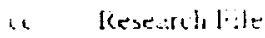


Appendix E

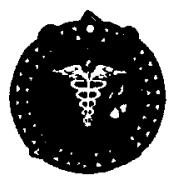

\section{Indian Health Council, Inc.}

March 28, 2012

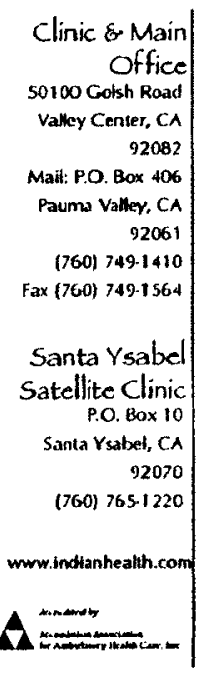

Clinic \& Main

Re: Quality of Life among Hepattis C American Indians in Rural
Southem Callfornia

Dear Mr. Todicheeney.

Your project referenced above was reviewed and approved in accordance with the Indian Health Council, Inc. (IHC) IRB assurance and federal requirements pertaining to human subjects protections within the Code of Federal Regulations (45 CFR 46; 21 CFR 50). In addition, your brochure and flyer for the project were also approved. This review is valid through March 28, 2013, and applies to the conditions and procedures described in your protocol. Please notify the IHC IRB Committee if your status as an USD student changes while conducting this research.

Your study recruitment will take place through IHC, but you must confirm those procedures with IHC staff prior to initiation of your study. If study recruitment takes place outside of IHC, you must confirm with that institution that you have permission to conduct the study prior to initiation of any study activities.

Your Consent Form must display the USD IRB stamp of approval along with the IHC IRB stamp of approval and must be read aloud to participants.

This approval, based on the degree of risk, is for 365 days from the date of IHC IRB review and approval unless otherwise stated in this letter. The regulations require that continuing review be conducted on or before the 1-year anniversary date of the IHC IRB approval, even thought the research activity may not begin until some time after the IRB has given approval.

Date of IRB review and approval: March 28, 2012

If you have any questions, please contact me: dmorton@ucsd.edu.

Deborah J. Morton, PhD, MA, Chair

Indian Health Council, Inc., Institutional Review Board 


\section{Appendix F}

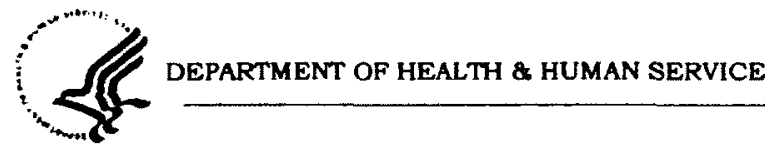

Public Health Service

Phoenix Area Indian Heatth Service

Two Renaissance Square

40 North Central, Suite 600

Phoenix, Arizona 85004-4424

December 7, 2012

Rydell Todicheeney, MSN, MBAHCM

Doctoral Candidate

Mahn School of Nursing and Health Science

University of San Diego

5998 Alcala Park

San Diego, CA 92110

Dear Mr. Todicheeney,

Thank you for subrnitting the protocol "uQuality of Life among Southwest American Indian/Alaska Natives Living with Hepetitis $C$ in Urban Dwellinge: It has been assigned the protocol number PXR 12.18. Please utilize this designation in any cocumentation and in all communication to the Phoenix Area IHS IRB related to this study.

Upon review by the Phoenix Area IHS IRB your protocol was "Approved with recommendations." Work may begin once the IRB receives a response of needed information. The Phoenix IHS IRB had the following recommendations that require a response:

Specific to the questionnaire to be used, the reviewers would like a response to the following

- Are validated questionnaires being used?

- QOL and HCV stigma scale - provide darification on their statistical reliability/validity

- PI stated the HCV stigma scale was an "adapled" instrument. If it was revised from another scale, what or how was it adjusted to "fit" the study? - making an adjustment to an established instrument requires some effort and documentation related to reliability and validity - how was the validity of the "adapted" instrument demonstrated?

Upon receipt of the response to the recommendations by the Phoenix Area IRB, the research may begin. Your study is approved for one year, through December 2, 2013.

Please be aware that any substantive changes in research activities may not be initiated without prior review and approval by the Phoenix Area IHS IRB. Federal regulation requires that any unanticipated problems involving risks to participants or others, or serious harm involving participants, be promptly reported to the IRB for immediate review. If findings for this research are to be used in any papers for publication, abstracts, oral or other presentations, this must be submitted to the Phoenix Avea IHS IRB before such activity is undertaken.

Please submit a Status Report and Renewal Application 30 days prior to the expiration date of this approval, November 2, 2013. The Status Report and Renewal Application form, along with additional information is available at unw.ins.gov/MedicalPrograms/Research/index.cfm Go to Human Subject Protection IRB then Forms and Other Resources. 


\section{Appendix G}

Rydell Todicheeney, MSN, MBAHCM

Doctoral Candidate

Hahn School of Nursing and Heatth Science

University of San Diego

5998 Alcala Park

San Diego, CA 92110

Dear Mr. Todicheeney,

Thank you for submitting a response, per the IRB's request, for protocol PXR 12.18 -"Quality of Life among Southwest American IndlaniAleaka Natlves Living with Hepatitis C in Urban Dwellings."

Upon review by the Phoenix Area IHS IRB, your protocol was approved "as is", and your research can begin. Your study is approved for one year, through Decernber $2,2013$.

Please be aware that any substantive changes in research activities may not be initiated without prior review and approval by the Phoenix Area IHS IRB. Federal regulation requires that any unanticipated problems involving risks to participants or others, or serious harm involving participants, be promptly reported to the IRB for immediate review. If findings for this research are to be used in any papers for publication, abstracts, oral or other presentations, this must be submitted to the Phoenix Area IHS IRB before such activity is undertaken.

Please submit a Status Report and Renewal Application $\mathbf{3 0}$ days prior to the expiration date of this approval, November 2, 2013. The Status Report and Renewal Application form, along with additional information is available at muvihs.gov/MedicalProorams/Research/index.cfm Go to Human subject Protection IRB then Forms and Other Resources.

On behalf of the IRB, thank you, and we wish you success with your research. If I may be of turther assistance please contact me.

Sincerely,

Cynthia Claus, PhD, MPH

Chair, Phoenix Area Institutional Review Board

Director, Office of Health Programs

Phoenix Area Indian Heatth Service 
Appendix $\mathrm{H}$

Invitation Letter for Study Participation

19 March 2012

\section{Dear Patient of Indian Health Council, Inc.:}

This Invitation Letter for Study Participation has received support from Indian Health Council, Inc. on behalf of Dale Todicheeney, a Navajo nurse who served our community and is a University of San Diego doctoral student. You are being invited to participate in a research study that Dale is conducting for the purpose of learning more about patients living with the Hepatitis C Virus.

For participating in this study, you will receive $\$ 25$ Cash or a $\$ 25$ Target Gift card. While Dr. Calac and his staff have mailed this letter to IHC patients who might be interested in a study like this, Dr. Calac or IHC is not sponsoring or funding this study. Nothing about your care at IHC or anything about your medical care/social services will change if you decide not to participate.

Your participation in this study about Hepatitis $\mathrm{C}$ is important and completely voluntary. If you are interested in participating, you will spend at least 60 minutes to complete the survey interview. You will have an opportunity to sit down with Dale at a private location, most likely at IHC, that is convenient for you and feel your privacy will be protected.

I hope you will be interested in participating and should you have any questions, please call Dale Todicheeney at 602-315-1315 or email him at dtodicheeney@gmail.com. Thank you.

Respectfully yours,

Dale Todicheeney, PhD(c), MBA/HCM, RN, PHN, ACNS-BC

Doctoral Student

Hahn School of Nursing and Health Science

University of San Diego

KE.P. THIS FOR YOI R RF.CORDS 
Appendix I

Invitation Letter for Study Participation

14 August 2012

\section{Dear PIMC Patient:}

This Invitation Letter for Study Participation has received support from Phoenix Area IHS on behalf of Dale Todicheeney, a Navajo nurse in our community and University of San Diego doctoral student. You are being invited to participate in a research study that Dale is conducting for the purpose of learning more about patients living with the Hepatitis $\mathrm{C}$ Virus.

For participating in this study, you will receive $\$ 25$ Cash or a $\$ 25$ Target Gift card. While PIMC has provided you this letter and have expressed interest in participating in this study, PIMC is not sponsoring or funding this study. Nothing about your care at PIMC or anything about your medical care/social services will change if you decide not to participate.

Your participation in this study about Hepatitis $\mathrm{C}$ is important and completely voluntary. If you are interested in participating, you will spend at least 60 minutes with Dale to complete the survey interview. You will have an opportunity to sit down with Dale at a private location, most likely at PIMC, that is convenient and feel your privacy will be protected.

I hope you will be interested in participating and should you have any questions, please call Dale Todicheeney at 602-315-1315 or email him at dtodicheeney@gmail.com. Thank you.

Respectfully yours,

Dale Todicheeney, PhD(c), MSN, MBA/HCM, RN, PHN, ACNS-BC

Doctoral Student

Hahn School of Nursing and Health Science

University of San Diego

KFEP THIS FOR YOL K REC ORDS 
Appendix J

ID Code \#

\author{
Today's Date: \\ University of San Dlego \\ Institutlonal Roviow Board \\ Research Participant Consent Form
}

For the research study entitied:

Quality of Life Among Hepatitis C American Indian/Alaska Natives in Rural Southern California

1. Purpose of the recearch study

Dale Todicheeney. a student from the University of San Diego (USD) is conducting a study to find out more about Hepatitis C virus (HCV) among American Indian/Alaska Natives (Al/ANs). You have been invited because you are: living with HCV, Al/AN, utilizing indian Health Council, Inc. (IHC) services.

\title{
II. What you will be asked to do
}

If you agree to be in this study, personal health information pertaining to your HCV diagnosis will be included in this study. This study involves questionnaires to better understand how you are living with HCV. The interview will last 60 minutes.

\section{Ill. Foreseeable rlaks or discomforts}

You will not be identified with your responses. No one but Dale will know how you answered these questions. Dale is responsible for managing the data and certified in confidentiality procedures. Sometimes when poople are asked to think about their foelings, they may foel sad or anxious. If you would Ilke to talk to someone about your feelings at any time, you may call: Indlan Health Council, Inc. - Human Services Department at 760-749-1410 or San Diego Mental Health Hotline at 1-800-479-3339

\section{Beneftis and riske}

Participation may involve a slight risk of loss of confidentiality, as none of the data gathered is highly sensitive. There may be no direct benefit to you; however, an indirect benefit is to know you are helping your community and health professionals to better understand how Al/ANs are living with HCV.

\section{Confidentiality}

Any information provided will remain confidential and be locked in a file and/or password-protected computer for a minimum of five years. All data collected will be coded with a number and your real name will not be used. The results of this study will only be presentedinaggregate form.

\section{Compensation}

You will recelve a $\$ 25$ Target Gift card or $\$ 25$ Cash for participating, oven if you do not complete the session.

\section{Voluntary Nature of this Research}

Your participation is entirely voluntary. You may refuse to answer any question or withdraw at any time. Deciding not to participate or not answering any of the questions will have no effect on any benefits you're entitled to, like your health care, or employment. You can withdraw from this study at anx time without penalty.

\section{Contact Information}

Dale has explained this study to me and answered my questions. The participant will be told if any important new information is found during the course of this study that may affect willingness to continue. You may contact Dale at (602) 315-1315 or the USD Institutional Review Board at (619) 2604653 for more information about your rights as a participant, or to report research-related problems. Agreement: I have read and understand this form, and consent to the research it describes to me. I have recelved a copy of this consent form for my records.

$$
\text { Print Name } / \text { Signature of Particloant }
$$

Rydell 'Dale' Todicheeney. PhD(c). RNI

$$
\text { Signature of Study Investigator }
$$

KFE.P THIS FOR YOI R RE.CORDS

Dato 


\title{
Appendix K
}

\author{
Institutional Review Board \\ Indian Health Council, Inc. \\ 50100 Goish Road \\ Valley Center, CA 92082 \\ (760) 749-1410 \\ (760) 749-1564 (FAX)
}

PROJECTAL SUBJECT'S BILL OF RIGHTS

The faculty and staff of the University of San Diego and Indian Health Council, Inc. wish you to know: Any person who is requested to consent to participate as a subject in a research study involving a medical project, or who is requested to consent on behalf of another, has the right to:

1. Be informed of the nature and purpose of the project.

2. Be given an explanation of the procedure to be followed in a research project, and any drug or device to be used.

3. Be given a description of any attendant discomforts and risks reasonably to be expected from the project.

4. Be given an explanation of any benefits to the participant reasonably to be expected from the project, if applicable.

5. Be given a disclosure of any appropriate alternative procedures, drugs, or devices that might be advantageous to the participant, and their relative risks and benefits.

6. Be informed of the avenues of medical treatment, if any, available to the participant after the project if complications should arise.

7. Be given an opportunity to ask any questions concerning the project or the procedures involved.

8. Be instructed that consent to participate in the research project may be withdrawn at any time, and the participant may discontinue participation in the research project without prejudice.

9. Be given a copy of a signed and dated written consent form when one is required.

10. Be given the opportunity to decide to consent or not to consent to a project without the intervention of any element of force, fraud, deceit, duress, coercion, or undue influence on the participant's decision.

If you have questions regarding the research project, Dale Todicheeney, PhD(c), RN or the Research Study's Interview Supervisor, Cynthia D. Connelly, PhD, RN, FAAN will be glad to answer them. You may seek information from the Indian Health Council, Inc. Institutional Review Board - established for the protection of volunteers in research projects - by calling or by writing to the above address.

\footnotetext{
$* * * * * * * * * * * * * * * * * * * * * * * * * * * * * * * * * * * * * * * * * * * * * * * * * * * * *$

Based on the results of thls research project, we may conduct future studies. There is no obligation to participate in a future study if you participate in the present study.
}

Please indicate however, if you agree for us to contact you in the future about possible participation in any future studies.

May we contact you in the future about additional research? Yes $\square$ No

If you checked yes, please provide your contact information (address, email, telephone): 


\title{
Appendix L
}

ID Code \#

\author{
Univeralty of San Dlego \\ institutional Roviow Board \\ Research Participant Consent Form \\ For the research study entitled: \\ Living with Hepattils $C$ in Urban Dwellings
}

Quality of Life among Southwest American Indlan/Alaska Natives

\section{Purpose of the research study}

Dale Todicheeney, a student from the University of San Diego (USD) is conducting a study to find out more about Hepatitis $\mathrm{C}$ virus (HCV) among Southwest American Indian/Alaska Natives (Al/ANs). You have been invited because you are: living with HCV, Al/AN, and utilizing Phoenix Indian Medical Center (PIMC) healthcare services.

\section{What you will be anked to do}

If you agree to be in this study, personal health information pertaining to your HCV diagnosis will be included in this study. This study involves questionnaires to better understand how you are living with HCV. The interview will last 60 minutes.

\section{Iil. Foreseeable riske or discomforts}

You will not be identified with your responses. No one but Dale will know how you answered these questions. Dale is responsible for managing the data and certified in confidentiality procedures. Sometimes when people are asked to think about their feelings, they may foel sad or anxious. If you would tike to talk to someone about your teelings at any time, you may call:

Arizona Crisis Hotline at 1-866-205-6229

\section{Boneflits and riaks}

Participation may involve a slight risk of loss of confidentiality, as none of the data gathered is highly sensitive. There may be no direct benefit to you; however, an indirect benefit is to know you are helping your community and health professionals to better understand how Al/ANs are living with HCV.

\section{Confidentiality}

Any information provided will remain confidential and be locked in a file and/or password-protected computer for a minimum of five years. All data collected will be coded with a number and your real name will not be used. The results of this study will only be presented in aggregate form.

\section{Compensation}

You will receive a $\$ 25$ Target Gift card or $\$ 25$ Cash for particlpating, oven if you do not complote the session.

Vi. Voluntary Nature of this Research

Your participation is entirely voluntary. You may refuse to answer any question or withdraw at any time. Nothing about your care at PIMC or anything about your medical care/social services will change if you decide not to participate or answer any of the questions. You can withdraw from this study at any time without penalts.

Vil. Contact Information

Dale has explained this study to me and answered my questions. The participant will be told if any important new information is found during the course of this study that may affect willingness to continue. You may contact Dale at (602) 316-1315 or the USD Institutional Review Board at (619) 260 4563 for more information about your rights as a participant, or to report research-related problems. Agreement: I have read and understand this form, and consent to the research $t \mathrm{describes}$ to me. I have recelved a copy of thls consent form for my records.

$\begin{array}{ll}\text { Print Nane / slencture of Partelpant } & \text { Date } \\ \text { Rydell Dale' Todichoeney, PhD(c). RN I } & \text { Date }\end{array}$




\section{Appendix M}

\section{PROJECTAL SUBJECT'S BILL OF RIGHTS}

The faculty and staff of the University of San Diego and Phoenix Area IHS / PIMC wish you to know: Any person who is requested to consent to participate as a subject in a research study involving a medical project, or who is requested to consent on behalf of another, has the right to:

1. Be informed of the nature and purpose of the project,

2. Be given an explanation of the procedure to be followed in a research project, and any drug or device to be used,

3. Be given a description of any attendant discomforts and risks reasonably to be expected from the project,

4. Be given an explanation of any benefits to the participant reasonably to be expected from the project, if applicable,

5. Be given a disclosure of any appropriate alternative procedures, drugs, or devices that might be advantageous to the participant, and their relative risks and benefits,

6. Be informed of the avenues of medical treatment, if any, available to the participant after the project, if complications should arise,

7. Be given an opportunity to ask any questions concerning the project or the procedures involved,

8. Be instructed that consent to participate in the research project may be withdrawn at any time, and the participant may discontinue participation in the research project without prejudice,

9. Be given a copy of a signed and dated written consent form when one is required, and

10. Be given the opportunity to decide to consent or not to consent to a project without the intervention of any element of force, fraud, deceit, duress, coercion, or undue influence on the participant's decision.

If you have questions regarding the research project, Dale Todicheeney, PhD(c), RN or the Research Study's Interview Supervisor, Cynthia D. Connelly, PhD, RN, FAAN will be glad to answer them. You may seek information from the Phoenix Area IHS - Institutional Review Board - established for the protection of volunteers in research projects - by calling (602) 364-5189 or writing to: Two Renaissance Square, 40 North Central Avenue, Suite 600, Phoenix, Arizona 85004.

$* * * * * * * * * * * * * * * * * * * * * * * * * * * * * * * * * * * * * * * * * * * * * * * * * * * * *$

Based on the results of this research project, we may conduct future studies. There is no obllgation to participate in a huture study if you participate in the present study.

Please indicate however, If you agree for us to contact you in the future about possible participation in any future studles.

May we contact you in the future about additional research?

Yes No

If you checked yes, please provide your contact information (address, e-mail, telephone):

Address:

E-mail:

Telephone:

KFE.P THIS FOR YOL R RECORDS


Appendix $N$

$$
\begin{aligned}
& \text { Institutional Review Board } \\
& \text { Indian Health Counci, Inc. } \\
& 50100 \text { Golsh Road } \\
& \text { Valley Center, CA } 92082 \\
& \text { (760) 749-1410 } \\
& \text { (760) 749-1564 (FAX) }
\end{aligned}
$$

HCV Research Study Participant Incentive

For your voluntary participation in this HCV Research Study, you may choose one of the following incentives. Please check the box indicating which incentive you would like to receive:
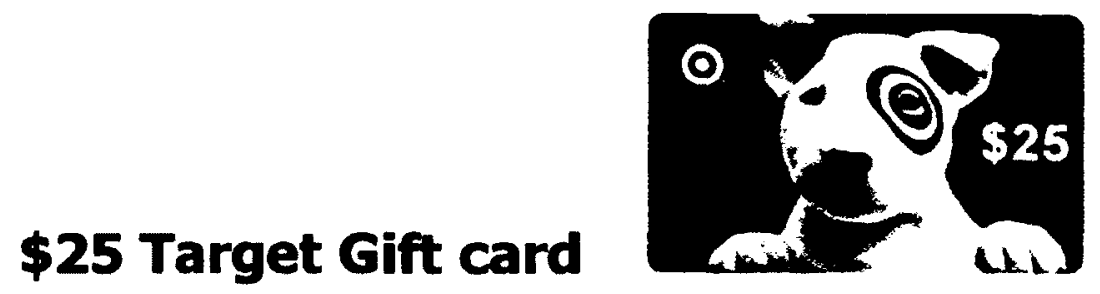

$\square \$ 25$ Cash
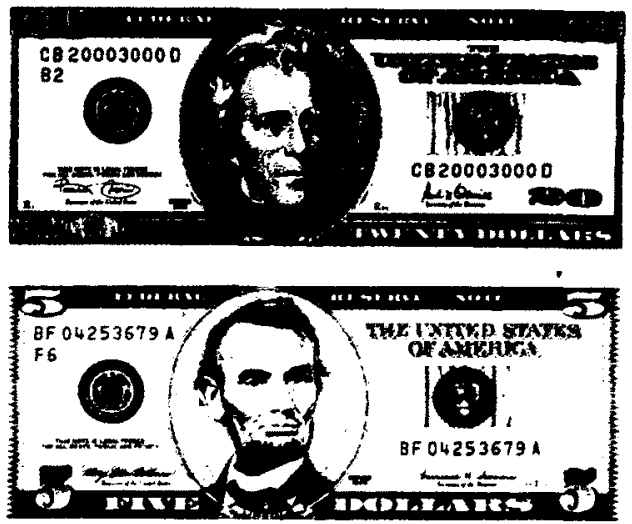

Print Name / Signature of Particlpant

Date 
Appendix $\mathrm{O}$

ID Code \#

University of San Dlego Institutional Review Board

Research Participant Incentive Form

For your voluntary participation in this HCV Research Study, you may choose one of the following incentives. Please check the box indicating which incentive you would like to receive:

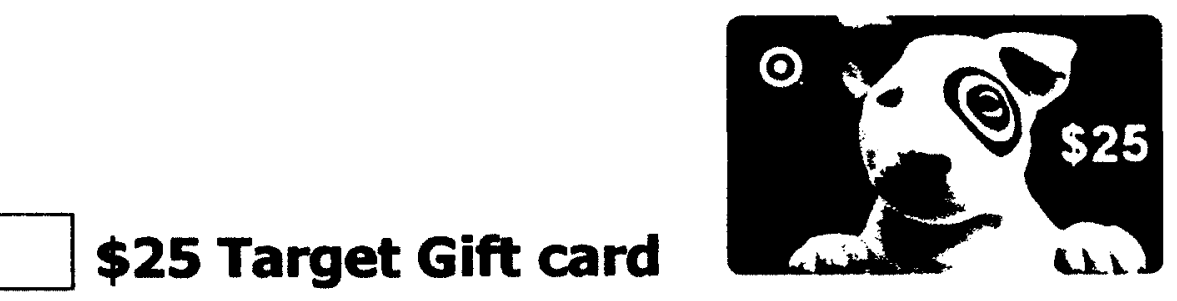

$\square$ \$25 Cash
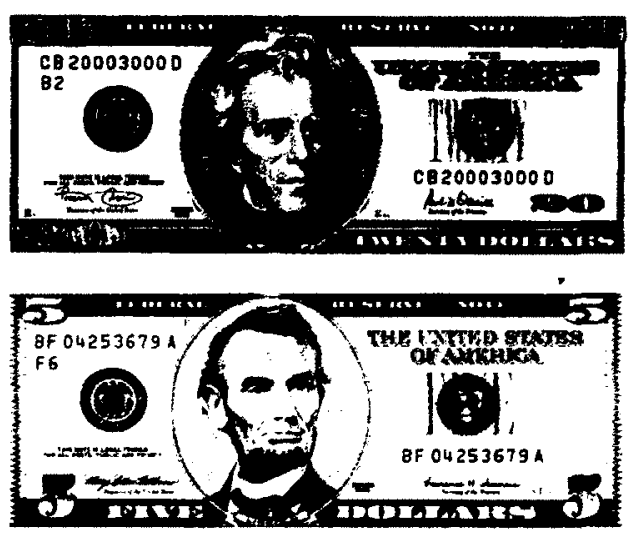
Appendix P

- SFTUINirich:

\section{NON-COMMERCIAL AMENDMENT TO LICENSE AGREEMENT}

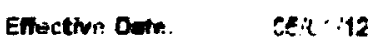

Amentmome Number: OW:actes:

Amendmert To: Licitss

Ucemoe Narne: [.3. Te.sichesher

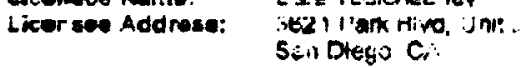

: 2103

Aoproved Purpone: Thesial histartarion ON_y

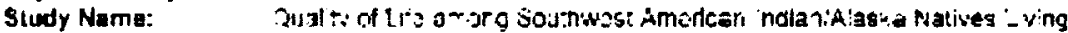
wir Hepalts

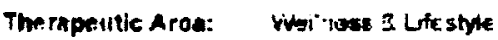

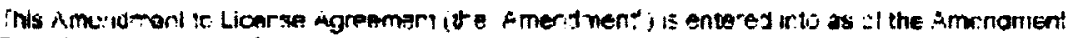

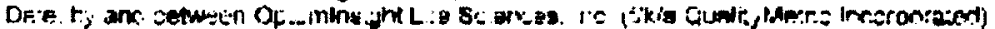

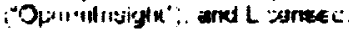

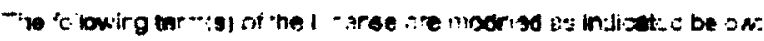

Liconase In: $\quad 50$ (son appondix b)

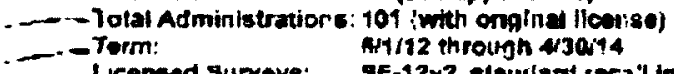

Leenead Surveys: SF-12v2, starriard, ieca'l in U8-[ngltsh

Omwir Change: nio

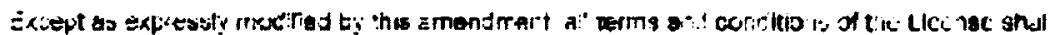

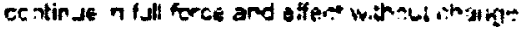

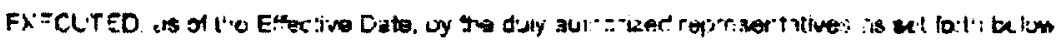

IC:5turim signt

Optunins ghi Lile Sclences, inc. Defo Todicheeney sio Univorsity of San Oimgar

Stgratu:e.

Simns".e

Nank: Michelle White $\quad$ Dirccior of Consulting SClentip Ne

Te: -......... lite

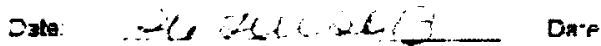




\section{CES-D Scale Questionnaire}

Today's Date:

Instructions: This questionnaire contains 20 statements people might make about how they feel. Please do not write your name on this form. Please read each statement carefully and pick the best response that best indicates how often you felt that way during the past week. For each item, circle your answer: Then circle the number below the response you have picked.

1. I was bothered by things that usually don't bother me

neming of

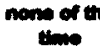

(<1 d d n

2. I did not feel like eating; appetite was poor

3. I felt that I could not shake of the blues, even with help from my family or friends

4. I felt that I was just as good as other people

5. I had trouble keeping my mind on what I was doing

6. I felt depressed

7. I felt that everything 1 did was an effort

8. I felt hopeful about the future

9. I thought my life had been a failure

10. I felt feartul

11. My steep was restless

12. I was happy

13. I talked less than usual

14. I felt lonely

15. Peopte were unfriendly

16. I enjoyed tife

17. I had crying spells

18. I folt sad

19. I felt that people disliked mo

20. I could not get going somere

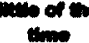

(1-2 anse)

0

0

0

0

0

0

0

0

0

0

0

0

0

0

o

0

0

0

0

0

$\begin{array}{cc}\text { cos } \\ \text { (3) } \\ 2 & 3 \\ 2 & 3 \\ 2 & 3 \\ 2 & 3 \\ 2 & 3 \\ 2 & 3 \\ 2 & 3 \\ 2 & 3 \\ 2 & 3 \\ 2 & 3 \\ 2 & 3 \\ 2 & 3 \\ 2 & 3 \\ 2 & 3 \\ 2 & 3 \\ 2 & 3 \\ 2 & 3 \\ 2 & 3 \\ 2 & 3 \\ 2 & 3 \\ 2 & 3 \\ 2 & 3\end{array}$

Thank you for taking the time to complete the CES-D Scale Questionnaire! 
Appendix R

ID Code \#

Today's Date:

\section{Alcohol Use Disorders Identification Test (AUDIT)}

Script: Now I'm going to ask 10 questions about Alcohol Use and have made a 'response card' with answer choices to help you select the best response Instructions: Alcohol use can affect one's health and interfere with certain medications \& treatments. It's important that I ask some questions about alcohol use. Please do your best to answer each question honestly. To help you answer correctly, I have listed the standard drink serving size on the next page. For each of the following questions, please mark a $\mathrm{a}$ in the box that best describes your answer. Please do not write your name on this form.

\begin{tabular}{|c|c|c|c|c|c|}
\hline & Nower & monithy & $2+4 \operatorname{mon} x=$ & 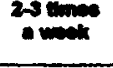 & 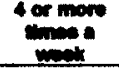 \\
\hline \multirow[t]{2}{*}{$\begin{array}{l}1 \text { How often do you have a drink containing alcohol? } \\
\text { Sklp to Owestione } 9 \text { and } 10 \text { th answer for } 1=\text { NEVER }\end{array}$} & $\square$. & $\square_{1}$ & $\square_{2}$ & $\square_{3}$ & $\square$. \\
\hline & 1002 & 304 & $60 \%$ & $7,4,00$ & 10 or mone \\
\hline \multirow[t]{2}{*}{$\begin{array}{l}2 \text { How many standard drinks containing alcohol do } \\
\text { you have on a typlcal day when drinking? }\end{array}$} & 口. & $\square$. & $\square_{2}$ & $\square$, & 口. \\
\hline & Nover & Toesthen & Morranty & Wooldy & Deliyo or \\
\hline $\begin{array}{l}3 \text { How often do you have alx or more drinks on one } \\
\text { occasion? skip to Questions } 9 \text { \& } 10 \text { if Tolal Score for } / 2+3=0\end{array}$ & $\square$. & 口. & $\square$ : & $\square$. & $\square$. \\
\hline $\begin{array}{l}\text { 4During the past year, how often have you found } \\
\text { that you were not able to stop drinking once you } \\
\text { had started? }\end{array}$ & 口. & $\square$. & $\overline{\square_{2}}$ & $\square$, & $\square$. \\
\hline $\begin{array}{l}5 \text { During the past year, how often have you failed to } \\
\text { do what was normally expected of you because of } \\
\text { drinking? }\end{array}$ & $\square$. & $\square$. & $\overline{\square_{2}}$ & 口, & $\square$ \\
\hline $\begin{array}{l}6 \text { During the past year, how often have you needed } \\
\text { a drink in the morning to get yourself going after a } \\
\text { heavy drinking session? }\end{array}$ & D. & $\square$ 口 & $\square_{2}$ & $\square_{3}$ & $\square$ \\
\hline $\begin{array}{l}7 \text { During the past year, how often have you had a } \\
\text { feeling of guilt or remorse after drinking? }\end{array}$ & $\square$. & $\square$, & $\square_{2}$ & $\square$, & $\square$. \\
\hline \multirow[t]{2}{*}{$\begin{array}{l}8 \text { During the past year, have you been unable to } \\
\text { remember what happened the night before } \\
\text { because you had been drinking? }\end{array}$} & 口. & 口. & $\square_{2}$ & $\square_{3}$ & $\square$. \\
\hline & No & & rembation & & Yas, ovition \\
\hline $\begin{array}{l}9 \text { Have you or someone else been injured as a } \\
\text { result of your drinking? }\end{array}$ & 口. & & $\square_{2}$ & & $\square$. \\
\hline $\begin{array}{l}10 \text { Has a relative or friend, doctor or other health } \\
\text { worker been concerned about your drinking }\end{array}$ & $\square$ & & $\bar{C}$ & & \\
\hline
\end{tabular}
suggested you cut down?

Total Score:

Please, stop here!

This concludes this section. Thank you for taking the time to answer the Alcohol Use survey! 


\section{Alcohol Use Disorders Identification Test (AUDIT)}

\section{Rating your score}

0 - 7: You're at low risk for problems caused by drinking alcohol.

8 - 15: You could be at risk for problems caused by drinking alcohol. Making changes in your drinking habits can help lower your risk.

Above 16: Scores above 16 could mean drinking alcohol is causing problems in your life.

Talk to your health care provider about these questions and your score. He or she will be able to work with you to help you cut down or stop drinking, and discuss any concerns or questions you may have.

Standard serving of one drink:
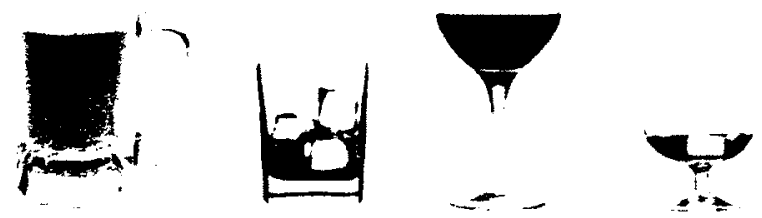

12 ounces of beer or wine cooler 1.5 ounces of 80 proof liquor 5 ounces of wine

4 ounces of brandy, liqueur or aperitif

\section{Thank you, \\ for taking the time to complete the AUDIT Screening Tool!}




\section{Appendix S}

\section{HCV Stigma Scale - (modified)}

Today's Date:

Instructions: This survey asks about some of the social and emotional aspects of having HCV. Please do your best to answer each question. Some questions may look like others, but each one is different. If you are unsure about how to answer a question, please give the best answer you can. For most of the questions, just circle the letters that go with your answer. There are no right or wrong answers.

Feel free to write in comments as you go through the questions. Please do not write your name on this form. This first set of questions asks about some of your experiences, feelings, and opinions as to how people with HCV feel and how they are treated. For each item, circle your answer: Strongly Disagree (SD), Disagree (D), Agree (A), or Strongly Agree (SA).

1. In many areas of my life, no one knows that I have HCV.
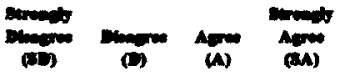

2. I feel guilty because I have HCV.

SD

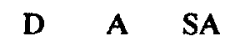

3. People's attitudes about HCV make me feel worse about myself. SD $\quad$ D $\quad$ A $\quad$ SA

4. Telling someone I have HCV is risky SD D A SA

5. People with HCV lose their jobs when their employers find out

SD

D A SA

6. I work hard to keep my HCV a secret.

SD

D A SA

7. I feel I am not as good a person as others because I have HCV.

SD

D A SA

8. I never feel ashamed of having HCV

SD

D A SA

9. People with HCV are treated like outcasts.

SD $\quad$ D $\quad$ A $\quad$ SA

10. Most people believe that a person who has $\mathrm{HCV}$ is dirty.

SD D A SA

11. It is easier to avoid new friendships than worry about telling someone that I have $\mathrm{HCV}$.

12. Having HCV makes me feel unclean.

13. Since learning I have HCV, I feel set apart and isolated from the rest of the world.

14. Most people think that a person with $\mathrm{HCV}$ is disgusting.

SD D A SA

15. Having HCV makes me feel that I'm a bad person

SD

D A SA

SD D A SA

SD D A SA

SD $\quad$ D $\quad A \quad$ SA

$\begin{array}{llll}\text { SD } & \text { D } & \text { A } & \text { SA }\end{array}$

Please, continue to next page 


\section{HCV Stigma Scale - (modified)}

Today's Date:

For each item, circle your answer: Strongly disagree (SD), Disagree (D), Agree (A), or Strongly Agree (SA).

16. Most people with HCV are rejected when others find out..

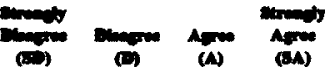

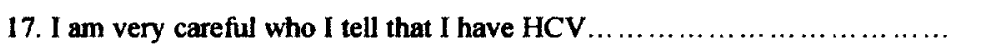

SD D A SA

18. Some people who know I have HCV have grown more distant..............

19. Since learning I have HCV, I worry about people discriminating against me

20. Most people are uncomfortable around someone with HCV

SD D A SA

21. I never feel the need to hide the fact that I have $\mathrm{HCV}$.

SD D A SA

SD D A SA

22. I worry that people may judge me when they learn I have $\mathrm{HCV} \ldots \ldots \ldots \ldots$

SD D A SA

23. Having HCV in my body is disgusting to me

SD $\quad$ D A SA

SD $\quad$ D $\quad A \quad S A$

SD D A SA

Instructions: Many of the items in this next section assume that you have told other people that you have HCV, or that others know. This may not be true for you. If the item refers to something that has not actually happened to you, please imagine yourself in that situation.

For each item, circle your answer: Strongly Disagree (SD), Disagree (D), Agree (A), or Strongly Agree (SA) based on how you think you would feel or how you think others would react to you.

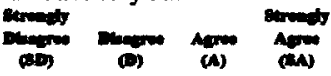

24. I have been hurt by how people reacted to learning I have HCV. SD D $\quad$ A $\quad$ SA

25. I worry that people who know I have HCV will tell others. SD D A SA

26. I regret having told some people that I have HCV.

SD D A SA

27. As a rule, telling others that I have HCV has been a mistake.

SD D A SA

28. Some people avoid touching me once they know I have HCV.

SD D A SA

29. People I care about stopped calling after leaming I have HCV

SD D A SA

Please, continue to next page 


\section{HCV Stigma Scale - (modified)}

For each item, circle your answer: Strongly Disagree (SD), Diagree (D), Agree (A), or Strongly Agree (SA) based on how you think you would feel or how you think others would react to you.

$\begin{array}{llll}\text { SD } & \text { D } & \text { A } & \text { SA } \\ \text { SD } & \text { D } & \text { A } & \text { SA } \\ \text { SD } & \text { D } & \text { A } & \text { SA } \\ \text { SD } & \text { D } & \text { A } & \text { SA } \\ \text { SD } & \text { D } & \text { A } & \text { SA } \\ \text { SD } & \text { D } & \text { A } & \text { SA } \\ \text { SD } & \text { D } & \text { A } & \text { SA } \\ \text { SD } & \text { D } & \text { A } & \text { SA } \\ \text { SD } & \text { D } & \text { A } & \text { SA } \\ \text { SD } & \text { D } & \text { A } & \text { SA } \\ \text { SD } & \text { D } & \text { A } & \text { SA }\end{array}$

30. People have told me that getting HCV is what I deserve for how I lived my life

31. Some people close to me are afraid others will reject them if it becomes known that I have HCV

32. People don't want me around their children once they know I have HCV

33. People have physically backed away from me when they learn I have HCV

34. Some people act as though it's my fault I have HCV

35. I have stopped socializing with some people because of their reactions to my having HCV

36. I have lost friends by telling them I have HCV

37. I have told people close to me to keep the fact that I have HCV a secret

38. People who know I have HCV tend to ignore my good points

39. People seem afraid of me once they leam I have HCV

SD

A SA

Please, stop here!

\section{Thank you, for taking the time to complete the HCV Stigma survey!}


Appendix T

ID Code \#

Today's Date:

$12012 / 2013$

\section{Personal Data Collection}

Ecript. Thank you for egreaing to participate. I am going to limit the amount of time I spend on each queation. If there is a question that you are unoure about or want mone information on, we can discuss it at the conclusion of our session. I have provided RESPOAsE CARDS to allow you to answer the questions.

Instructions: Please respond to the following questions, in order to better understand you and the impact your life experience and health history. Your responses will remain confidential so please do your best to answer each question to the best of your ability.

KEY: The answer choice "DK / Rer means Don't Know or Refused to answer

PATIENT DEMOGRAPHICS:

1. What is your Gender?

$\square$ Female (1)

Male (2)

If Other, please specify:

2. What is your Age?

$$
\text { Age in years } \square \text { DK/Ref (9) }
$$

3. What is your Race / Ethnicity? (Check all that apply) Yes No DK/Ref

\begin{tabular}{llll} 
3a. Alaska Native & 1 & 2 & 9 \\
\hline 3b. American Indian & 1 & 2 & 9 \\
\hline 3c. Asian & 1 & 2 & 9 \\
\hline 3d. Black or African American & 1 & 2 & 9 \\
\hline 3e. Hispanic or Latino & 1 & 2 & 9 \\
\hline 3f. Mexican or Mexican American & 1 & 2 & 9 \\
\hline 3g. Native Hawaiian / Pacific Islander & 1 & 2 & 9 \\
\hline 3h. White or Caucasian & 1 & 2 & 9 \\
\hline 3i. If Other, please specify: & 1 & 2 & 9
\end{tabular}

4. Which Language do you use most often?

$\square$ My native / tribal language:

$\square$ English (2)

$\square$ Spanish (3)

$\square$ If Ohmer, please specify:

$\square$ DK / Ref (9) 
ID Code \#

Today's Date:

$12012 / 2013$

\section{Personal Data Collection}

5. Do you currently Reside / Live on American Indian reservation / land?
Yes (1)
$\square$ No (2)
$\square$ DK/Ref (9)

6. What is your current Marital Status? (Circle one)
$\square$ Single / Never married (1)
$\square$ Married / Partnered (2)
Divorced / Separated (3)
$\square$ Widowed (4)

7. Do you currently have a Primary Partner? A primary partner is someone with whom you love more than anyone $\theta / \mathrm{se}$ and feel a unique commitment?
$\square$ Yes (1)
$\square$ No (2)
$\square$ DK/ Ref (9)

(if no, SkJp question 18 and 9 )

8. Is your Primary Partner someone of the Same sex, Opposite sex, or Both?
Same sex (1)
Opposite sex (2)
$\square$ Both sexes (3)
DK / Ref (9)

9. Do you currently Live with your husband, wife, primary partner, or significant other?
$\square$ Yes (1)
No (2)
$\square$ DK / Ref (9)

10. What is the Highest Level of formal education you completed or the highest degree you have received?

$\square$ Never attended school (1)

$\square$ Grades 1 through 8 (Elementary) (2)

Grades 9 through 11 (Some high school) (3)

Grade 12 (High school graduate) (4)

GED (5)

$\square$ Some college, no degree (6)

AA degree (7)

BA, BS degree (8)

$\square$ Some graduate or professional school (9)

$\square$ Graduate or professional degree (10) Specify degree:

Please, continue to next pagel 
ID Code \# Today's Date:

$12012 / 2013$

\section{Personal Data Collection}

11. What is your Occupational status?

$\square$ Full-time outside the home (1)

$\square$ Full-time in the home (2)

$\square$ Part-time outside the home (3)

$\square$ Student (4)

$\square$ Retired (5)

$\square$ Volunteer (6)

$\square$ Unable to work / Unemployed (7)

$\square$ Disabled / Handicapped (8)

12. Which of the following Categories best describes your present or most recent job or occupation?

$\square$ Professional / Administrative (1)

Clerical, Administrative Support, Sales or Marketing (2)

$\square$ Crafts, Trades, Factory Work, Retail Sales, or Labor (3)

Military (4)

Casino (5)

If Othor, please specify:

DK/Ref (9)

13. Which category best describes your Total Yearty Income of ALL members of your household?

$\square \$ 0-\$ 10,000(1)$

$\$ 10,001$ to $\$ 20,000(2)$

$\square \$ 20,001$ to $\$ 30,000(3)$

$\square \$ 30,001$ to $\$ 40,000(4)$

$\$ 40,001$ to $\$ 50,000(5)$

$\$ 50,001$ to $\$ 75,000(6)$

$\$ 75,001$ to $\$ 100,000(7)$

$\$ 100,001$ to $\$ 150,000(8)$

Greater than $\$ 150,000(10)$

DK/Ref (9)

Please, continue to next paget 
ID Code \#

Today's Date:

$12012 / 2013$

\section{Personal Data Collection}

14. Have you ever served in the U.S. Armed Forces? Active duty includes serving in the U.S. Armed Forces as well as activation from the Reserves or National Guard.

$\square$ Yes, on active duty in the past, but not now (1)

$\square$ Yes, now on active duty (2)

$\square$ No, never on active duty except for initialbasic training (3)

$\square$ No, nover served in the U.S. Amed Forces (4)

(If Never Served, Skip question \#15)

15. In which branch or branches did you serve on active duty? (Check all that apply)

$\square$ Army (1)

$\square$ Navy (2)

$\square$ Air Force (3)

$\square$ Marine Corps (4)

$\square$ Coast Guard (5)

$\square$ Outer (e.g. . Public Health Service, Environmental Services Administration, National Oceanic and Atmospheric Administration, U.S. Merchant Marine) (6)

16. How easy is it for you to Afford (access) medical treatment for Hepatitis $C$ ?

$\square$ Very easy (1)

$\square$ Somewhat easy (2)

$\square$ Somewhat difficult (3)

$\square$ Very difficult (4)

17. This DOES NOT include Indian Health Service, IHS or tribal clinics or doctors where uninsured patients are charged according to their income. Do you have any type of heatth care coverage other than Indian Health Service? (check all that apply)

$\square$ VA (Dept. of Veterans Affairs, CHAMPUS, CHAMPVA, TRICARE (Military) (1)

$\square$ County Services (2)

Arizona Health Care Cost Containment System (Medicaid) (3)

$\square$ Medicare, including Medigap supplement (4)

$\square$ Out of pocket by you or your family (copayment) (5)

$\square$ Private insurance purchased directly or by a family member, through a union, or from a current or former employer (6)

No other coverage (7)

If Oher source, please specify:

DK / Ref (9)

Please, continue to next page! 
ID Code \#

\section{Personal Data Collection}

18. What Treatments have you recelved for Hepatitis C? Please check all that apply $\square$ American Indian Traditional Healing / Ceremonial Practices (1)

18a. What kind(s)?

18b. When was the most treatment?

18c. For how long?

$\square$ Complementary and Alternative Medicine therapy (2)

For example: acupuncture, healing louch, Roiki, yoga, biofoedback, hypnosis, meditation, chiropractic, and massege

18d. What kind(s)?

180. When was the most treatment?

18f. For how long?

$\square$ Combined HCV Injection / Medication therapy (3)

18g. What kind(s)?

18h. When was the most treatment?

181. For how long?

$\square$ HCV injection therapy only i.e., interferon (4)

18j. What kind(s)?

18k. When was the most treatment?

181. For how long?

$\square$ HCV Medication therapy only i.e., Ribavirin, Telaprevir, Boceprevir (5)

$18 \mathrm{~m}$. What kind(s)?

18n. When was the most treatment?

180. For how long?

$\square$ Surgery / Organ Transplant (6)

18p. What kind(s)?

18q. When was the most treatment?

18r. For how long?

No treatment (7)

18s. Tell me why you opt NO treatment?

18t. How do you feel about treatment?

18u. Tell me your cultural beliefs about treatment?

DK/Ref (9) 
ID Code \#

Today's Date:

$12012 / 2013$

\section{Personal Data Collection}

Notes:

What

When

Where

Why / How

19. What was the reason for your Hepattis $C$ Testing: (check all that apply)

$\square$ Screening of Asymptomatic Patient with No Risk Factors (1)

$\square$ Screening of Asymptomatic Patient with Risk Factors (2)

$\square$ Blood / Organ Donor Screening (3)

$\square$ Evaluation of Elevated Liver Enzymes (4)

$\square$ Follow-up Testing for Previous Marker of Viral Hepatitis (5)

$\square$ Prenatal Screening (6)

$\square$ Symptoms of Acute Hepatitis (7)

$\square$ If Other, please specify:

$\square$ DK/Ref (9)

20. Did you experience any HCV signs/symptoms?

\begin{tabular}{|c|c|c|c|}
\hline 20a. Abdominal Pain & $\square$ Yes (1) & $\square$ No (2) & $\square$ DK / Ref (9) \\
\hline 20b. Arthralgia & $\square$ Yes (1) & $\square$ No (2) & $\square$ DK / Ref (9) \\
\hline 20c. Clay Colored Stool & $\square$ Yes (1) & No (2) & $\square$ DK / Ref (9) \\
\hline 20d. Dark Urine & $\square$ Yes (1) & $\square$ No (2) & $\square D K / \operatorname{Ref}(9)$ \\
\hline 20e. Diarthea & $\square$ Yes (1) & No (2) & $\square$ DK / Ref (9) \\
\hline 20f. Fatigue & $\square$ Yes (1) & No (2) & $\square$ DK / Ref (9) \\
\hline 20g. Fever & $\square$ Yes (1) & No (2) & $\square$ DK / Ref (9) \\
\hline Oh. Jaundice & $\square$ Yes (1) & $\square$ No (2) & $\square$ DK / Ref (9) \\
\hline 20i. Loss of Appetite & $\square$ Yes (1) & $\square$ No (2) & $\square$ DK / Ref (9) \\
\hline j. Nausea & $\square$ Yes (1) & $\square N_{0}(2)$ & $\square$ DK / Ref (9) \\
\hline 20k. Vomiting & $\square$ Yes (1) & $\square$ No (2) & $\square$ DK / Ref (9) \\
\hline
\end{tabular}


ID Code \#

Today's Date:

$12012 / 2013$

\section{Personal Data Collection}

\section{PATIENT HEALTH INFORMATION / HISTORY:}

During the 2 woeks - 6 months prior to onset of aymptoms

21. Were you a Contact of a person with Confirmed or Suspected Acute or Chronic HCV infection?

Aecte infection = having HCV infection for $<8$ monthe. Camonte infection a having HCV infection for $>6$ monthe $\square$ Yes (1) $\square$ No (2) $\square$ DK/Ref (9)

21a. If yes, was the Contact thru: (check all that apply)

$\square$ Blood / Organ Donation (1) $\square$ Household Member (non-sexual) (2)

$\square$ Injection Drug Use (3) $\quad \square$ Contracted due to being hospitalized (4)

$\square$ Occupational exposure (5) $\square$ HCV mother transmits to baby (6)

$\square$ Sexual / Intimate Partner (7) $\square$ If Othor, please specify

$\square$ DK/Ref (9)

22. In the 6 months before symptom onset (regandless of gender / sexual preference)

$\begin{array}{lllll}0 & 1 & 2-6 & >6 & \text { Unk }\end{array}$

22a. How many Male sex partners did you have? $\quad \square(1) \quad \square(2) \quad \square(3) \quad \square(4) \square(5)$

22b. How many Female sex partners did you have? $\square(1) \square(2) \square(3) \square(4) \square(5)$

22c. During those last 6 months, how many of those sex partners did you find through the Intemet? (Total \#)

During the 2 weeks - 6 months prior to onset of symptoms

23. Have you EVER been treated for a Sexually Transmitted Disease/lnfection?

$\square$ Yes (1) $\square$ No (2) $\square$ DK/Ref (9)

23a. If yes, please specify type(s): (check all that apply)
$\square$ Bacterial Vaginosis (BV) (1)
$\square$ Chlamydia (2)
Gonorihea (3)
$\square$ HepA Virus (4)
$\square$ HepB Virus (5)
$\square$ HepC Virus (6)
Herpes, Genital (7)
$\square$ HIV / AIDS (8)
Human Papillomavinus (HPV) / Genital Warts (10)
$\square$ Pelvic Inflammatory Disease (PID) (11)
$\square$ Syphilis (12)
$\square$ Trichomonas (13)
$\square$ Vaginitis (14)
DK/Ref (9)

23b. Year of most recent specified treatment?

Please, continue to next page! 
ID Code \#

Today's Date:

$12012 / 2013$

\section{Personal Data Collection}

24. Have you EVER used Street Drugs? (Smoked crack; Snorted meth, Injected cocaine)
$\square$ Yes (1)
$\square$ No (2)
$\square$ DK / Ref (9)

25. Have you EVER used or shared a Needle or Syringe to Inject Drugs intravenously not prescribed by a health care worker? (Even once)
$\square$ Yes (1)
$\square$ No (2)
$\square$ DK/Ref (9)

26. Have you EVER used or shared Equipment to Inject Drugs intravenously not prescribed by a health care worker? (Even once) (Reusing water, bottle caps, spoons, other containers, cotton or cigarette filters)
$\square$ Yes (1)
$\square$ No (2)
DK/Ref (9)

27. Has a Medical Doctor ever diagnosed you with Dlabetes Mellitus?
$\square$ Yes (1)
$\square$ No (2)
$\square$ DK / Ref (9)

27a. If yes, have you shared your diabetic supplies i.e., finger lancets / syringes?

$$
\square \text { Yes (1) } \square \text { No (2) } \square \text { DK/Ref (9) }
$$

28. Did you EVER have an Accidental Stick or Puncture with a needle or other object contaminated with blood?
$\square$ Yes (1)
No (2)
DK / Ref (9)

29. Have you EVER undergone / received long-term kidney Hemodialysis (a machine that removes certain waste and chemicals in the blood when your kidney is badly injured)?
$\square$ Yes (1)
$\square$ No (2)
$\square$ DK/Ref (9)

29a. If yes, Month and Year of hemodialysis:

30. Have you EVER received Blood / blood products [Transfusion] before duly 1902? (i.e., caesarean section, maternal-child transmission, cardiac surgery)
$\square$ Yes (1)
$\square$ No (2)
$\square$ DK / Ref (9)

30a. If yes, date of transfusion?

31. Did you EVER receive any Outpatient IV Infusions and/or Injections? (Outpatient Infusion centers provide intravenous infusions for antimicrobial therapy, therapeutic injections, i.e., IV antibiotics, fluid/electrolyte management, chemotherapy, or medication infusion therapy and allowing you to not be hospitalized)
$\square$ Yes (1)
$\square$ No (2)
$\square$ DK / Ref (9) 
ID Code \#

Today's Date:

$12012 / 2013$

\section{Personal Data Collection}

32. Have you EVER been in Contact with a Person's blood that had Hepatitis?

$\square$ Yes (1) $\square$ No (2) $\square$ DK/Ref (9)

32a. If yes, was the Contact: (check all that apply)

$\square$ Blood / Organ Donation (1) $\square$ Household Member (non-sexual) (2)

$\square$ Injection Drug Use (3) $\quad \square$ Contracted due to being hospitalized (4)

$\square$ Occupational exposure (5) $\square$ HCV mother transmits to baby (6)

$\square$ Sexual / Intimate Partner (7) पlf Other, please specify

$\square$ DK/ Ref (9)

33. Have you EVER been Exposed (vieible or not) to someone else's blood that had Hepatitis?

$\square$ Yes (1) $\square$ No (2) $\square$ DK/Ref (9)

33a. If yes, was the Contact: (check all that apply)

$\square$ Blood / Organ Donation (1) $\square$ Household Member (non-sexual) (2)

$\square$ injection Drug Use (3) $\quad \square$ Contracted due to being hospitalized (4)

$\square$ Occupational exposure (5) $\square$ HCV mother transmits to baby (6)

$\square$ Sexual / Intimate Partner (7) $\square$ If Othr, please specify

$\square D K / \operatorname{Ref}(9)$

34. Were you EVER employed in a Medlcal or Dental field involving direct contact / exposure mucosally (eye splash, nose, mucous membranes) or to non-intact skin with human blood or infected needles?

$\square$ Yes (1) $\square$ No (2) $\square$ DK/Ref (9)

34a. If yes, what was the frequency of the direct blood contact / exposure?
$\square$ Frequent (several times weekly) (1)
$\square$ Infrequent (2)

35. Were you EVER employed as a Public Safety / Emergency Worker having direct contact / exposure mucosally (eye splash, nose, mucous membranes) or to non-intact skin with human blood or infected needles?

$\square$ Yes (1) $\square$ No (2) $\square$ DK/Ref (9)

36a. If yes, please specify:

$\square$ Prison / Jail / Juvenile Facility (1)

$\square$ Fire Fighter (2)

$\square$ Law Enforcement Officer (3)

If Outer, please specify:

$36 \mathrm{~b}$. If yes, what was the frequency of the direct blood contact?

$\square$ Frequent (several times weekly) (1) $\square$ Infrequent (2)

Please, continue to next page! 
ID Code \#

Today's Date:

$12012 / 2013$

\section{Personal Data Collection}

36. Were you EVER a resident of a Long-Term Care Facility (i.e., Skill Nursing Facility)?

$\square$ Yes (1) $\square$ No (2) $\square$ DK/Ref (9)

37. Were you EVER a resident of an Inpatient Drug Treatment Program?
$\square$ Yes (1)
No (2)
DK/Ref $(9)$

38. Were you EVER a resident of a Malfway House?
$\square$ Yes (1)
$\square$ No (2)
DK / Ref (9)

39. Have you EVER been Incarcerated?
$\square$ Yes (1)
$\square$ No (2)
DK / Ref (9)

39a. If yes, what type of facility?
$\square$ Prison (1)
$\square$ Jail (2)
Juvenile Facility (3)

39b. If yes, what year was the most recent incarceration?

39c. For how long?

40. Did you EVER receive a Tattoo(s)?

$\square$ Yes (1) $\square$ No (2) $\square$ DK/Ref (9)

40a. If yes, where did you receive your tattoo? (check all that apply)

$\square$ Commercial Partor / Shop (1)

Prison / Jail / Juvenile Facility (2)

If Othor, please specify:

41. Did you EVER have any part of your Body Pierced (other than your ear)?

$\square$ Yes (1) $\square$ No (2) $\square$ DK/Ref (9)

41a. If yes, where did you receive your body piercing? (Check all that apply)

$\square$ Commercial Parlor / Shop (1)

$\square$ Prison / Jail / Juvenile Facility (2)

$\square$ If Other, please specify:

42. Have you EVER been diagnosed and / or treated by a Medical Doctor for Hemophilla? Hemophilia is a rare bleeding disorder in which your blood doesn't clot normally and you may bleed for a longer time than others after an injury. This bleeding can damage your organs and tissues and may be life threatening.

$\square$ Yes (1) $\square$ No (2) $\square$ DK/Ref (9)

42a. If yes, specify year:

Please, continue to next pagel

10 
ID Code \#

Today's Date:

$12012 / 2013$

\section{Personal Data Collection}

43. Have you EVER received blood clotting factor concentrates produced before 1907 in order to treat your Hemophilia blood disorder. Before 1987, most clotting factors were made from human blood can carry the viruses that cause HIVIAIDS and Hepatitis. The main treatment for hemophilia is called replacement therapy (concentrates of clotting factor)

$\square$ Yes (1) $\square$ No (2) $\square$ DK/Ref (9)

43a. If yes, specify year:

44. Did you EVER have Dental work or Oral Surgery prior to your Hepatitis $\mathrm{C}$ diagnosis?
$\square$ Yes (1)
$\square$ No (2)
$\square$ DK/Ref (9)

45. Did you EVER have Surgery (other than oral) prior to your Hepatitis $\mathrm{C}$ diagnosis?
$\square$ Yes (1)
$\square$ No (2)
$\square$ DK/Ref (9)

46. Have you EVER received a solid organ transplant before July 1992 ?
$\square$ Yes (1)
$\square$ No (2)
$\square$ DK/Ref (9)

46a. (Organ type)

46b. (Enter year)

Please, stop here!

This concludes this section. Thank you for taking the time to complete the Personal Data Collection survey! 
ID Code \#

Today's Date:

$12012 / 2013$

\section{Clinical Data Collection}

Instructions: Clinical data will be collected from your Medical Record, in order to better understand you and your Hepatitis $\mathrm{C}$ illness. Your health information will not link your name or medical record number. Thank you.

KEY: The answer choice "DK / Ref means Don't Know or Refused to answer

\section{CLINICAL AND DIAGNOSTIC DATA:}

1. Reason for Hepattis C Testing: (check all that apply)

$\square$ Screening of Asymptomatic Patient with No Risk Factors (1)

$\square$ Screening of Asymptomatic Patient with Risk Factors (2)

$\square$ Blood / Organ Donor Screening (3)

$\square$ Evaluation of Elevated Liver Enzymes (4)

Follow-up Testing for Previous Marker of Viral Hepatitis (5)

Prenatal Screening (6)

Symptoms of Acute Hepatitis (7)

ourer (specify)

DK/Ref (9)

\section{CLINICAL DATA I SYMPTOMS:}

2. Hepattis $\mathbf{C}$ dlagnosis date: 1 1

3. le Patient Symptomatic? $\square$ Yes (1) $\square$ No (2) $\square$ DK/Ref (9)

3a. If yes, onset date:

1

4. Is / was Patient hospltallzed? $\square$ Yes (1)

4a. Adm Date:

4b. D/C Date:

5. Is Patient currently Prognant? $\square$ Yes (1)

5a. Date of Delivery: 
ID Code \#

Today's Date:

$12012 / 2013$

\section{Clinical Data Collection}

6. Did the patient experience? (Answer for each symptom below)

$\begin{array}{llll}\text { 6a. Abdominal Pain } & \square \text { Yes (1) } & \square \text { No (2) } & \square \text { DK/Ref (9) } \\ \text { 6b. Arthraigia } & \square \text { Yes (1) } & \square \text { No (2) } & \square \text { DK/Ref (9) } \\ \text { 6c. Clay Colored Stool } & \square \text { Yes (1) } & \square \text { No (2) } & \square \text { DK/Ref (9) } \\ \text { 6d. Dark Urine } & \square \text { Yes (1) } & \square \text { No (2) } & \square \text { DK/Ref (9) } \\ \text { 6e. Diarthea } & \square \text { Yes (1) } & \square \text { No (2) } & \square \text { DK/Ref (9) } \\ \text { 6f. Fatigue } & \square \text { Yes (1) } & \square \text { No (2) } & \square \text { DK/Ref (9) } \\ \text { 6g. Fever } & \square \text { Yes (1) } & \square \text { No (2) } & \square D K / \operatorname{Ref}(9) \\ \text { 6h. Jaundice } & \square \text { Yes (1) } & \square \text { No (2) } & \square \text { DK/Ref (9) } \\ \text { 6i. Loss of Appetite } & \square \text { Yes (1) } & \square \text { No (2) } & \square \text { DK/Ref (9) } \\ \text { 6j. Nausea } & \square \text { Yes (1) } & \square \text { No (2) } & \square D K / \operatorname{Ref~(9)~} \\ \text { 6k. Vomiting } & \square \text { Yes (1) } & \square \text { No (2) } & \square \text { DK/Ref (9) }\end{array}$

VACCINATION HISTORY:

7. Has participant ever received Hepotitis A vaccine?

$\square$ Yes (1) $\square$ No (2) $\square$ DK/Ref (9)

7a. If yes, how many doses? $\square 1$ dose (1) $\square \geq 2$ doses (2)

7b. Last Hepatitis A dose (year):

8. Has participant ever received Hopattis $\mathbf{B}$ vaccine?

$\square$ Yes (1) $\square$ No (2) $\square$ DK / Ref (9)

8a. If yes, how many doses? $\square 1$ dose (1) $\square 2$ doses (2) $\square 3+$ doses (3)

8b. Last Hepatitis B dose (year):

9. Was participant ever given Immune Clobulin?

$\square$ Yes (1) $\square$ No (2) $\square$ DK/Ref (9)

9a. If yes, month/year last dose received?

1

10. Date when (1st) blood drawn for Hepalis $B$ teating?

10a. Reporting Laboratory: 
ID Code \#

Today's Dato:

$12012 / 2013$

\section{Clinical Data Collection}

\section{DIAGNOSTIC TESTS:}

11. HAV / HBV / HCV serology results: (chock all that apply)

11a. Total Antibody, Hepatiti A Virus [total anti+HAV]

$\square$ Positive (0) $\square$ Negative (1) $\square$ Not Done (2) $\square$ DK/Ref (9)

11b. IgM Antibody, Hepatitis A Virus [gM antiHAV]

$\square$ Positive (0) $\square$ Negative (1) $\square$ Not Done (2) $\square$ DK/Ref (9)

11c. Hepatile B Surface Antigen [HBsAg]

$\square$ Positive (0) $\square$ Negative (1) $\square$ Not Done (2) $\square$ DK/Ref (9)

11d. Total Antibody, Hepatitb B Core Antigen [total anti+HBc]

$\square$ Positive (0) $\square$ Negative (1) $\square$ Not Done (2) $\square$ DK/Ref (9)

110. IgM Antibody, Hepatib B Core Antigen [lgM anti+HBc]

$\square$ Positive (0) $\square$ Negative (1) $\square$ Not Done (2) $\square$ DK/Ref (9)

11. Supplemental AntH+HCV assay [0.g., RIBA]

$\square$ Positive (0) $\square$ Negative (1) $\square$ Not Done (2) $\square$ DK/Ref (9)

11g. HOV RNA [e.g., PCR]

$\square$ Positive (0) $\square$ Negative (1) $\square$ Not Done (2) $\square$ DK/Ref (9)

11h. Antibody to Hepatitis C Virus [antiHCV]

$\square$ Positive (0) $\square$ Negative (1) $\square$ Not Done (2) $\square$ DK/Ref (9)

11i. anti - HCV signal to cut-off ratio.

Liver Enzyme Values:

12.a.b.c. SGPT (ALT) ___ Test date: _ _ I U Uper limit normal:

13.a.b.c. SGOT (AST) _____ Test date: $1 \quad 1 \quad$ Upper limit normal:

14. Other teats) i.e. Abdominal U/S

Genotype

Transplant List 